\title{
JOURNEYS CROSS DIVIDES: \\ NURSES AND MIDWIVES' EXPERIENCES OF CHOOSING A PATH FOLLOWING SEPARATION OF THE PROFESSIONS
}

by

Dianne Mary Mulcahy
A thesis submitted to the Victoria University of Wellington
in partial fulfilment of the
requirements for the degree of
Master of Arts (Applied)
in Nursing

Victoria University of Wellington 


\begin{abstract}
In 2003 the Health Practitioners Competence Assurance Act was introduced and established separate regulatory authorities for nursing and midwifery. This study is designed to explore the experiences of dually registered practitioners affected by this divide, as now there are two separate and possible paths, and two corresponding sets of competencies to fulfil.
\end{abstract}

The design for this qualitative descriptive study utilised the written and oral narratives of three practitioners affected by this professional regulation and demonstrated its impact on their career development. Individual storytelling, as narrative, provided a theoretical lens aiding insight into their experience and pattern of decision making. In addition, symbolic consideration of the study data was provided by collective storytelling via the perennial myth of the hero journey.

Shifting professional ground following the Health Practitioners Competence Act 2003 generated a focus for the inquiry into practitioners' modes of adjustment. For the practitioners in the study, transition between the occupational roles of nursing and midwifery comprised the possible career trajectories. A status passage, as the process of change from one social status to another, is described and includes the transitional experience of anticipation, expectation, contrast, and change.

The findings from this research provide illumination of the nuances of professional decision making as a lived experience, and highlight how these practitioners dealt with shifting meaning, values, awareness, choices, and relationships. Aspects of group agency and identity, change management, and professional role transition were revealed. Life pattern, revealed through narrative, was an important research construct for exposing the ways in which the participants negotiated change, and displayed the function of their thinking and reasoning through dilemmas. Perception of individual and group identity revealed attitudes of esteem to the dominant discourse, and exposed dynamic tension between work patterns and life stage. Renegotiating arrangements of personal and professional commitment resulted from this dynamic interplay, and the relationship to stress and burnout was explored.

Keywords: career planning and development, professional role transition, professional regulation, metaphoric and symbolic transitions, narrative. 


\section{Dedication}

for my fellow colleagues

nurses and midwives

for safe and supported

work environments

for inclusion

for education

for information

for value

for freedom

to enjoy our work 


\section{Acknowledgements}

The help and support of a number of people have enabled me to bring this research to fruition.

I would like to sincerely thank Mary, Susan, and Jo who took the time to write and share their experiences so honestly. As you retold and reconstructed your experience of professional decision making, your words portrayed the human experience of integrating personal and professional lives. Your stories bring a greater awareness to the process of negotiating and expressing the effects of shift and change within the nested landscapes of home, nursing, midwifery, healthcare, and the greater social landscape.

This study interest emerged from my own narrative investigation into the dilemma of shifting professional terrain. As I negotiated the postgraduate curricula of a Masters programme I discovered the freedom of intermingling stories of experience with academic inquiry. Although the academic disciplines of midwifery and nursing are now separate the faculty staff of Wintec and the Graduate School of Nursing, Midwifery and Health at Victoria University of Wellington, recognised the historical context as informing daily practice. This process coupled the rational mind with the voice of the heart, to incorporate a sense of wholeness. I will always be grateful to their vision and capacity as educators, which allowed me to discover new ways of learning. The challenge of the journey developed a level of character, and a style of learning that contrasted dramatically with the era of the seventies.

Special acknowledgement must go to Associate Professor Cheryle Moss who supported this last challenge, as my supervisor for this study. For the purposes of this project she became my threshold guide, encouraging and challenging me, all at the same time. I would never have explored half of the territory without her ability, with only a brief comment, to send me off on adventurous searches. 
My two partners in crime; Sheree Gare and Ross Turner provided peer encouragement and support just when they were needed.

Last, but not least, my fantastic family, Mark, James, and Liam, who put up with my obsessive drive to see this project through. I would never have been able to complete it without your love and support. 


\section{Table of Contents}

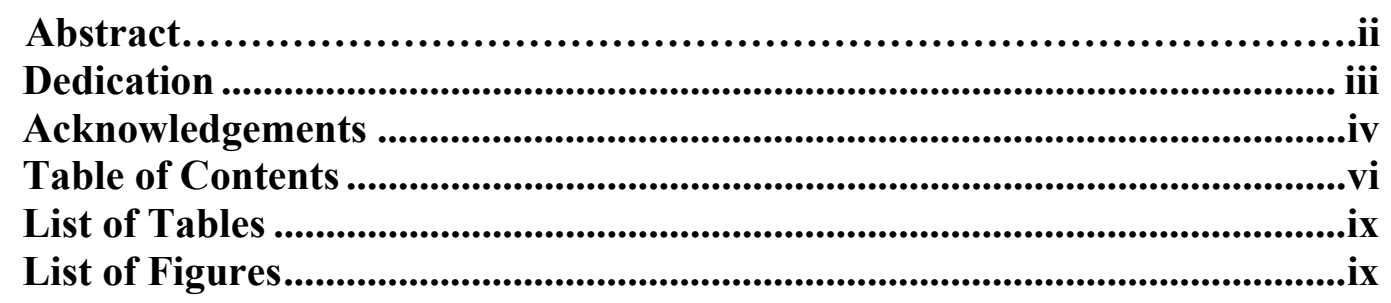

Part One: The Call to Adventure ........................................................................ - 1 -

Chapter One Heeding the Call............................................................... - 3 -

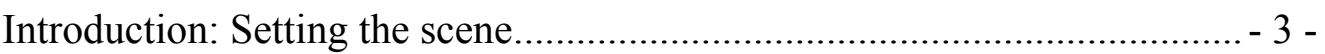

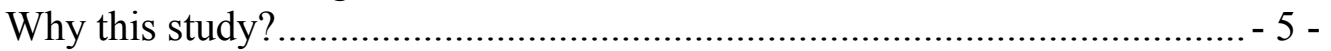

Purpose of the study and research questions............................................ 8 -

Justification for the study ..................................................................... 10 -

Structure, style, and outline of the thesis ................................................ - 12 -

Chapter Two Maps and Destinations............................................................ - 16 -

Transition: The missing link ................................................................. 17 -

The map of midwifery .......................................................................... - 18 -

The map of nursing .............................................................................. 21 -

Map and compass in the current context................................................... - 22 -

Navigating the external and the internal landscape ................................. - 26 -

Chapter Three Preparing for the Journey: Validating the Circle of Inquiry .................................................................. 30 -

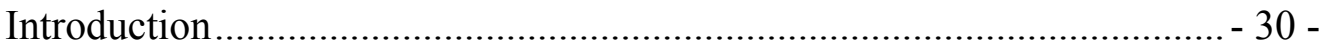

The map is not the territory ..................................................................... 30 -

The journey as status passage .................................................................... 31 -

Narrative as both methodology and method ............................................ - 33 -

Symbolic considerations ...................................................................... 35 -

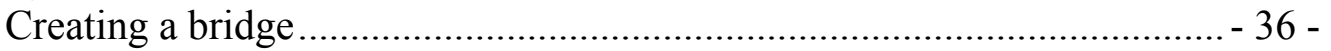

The collective story of the hero journey ................................................ 41 -

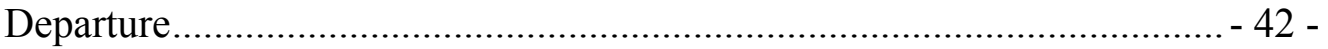

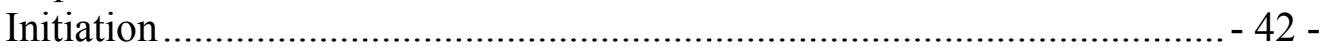

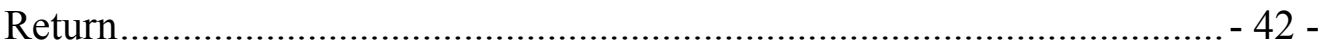

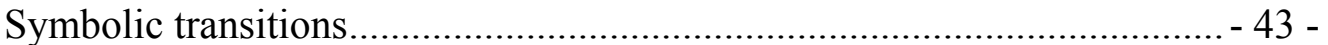

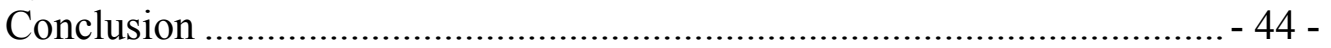

Chapter Four Study Design ................................................................. 46 -

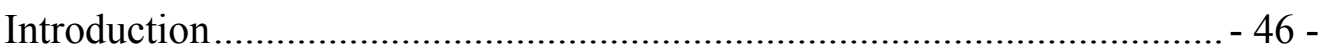

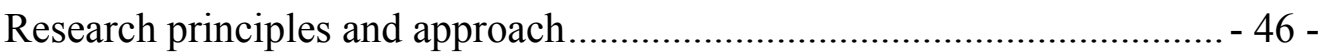

Study design and considerations ....................................................... - 47 - 
Ethical approval and considerations for the research project $-49-$

Negotiating the field of inquiry

Beginning the journey with the research participants .............................. - 51 -

Data collection methods....................................................................... 51 -

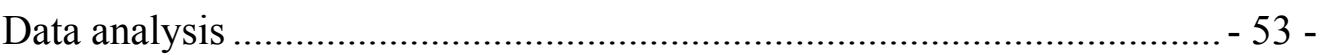

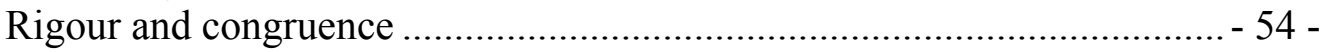

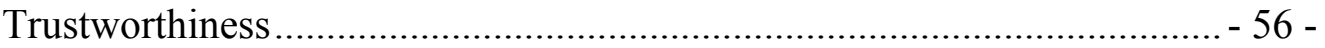

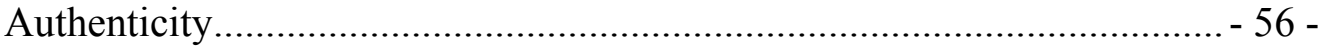

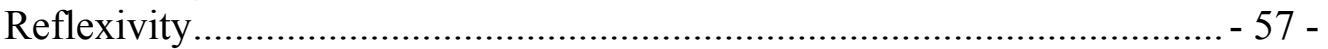

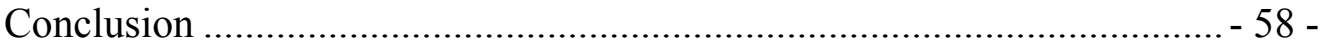

Part Two: Departure, Initiation, and, Return ..................................................... - 59 -

Chapter Five Mary's Story: Finding a Path with Heart ........................ - 61 -

A journey to becoming: Status passage into nursing and midwifery.......... 62 -

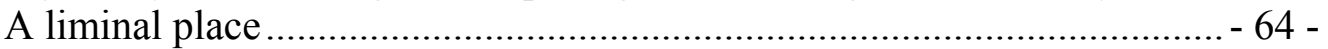

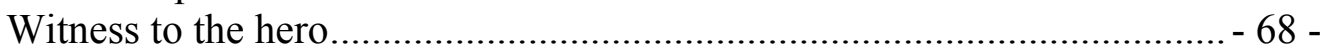

Chapter Six Susan's Story: Dragons of Initiation .................................. - 71 -

A journey to becoming: Status passage into nursing and midwifery.......... 72 -

A liminal place .................................................................................. 74 -

Witness to the hero.............................................................................. 77 -

Chapter Seven Jo's Story: The Portal of Transformation...................... - 82 -

A journey to becoming: Status passage into nursing and midwifery.......... - 82 -

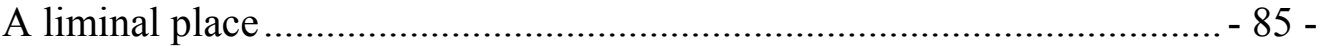

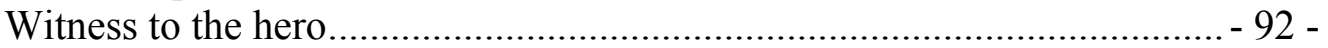

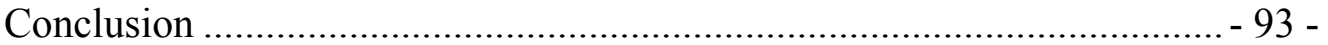

Part Three: The Master of Two Worlds ........................................................... - 95 -

Chapter Eight Discovering the Boon...................................................... - 97 -

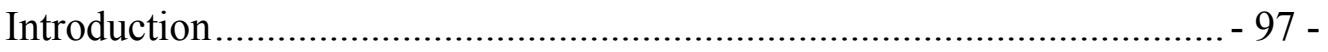

Narrative functions of thinking and reasoning in decision making ........... 99 -

Factors affecting individual and group identity ..................................... - 104 -

The juxtaposition of esteem to the dominant discourse ........................... - 107 -

Reconciliation of work pattern and life stage/Midlife ............................. - 109 -

Stress and Burnout .............................................................................. 113 -

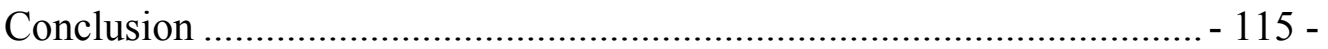

Chapter Nine Back to the Future: Toward a New Mythology ........... - 117 -

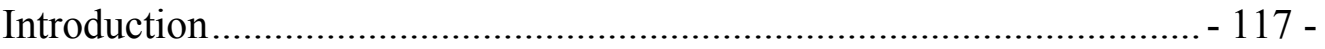

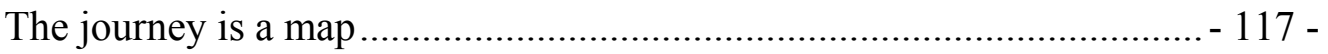

Reflections on the research process ........................................................ 119 -

Back to the future: Significant findings ............................................... - 124 - 
What might a new mythology imagine?

$-127-$

Conclusion

Appendix 1: Ethics Approval.......................................................... - 131 Appendix 2: Advertisement ......................................................................... - 132 Appendix 3: Participant Information Sheet ........................................... - 133 Appendix 4: Consent for participation .......................................................... - 135 Appendix 5: Transcriber Confidentiality Form........................................ - 137 References .......................................................................................................... 138 - 


\section{List of Tables}

Table One: Study design considerations ................................-48-

\section{List of Figures}

Figure 1: A macro-cultural perspective $\ldots \ldots \ldots \ldots \ldots \ldots \ldots \ldots \ldots \ldots \ldots \ldots \ldots .28$ -

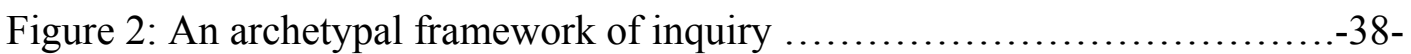




\section{Part One}

\section{The Call to Adventure}




\section{The Call to Adventure}

The call is to leave a certain social situation, move into your own loneliness and find the jewel, the centre that's impossible to find when you're socially engaged.... You are thrown off centre, and when you feel off-centre, its time to go. This is the departure when the hero feels something has been lost and goes to find it. You are to cross the threshold into new life. It's a dangerous adventure, because you are moving out of the sphere of the knowledge of you and your community.

(Campbell, as cited in Osbon, 1991, p 77) 


\section{Chapter One Heeding the Call}

A journey across a divide provides the subject of this thesis and relays the experience of dually registered nurses and midwives as they decide and choose a career path following the regulatory separation of the professions.

\section{Introduction: Setting the scene}

Due to a shift in legislation the position of the nursing and midwifery professions has changed following separation of their regulatory framework, so the divide is both figurative and literal. Try to define 'divide' and we might call for the skills of a mediator, a cartographer, a mountaineer, or a mathematician. Each skill set appreciates the multiplicity of meanings that fit, however, for the purpose of this study there is the possibility that they all might apply. What was the sum of the past has now been split into equal parts. The current social context necessarily grounds our thoughts and memories of the landscape of both professions, but as practitioners re-orient themselves, the cleavage between 'now' and 'where we used to be' calls for interpretation and understanding. We might begin to appreciate the impact of culture on personal and professional geographies by engaging, through language, with the journeys of nurses and midwives as they negotiate this historical period of choice and change in New Zealand healthcare. I have therefore called this thesis Journeys Cross Divides and seek to investigate the experience of choosing a path following the regulatory separation of the professions.

The Health Practitioners Competence Assurance Act 2003 (HPCAA) highlights the position of professionals in healthcare that now exists. The HPCAA was developed as legislation in response to healthcare consumer expectations that all health professionals be accountable for maintaining and demonstrating professional competence. Components of the Act have to do with health professionals reviewing their practice and knowing what the public expects (competencies), and what the profession expects (standards, code of ethics and philosophy). Notable professional changes are the introduction of scopes of practice, competency for performance based practicing certificates, and a multi-disciplinary Health Practitioners Disciplinary 
Tribunal. In addition the Act made provision for the introduction of new regulatory authorities for various health professions. Authorities were set up for Midwifery, Nursing, Medicine, Physiotherapy, Chiropractors, Dental, Pharmacy, Psychology, Dieticians, Occupational Therapy, Osteopathy, Optometrists, Medical Laboratory Technologists, Radiation Technologists, and Podiatrists (Dawbin, 2005/2006; Guilliland, 2003; Ministry of Health, 2003).

The HPCAA continues the core functions that the Nursing Council had under the Nurses Act 1977 of setting and maintaining standards for nursing education programmes: registration and maintaining the register; investigation of nurses; and health and disability monitoring (Nursing Council of New Zealand, 2005). All complaints are now channelled through the Health and Disability Commissioner's Office. As an independently chaired, single disciplinary tribunal it offers advantages for the public in its common standards approach.

The midwifery register was transferred from The Nursing Council to The Midwifery Council on 18 September 2004, and, as a separate regulatory body, now fulfils the same function respectively for its members. The Midwifery Council and The Nursing Council now issue practising certificates separately for each profession. At the time of the development of the HPCAA, New Zealand was considered a forerunner for this type of legislation, and the then Minister of Health, Annette King, received international interest and enquiries about this legislative approach to the accountability of health professionals (Cassie, 2003). It has however, resulted in some significant changes for practitioners, and these changes have resulted in degrees of anxiety as nurses and midwives come to grips with what these will mean for them. Up until now practitioners had moved freely between the two professions, the only requirement being to have an Annual Practicing Certificate (APC). Now nurses and midwives need to demonstrate continuing practice competence in order to hold an APC.

Despite efforts by the professional bodies to educate their members, general confusion about what was actually required occurred. Norma Campbell, New Zealand College of Midwives (NZCOM) Midwifery Advisor responded to confusion about the role of the Midwifery Council of New Zealand (MCNZ) versus the role of the NZCOM (Campbell, 2005). Issues were also highlighted in the letters' pages of the New 
Zealand journal of nursing, Kai Tiaki, where calls were made for a review of Nursing Council procedures around dual registration (Davies, 2006; DeBock, 2006; Gilmer, 2006). Their claims were of inconsistent approaches to applications, and concern regarding the overlap between the competencies required from both professions, particularly in areas related to secondary or tertiary maternity settings. So, it would seem that one of the definitions of divide, as being at variance, could also be relevant. The New Zealand Nurses Organisation (NZNO) developed a discussion paper on the issue and in response to this, and feedback from nurses, the Council reviewed and amended its definition of nursing practice (Trim, 2006). The new definition seeks to clarify what practitioners must provide in order to ensure a sound case for a successful application.

\section{Why this study?}

I was interested in understanding what this period in our professional history meant for practitioners with dual registration. In order to acquire the necessary skills and knowledge to practise, the majority of practitioners with dual registration began their professional socialisation process with formal education in nursing. There was a time when midwifery was considered a post basic specialist area of nursing practice, so practitioners would proceed on to studying midwifery as a specialist working arena. This type of scenario illustrates the linkage of professional identity of what it is to be a nurse, as being intertwined with what it is to be a midwife. This intertwined persona is therefore integral to, and constitutes individual identity and self definition. It would be interesting to see whether this historical preparation exerted any sort of influence on nurses and midwives' identities, and whether or not it had any effect on the process of relinquishing one discipline.

I worked with some practitioners who held part-time employment in both disciplinary categories, and I was aware of some practitioners working in tertiary settings who felt strongly that they utilised both skill sets in the course of their work. Applications for APCs now require a self declaration related to relevant hours of practice, and for some dually registered practitioners the concern became whether current work practices could be sustained. It was not unusual to hear colleagues expressing displeasure at 
being placed in this position of choice, particularly as whatever decision was made would affect future professional options and as a flow on effect, personal lives. So initially some confusion and discontent was evident. Other viewpoints were also confused but anticipating ways to make the best of the imminent change.

There were practical repercussions for supporting the rhetoric of advancing professional identity and autonomy by separate governance. Change echoed the question: where are we heading? For individual practitioners in this context it became: where do I want to be? In order to change, an individual must start out from something to head toward something else which may disturb equilibrium, and trigger a process of personal transition. Focussed attention on all of the issues grew and encouraged conversations within the professions on how to sustain one or more registrations in creative and innovative ways.

The popular view of navigation is that it is a conscious, goal directed activity in which someone is trying to reach a destination. What is missing here is the failure to appreciate how environments are conceived by people, as opposed to simply perceived by people. Rather than just adaptation to a physical structure, people play a role in producing their environment through their activities and practice. This space then is subjectively defined. It is the context of this space that differentiates navigation from way finding (Benyon, 1998). People may navigate through places, so navigation is not always directed towards a destination. Some practitioners may have navigated through nursing to train to be a midwife, and someone else might be trying to get away from shift work or work stressors. In the latter, navigation is away from a place or geographical space toward a social space or a place of safety. Practitioners will have different conceptions of landmarks depending on their positioning. My own sense of positioning was challenged as I had the traditional passage of carrying my midwifery registration in concert with my nursing registration, renewing certification each year through the Nursing Council. Over several years, I had worked between the professions, so suddenly this penchant for a variety in work practice was lifted and challenged. There would now be two separate scopes of practice, each with their own set of competencies to be considered if I were to maintain the luxury of an expanded set of options for future employment. Could I really sustain two sets of competencies and serve both professional discourses? 
If this was a professional highway, I was sitting on the curb. The forthcoming HPCAA posed a dilemma as I was working in a community Family Centre, in a position defined as nursing. I'd always considered that my dual registration suited my practice in this context as I used both sets of knowledge. The clientele was composed of mothers and babies from birth through to one year of age. But a look at my practice in light of the now separate competencies revealed that I was not meeting the antenatal and delivery components and therefore not practicing explicitly as a midwife; I was on the other side of the divide. This meant that I would not be able to satisfy the requirements and stay in the same job. This was a call to decide how I was going to fashion my professional future and involved evaluating what now constituted my perspective on the world, along with the realisation that a sense of loss would accompany whatever choice was made.

In contemplating this predicament I was drawn to reflect on how I had created my current identity from my past; I was my history. The basic instrument for refining what my sense of 'being-in-place' should be was my emotionally loaded and culturally coded memories and experiences. It is precisely these patterns which make each one of us different. A perceived sense of loss in not renewing my midwifery APC contributed to a prolonged transition phase between my sense of identity as a midwife, and full incorporation into my practice as a nurse. The centrality of this history to the interpretive stance I take in this study means that at times this transition phase is framed from a perspective of what was relinquished. My personal construction of reality, therefore, afforded a pre-understanding of the experience of dual practitioners that was subjective. The experience triggered in me the realisation that all affected practitioners would have a story to tell about how they went about this process of choice and change, and what this process meant to them. We each search through our store of experiences, past and present, to find a path for the future. We align our world view with what we each know individually, and what is supportive and empowering. We are a part of our own and others stories, and we will all be a part of the story telling embedded in our professions. I wanted to hear about the internal compass of other practitioners and what conceptualised their journeys. What is involved in shaping our sense of professional self, and how would nurses and midwives in this position restate themselves now that they were further along on their 
professional journey? How do we reclaim some semblance of participation in the changing professional landscape? Do the roles that we play have any influence on how we see ourselves and others; and how does the shifting ground of professional life affect personal lives? Finding out from affected practitioners what factors were important in making a decision would make it possible to see change negotiated from the 'inside-out'. We might gain a greater understanding of how, at the point of discontinuity and change, the underlying dynamics of social process affects our personal journey.

\section{Purpose of the study and research questions}

We could imagine, therefore, two different and connected research spaces. At ground level and visible are the political machinations and effects on the professional workface; and then a second space below ground are the reverberations of social change on people's personal and individual lives.

The purpose of this research is to illuminate and give voice to the experience of dually registered practitioners who have been involved in the process of making a choice about which profession to commit to in their immediate future. I recruited three practitioners: one who has relinquished her nursing APC, and is practicing as a midwife; one who has retained both APCs; and one who has recently relinquished her midwifery APC, and is practicing as a nurse. I explore how the three came to their eventual decisions and the issues involved in helping shape that decision. By giving voice to their experiences and revealing behavioural, social/emotional, cultural/historical aspects of their lives, I surface and theorise about the process of their individual journeys across the divide now apparent between the professions of nursing and midwifery.

In order to give voice to their experiences, the research questions addressed were:

What becomes important to us when we have to consider the issue of professional change? 
Is their current positioning as a result of the HPCAA, or would they have made these changes anyway?

What was the process of decision making and was there a familiar pattern or trend to the way that they made decisions in the rest of their lives?

What would they describe as useful strategies for change?

It became evident from a review of the literature that there is no record about the impact of this legislation on individual practitioners. This is possibly due to the currency of the HPCAA. Diekelman (2001) advises that the use of narrative becomes an interpretive phenomenological approach to learning when clinicians publicly share and interpret their experiences in the context of education that issues from research. Therefore I selected a narrative approach to engage each of the participants in dialogue following reconstruction of their experience through story. Rather than being random and meaningless, social role behaviour tends to be patterned. A narrative pedagogy describes the recurring patterns, common meanings, and shared experiences of those participating; it thereby offers the audience an opportunity to understand issues in new and different ways. As a dynamic perspective the different narrative accounts illuminated a range of variability among individuals enacting or anticipating the same role transition.

The career transition literature seemed to focus on role transition as a boundary crossing, and this thesis discusses it as crossing a divide. At a symbolic level, transitions not only 'do' but also 'say' something, having meaning beyond their pure content. Symbolic stories embody the enduring and universal qualities of our experience in myths. As our reality is in a constant state of movement and change it is possible that if we consider the symbolic component of identity, in the language of mythology, we might uncover new maps and destinations. By discovering what lies at the ontological core of our being, in spite of the words, we find 'memories' that paradoxically we never thought or felt before (van Manen, 1997).

The theme of the hero journey will become the winding thread of the study's path through the labyrinth of storytelling. Joseph Campbell (1904-1987), through his prodigious readings, writings, and travels, discovered remarkable parallels in the world stories and was convinced that the common themes and archetypes concentrated 
on similarities. The story of the hero journey, according to Campbell (1968a), is a 'monomyth', a cycle of mythology that has existed in its basic form since the beginning of storytelling. Reviewing the hero journey seems most appropriate to contemplation on path-taking. The choice is in which plotline to live and expand, and which to turn aside from, meaning that the old map may now be less than useful. What would happen if we lost the map and the destination? Campbell describes mythology as an interior road map of experience that opens the world so that it becomes transparent to something that is beyond speech, and beyond words (Cousineau, 1999; Smith, 2002). Stories are a way of redrawing maps and finding new destinations, so, as researcher I might be able to uncover this map by understanding the hero embedded within the story. A narrative approach not only addressed the research question but became a vehicle for the unique lens of the heroic quest to emerge as a key construct in this thesis.

The basic motif of the universal hero journey is leaving one condition and finding the source of life to bring the traveller into a richer or mature condition (Flowers, 1988). This same motif applies to practitioners traversing professional changes and their insights will be central to the boon, or the gift that the traveller returns to share with us. The winding thread of the hero journey will comprise further discussion as we go along. The basic map is that of a cycle; heeding the call, a going, and a returning. It will provide the skeletal framework for the layout of this thesis.

\section{Justification for the study}

The theoretical literature following the HPCAA has concentrated almost exclusively on organisational change but no specific evaluation of the impact on individual practitioners. Understanding personal experiences of work role transitions could have significance for the development of individuals and their organisations. Important voices, questions, and evidence are missing that, if present, would add greater depth and context to this period in our joint professional histories.

Future workforce planning is dependent upon an accurate description of the needs of the population and the ability of the workforce to meet these requirements. Succession 
has been described by Nicholson (1984) as a key element in the process of exchange between the cultures of organisations and their environments; therefore role changes trigger major shifts in workforce ideology, population, and practice as practitioners migrate, or cross the divide between professions. The outcomes of this study therefore not only contribute to thinking about the consequences of mobility, but also relate to how organisational change reshapes individual group membership and goals.

Classic work by Glaser and Strauss (1971) describes work role transitions as any change in employment status, and any major change in job content including all instances of status passages. This represents the process of change from one social status to another, and in this report, transition occurs between the occupational roles of nursing and midwifery. This involves a 'letting go' of some aspects of a previous status before the threshold of a new experience is crossed. The status passage includes the anticipations, entry, reporting of contrasts and changes, often accompanied by surprise and reality shock before the passage is made sense of some months later. Subpassages might include the subtle process of divestiture which results in loss of personal identity (Bradby, 1990). Personal and organisational adjustment outcomes have been found to be associated with the characteristics of the person, the role, and the organisation. So, by studying individual adjustment to this particular transition process we might be better informed about whether the impact of changing work role experiences might be a function of job characteristics and demands, or from reaction to the shifting professional environment.

History proves that control over health work is continually being negotiated and contested between various occupational groups. Each group will make different claims about their knowledge and expertise, and their relationship to consumers in an effort to secure some jurisdiction over their service claims. From my own experiences of negotiating the boundaries of the two professions, I consider that we must continue to work and develop relationships of mutual support. The two professions help shape the health care environment for young families in Aotearoa/New Zealand. I have gained a greater awareness of this now, having worked as a dually registered practitioner on this inter-professional boundary; in a community Family Centre, and as a Well Child Health Nurse. I have witnessed the profound effect on clients of the values, attitudes, and words we convey in the course of our everyday work that 
detracts from constructive relationships. An ideal application of an integrative view to my current practise area would see a seamless process of transfer of care of a pregnant woman from a General Practitioner, to a Midwife as Lead Maternity Carer, to a Well Child Nurse; all in a timely fashion with the full and involved consent of the client and her family. This incorporates a sense of trust that includes all that has gone before, and a vision toward the future. By acknowledging health as the pattern of the whole, ideally there should be no boundary.

It is time to give voice to practitioners' stories as testimony and witness to the experience of professional decision making. To date, we have not considered what fates befell those nurses and midwives caught on the threshold of change. Therefore, it is my intention that this thesis will contribute to knowledge that charts the possible maps and destinations of dually registered practitioners following the HPCAA. Participants co-authored their experience which meant that they studied themselves, challenged their own situated knowledge, and empowered their own transformations.

\section{Structure, style, and outline of the thesis}

There are nine chapters in this thesis report, each chapter addressing a key aspect of the research. The significant work of Campbell (1968a; 1968b) details the perennial myth of the hero journey, and informs the shaping of the three sections of the thesis. Campbell's schematic of departure, initiation, and return of the hero's journey works well to describe the narrative structure of quest stories and appreciates life pattern common to people of all cultures and all times, so the text as a whole aims at a certain effect. As dually registered practitioners are faced with the question of choice and change the sections of the study are positioned at liminal points i.e. refusal to heed the call, or refusal to return are the options at each juncture. Universal themes enable meaning and action in our lives to be framed in such a way as to illustrate our connectedness to each other. Any journey that crosses a divide has a universal and perennial significance. The coded matrices of new steps and pattern are portrayed in myth and provide templates for transformation. By considering the symbolic qualities 
present in storytelling there lays the discovery that these stories are our own, bearing amplified pattern of certain rhythms and cadences that we recognise.

The report is a synthesis of the relevant literature and theoretical viewpoints that underpin the three narrative accounts. As a difficulty in qualitative research can be reflecting the participants' voices accurately, there are places in this text where they are presented verbatim as active examples of participation in the research process. Together the texts might be seen as a collage of layers of response illuminating some common themes. Chapter one starts the hero's call to adventure in Part One. The goal of narrative strategy is that the narrator's voice is heard, so I foreground my own autobiographical statements at the beginning of the study. In this chapter I have introduced the study and the social dynamics of the system it is situated in. My values and assumptions as researcher, derived through active and connected engagement with the experience, are presented so that readers understand my own discursive positioning. Two key constructs that were introduced were role transition, and the metaphorical lens of the hero journey.

The cultural nature of nursing and midwifery's history binds the investigation of dual practitioners experience and social reform together. In Chapter two, by displaying a macro-cultural perspective, I look at the cultural origins, characteristics, and functions of working within both disciplines. To identify steps and stages, and the high points and low points of a journey crossing a divide, maps mark out the territory. Here the historical and socio-political context of nursing and midwifery in Aotearoa/New Zealand are portrayed, emphasising the socially organised nature of knowledge. The HPCAA re-positions the two professions and sets the scene for the study. Understanding everyday experience is to appreciate these links and weave into the fabric of nursing science the perspectives of those who find themselves on the margins.

In Chapter three the epistemological considerations are shaped by the research question, and in turn shape the task of the research by looking at how we construe reality. As all research is interpretive, they will be guided by a set of beliefs about the world and how it should be understood and studied. The use of a narrative pedagogy is explored as an approach to storying experience, and the myth of the hero journey as an epistemic form is examined in greater detail. Having constructed a version of reality 
the methodology is considered, focussing on the best means for acquiring knowledge and insight into the experience of professional choice and change. As this role behaviour is contextually bound then the study data will make essential, unobservable principles of work role transition explanatory and will highlight the relationship between these processes and culture. Micro-cultural understanding and social role theory aid exploration of psychological processes and transition from one role to another.

The design and methods for applying, conducting, and analysing the research process are detailed in Chapter four. The methods utilised include participant narrative, in depth interview, and textual analysis. The question of interpretive rigour and congruence is considered. The readers are prepared then for the participants' stories linking the theoretical and methodological preparation with the story themes about to emerge. The tasks inherent in the departure, initiation, and return phases of the hero journey provide a lens for considering the unique circumstances in each narrative.

In Part Two the experiences of Mary (chapter five), Susan (chapter six), and Jo (chapter seven) co-construct the hero journey of departure, initiation, and return. The hero journey involves a series of tests unique to each individual, commonly known as the road of trials. Such tasks prepare the hero for the ultimate goal, and move her toward self reliance. Crossing the return threshold brings the hero full cycle. Pseudonyms are used to protect their identity, and each story is representative of the three possible stances or positions. Mary currently has relinquished nursing and prioritised midwifery; Susan has relinquished her midwifery APC and is employed in a nursing position; and Jo has retained both APCs, working between the two professions meantime until she decides which path to concentrate on.

Part Three of the hero's journey, 'the master of two worlds' introduces Chapter eight's intent of discovering the boon, or the gift inherent in the stories. This concept is analogous with living from the centre of one's truth. The discussion focuses on a synthesis of insights, ideas, and claims that arise in the participants' stories. There are five sections within this chapter. The first considers the functions of thinking and reasoning that assisted in the process of coming to a realisation, and eventually a 
decision. The second explores individual and group identity construction. The third section relates the juxtaposition of esteem to the dominant discourse. Midwifery was the dominant discourse, and therefore lens, through which the participants in this study viewed their professional practice knowledge and identity up until the current scenario. The notion of liminal space, holding paradox in-between stories explores and challenges the status of subjective professional knowledge, and surfaces the tensions that are experienced in occupying an interstitial position. Section four considers the reconciliation of work pattern and life stage. Statistics show us that the majority of affected practitioners will be positioned in the middle of life. They will already have accumulated plenty of work and life experience, and so may have a different orienting world view. Section five examines aspects of stress and burnout signalled by practitioners as indicative of the need for some form of change.

Chapter nine presents my concluding comments. I provide personal reflections on the research processes, and areas of limitation. I then discuss the significant findings in relation to the journeys taken or not taken across the divide; in particular the emergence of myth as a heuristic device. The implications of the findings are envisioned as a new mythology shaping our personal and professional futures.

The aim of this research is to make visible the subjective experience of nurses and midwives as people who are constantly re-negotiating arrangements of family, community, and professional practice. Before we examine what might be involved in revising our self definition I address, from a macro-cultural perspective in the next chapter, the evolution of group membership through the historical roots of nursing and midwifery in New Zealand. 


\section{Chapter Two Maps and Destinations}

Experience mediates every aspect of what we understand as reality and reveals the variety of ways that we process information. A person's cognitive map is built up from observations gathered as they travel through the environment, so, the sieve that is history is always in transit. One might then ask the question: is history about the events or about how we perceive events?

Transition theory differentiates between two opposing dynamics, transition and change. Change can be described as external to the individual, while transition occurs internally. The HPCAA (2003) has changed the mechanism by which individual practitioners make application for a right to practice professionally. Thus, this change is easily demarcated in time, was scheduled and structured in steps, and then presented as new legislation. On a rational basis it denotes modification, improvement, and innovation. There is, therefore, a certain minimising of the impact and effects. Paradoxically such a change triggers in the individual the start of a process of personal transition. This is more likely to be slow and progressive, not demarcated in time, and related to each individual. Nortier (1995) locates this type of transition in the here and now, not what tomorrow seeks. It echoes the question: where am I, and relates to the daily impact of choice and change.

The context of this study, then, might consider change and transition condensed to four common elements. First consideration is the work related element, such as the transition from self employed to employee, or the transition from one professional discipline to another. Just as significant are the notions of change and transition occurring at a symbolic level. Transition meanings go beyond their pure content and might be linked with rites of passage (Van Gennep, 1960). Individual adaptation to career transition has potential consequences for all areas of life; and at a collective level, transitions convey messages to the social context of the individual and simultaneously the social context uses transition to exert influence on the individual (Chudzikowski, 2005). 


\section{Transition: The missing link}

Transition could be conceptualised as a phase of change bridging two zones, a missing link that enables us to move from the before to the after. The nature of change being experienced in career following the HPCAA (2003) means that the old maps are no longer appropriate. Maps are presentation devices that display an abstract view of a portion of the world with an emphasis on selected features. The metaphor of maps and destinations seeks to orient the reader using typographical landmarks to enhance direction and depth perception, and will assist in examining the external and the internal landscapes throughout this study. If we were to compare the understanding that a map brings to the reader to a linear text, the difference is in the spatial relationship accomplished by map reading. Spatial thinking is an essential part of our relationship to our physical and cultural environment. There are social and cultural conventions associated with the space between nursing and midwifery, lending the experience a certain qualitative dimension; also, the objective distance may not accord with the felt distance between the two spaces.

The amount of detail shown by a map is dictated by the scale of the map, and utilises the natural action of bringing objective areas of interest closer, in order to see them better. By developing a design with enough variety of forms and spaces, yet organising them clearly, landmarks of the grid are established. The grid is the conceptual and regular placement of forms and spaces in a rhythm or regular pattern. Landmarks are the variations in the pattern which serve as unique elements, or points of reference by which to orient, and will be considered as subheadings within the chapter. Depth perception is also valuable for orientation, and by means of magnification of the underlying map the lens of the hero journey will provide a smooth transition later between levels of detail. This interface should allow information objects, and the structure embedding them to be displayed at many different magnifications or scales.

For the purposes of this study, and to provide perspective information, we might imagine the columns of our professional grid as midwifery, and the rows as nursing. The grid of the map casts into relief a certain spatial region. By concentrating on each cell, navigation is more efficient, revealing nuance and detail. These will be the 
accounts given later by the three participants. The scale, however, is one of the first parameters to be set in designing a map. We will consider the well trodden paths linking origins and destinations by beginning our discussion firstly with the profession of midwifery. Midwifery is about the map as its movement has created a new relationship with nursing. When relationships change, maps and destinations change also.

\section{The map of midwifery}

Two major reference sources were utilised to provide an expanded cause for reflection on the relations between the various professional groups, clients/consumers, and the state. First; from various positions, as Head of the School of Midwifery and Manager of Health, Otago Polytechnic, Dunedin; Chair of the Midwifery Council of New Zealand; and Education Consultant to the NZCOM, Pairman charts the course of educating midwives across a century in a two part discourse: 'from autonomy and back again' (Pairman, 2005; Pairman, 2006). Second; Tully and Mortlock's text (1999) provides a sociological lens on the changing relationships between occupational groups in the health care division of labour in Aotearoa/New Zealand.

It has taken New Zealand midwifery one hundred years to come full circle. Over the century from 1904 to 2004 midwifery practise shifted from a practice of relative autonomy, to dependent practice under medical supervision, to full professional autonomy (Pairman, 2005). The return to being recognised as a legitimate profession, with midwives practicing as autonomous professionals, was brought about by the enactment of the Health Practitioners Competency Assurance Act in September 2003, and the birth of the fully functional Midwifery Council on 18 September 2004. Now midwifery is regulated separately from nursing in recognition of midwifery as a distinctly different discipline. This creation of an occupational distinction between nursing and midwifery was effected through changes in their training and scope of practice. The professionalizing strategies adopted by midwifery leaders and maternity consumers and activists emerged from these mutually dependent relations (Tully \& Mortlock, 1999). 
As early as 1904, in response to government concern over increasing maternal and neonatal mortality rates, the Midwives Registration Act was passed. It provided for the establishment of state maternity hospitals, later named St. Helen's hospitals, to train and prepare midwives for registration. This was the beginning of the state maternity system. The ensuing history is complex and embedded in the evolution of New Zealand society. An important factor contributing to the blurring of the boundaries between nursing and midwifery work was the shift of birthing from home to hospital. High maternal mortality rates in the 1920 s led to regulations aimed at eliminating puerperal sepsis, and the medicalisation of childbirth dominated midwifery practice through to the early 1980s. Consequently midwives were to lose their role as guardians of normal birth, and their role was reduced to one of assistant to the doctor (Guilliland, 2004; Pairman, 2005). As childbirth came to be understood as a pathological event most safely managed in hospital, the majority of maternity care came to be provided by maternity nurses working with doctors (Donley, 1986; Hill, 1982).

Changes to the nursing curriculum in 1957 incorporated maternity/obstetric nursing into the three year registration programme. By the passing of the 1971 Nurses Act, midwifery was virtually indistinguishable from nursing as it removed midwives' right to practise independently of doctors (Tully \& Mortlock, 1999; Pairman, 2005). By 1978 the six month midwifery course previously offered was closed and instead midwifery became an 'option' module within the polytechnic Advanced Diploma of Nursing (ADN).

Most midwives, by the 1970s, were working in base hospitals under the supervision of obstetricians. They formed a small sectional group within the New Zealand Nurses Association (NZNA), and were later to commence lobbying to achieve a separate identity to nursing. Meanwhile a small handful of domiciliary midwives worked alongside sympathetic GPs in the community, providing services for women to give birth at home. The existence of domiciliary midwives created cause for disagreements about the preparation and role of the midwife, and attempts were made to control their practice and reduce the number of homebirths. Despite a major rift, domiciliary midwives successfully opposed the transfer of their contracts from the Department of Health. Because this group was able to preserve its contract for service independently 
of hospital boards, there was an existing mechanism available to midwives to later claim payment directly from the maternity Benefit Schedule managed by the Department of Health, following the Nurses Amendment Act 1990 (Pairman, 2006).

In the interim, the formation of maternity consumer groups had significant consequences for midwifery-nursing relations as they undertook various political activities. By the 1980s they were expressing their concerns about the increasing intervention, and identified the threat to midwifery as contributing to their lack of control over their childbirth experience. Consumer groups such as Parent Centre New Zealand, and the Homebirth Association began active campaigning for changes to midwifery education that would support women to have better birth experiences (Dobbie, 1990; Kedgley, 1996; Strid, 1987).

Nursing's dominant position, in relation to midwifery in New Zealand, was consolidated in the Nurses Amendment Act 1983 (Donley, 1986; Pairman, 1998, 2005, 2006; Tully, 1999; Tully \& Mortlock, 1999). This allowed nurses/non-midwives to provide maternity care. A highly significant outcome of this legislation, however, was the emergence of collaborative relations between the more politically active midwives and the aforementioned consumers. When faced with opposition from nursing leaders over the stand to separate from nursing, midwives turned to maternity consumer groups for support. The public's concern about the rights and needs of maternity service consumers, continued to increase, and was heightened in 1987 following an inquiry into allegations concerning the treatment of cervical cancer at National Women's Hospital. It will be remembered as one of the most significant medical controversies of the twentieth century. Although it focussed on a gynaecological issue, the inquiry broadened to encompass scrutiny of research practices, teaching methods, patients' rights, and medical power, having important implications for the future of medicine in New Zealand (Coney, 1988; Tully \& Mortlock, 1999).

A further claim was that key policy advisers to the health sector at the time recommended introducing competition between providers of health services, arguing greater efficiency and responsiveness to consumer needs (Cheyne et al, 1997). This made midwifery's claims about their appropriate role in 'normal' childbirth compatible with the states interest in containing costs, increasing consumer choice, 
and diminishing professional control, according to Tully and Mortlock (1999). All of these factors contributed to a political climate that created a groundswell of approval for the passing of the Nurses Amendment Act in 1990, affording midwives the autonomous status. Independent of doctors, midwives could now prescribe and administer certain medications, request routine diagnostic tests, and transfer clients to specialist services. Recognition as an independent profession meant that specific education programmes were designed that did not rely on the pre-requisite nursing preparation. Since 1992 this has been through a three year Bachelor of Midwifery programme (Pairman, 2006).

\section{The map of nursing}

The discussion about midwifery comprises a large section in this chapter because its movement has created a new relationship with nursing, and carries the larger shift. Nursing, however, has similar shifts and movement, and a lot of its history is intertwined with midwifery, and has been mentioned in the previous section. Nursing care in New Zealand is currently being delivered by a range of providers with a variety of scopes of practice, titles, and levels of educational preparation. The exact nature of nursing was recently redefined by the Nursing Council in June 2006 as "Nursing practice is using nursing knowledge in a direct relationship with clients or working in nursing management, nursing administration, nursing education, nursing research, nursing professional advice or nursing policy development roles, which impact on public safety" (NCNZ, 2006).

Significant changes have occurred in nursing following a major review by a ministerial taskforce in 1998, and an independent consultant, commissioned by the Nursing Council, in 2000 (Department of Health, 1998; NZNO, 1998; Papps \& Kilpatrick, 2002). Entry into practice now is by means of an undergraduate degree programme undertaken at a polytechnic or university. Formal specialty specific education is now available through post-registration education programmes and these have been designed to better align practice with health care strategies. The Nursing Council of New Zealand framework outlines a pathway of educational preparation for registered nurses, extending from the first year of practice through to advanced 
nursing practice and culminating in the nurse practitioner role (Ministry of Health, 2007; NZNO, 2007). This focus in nursing is representative of a time when consumers' needs are paramount. Prescribing, advanced practice and the move to competency based practising certificates are a shift away from the biomedical model of care, to a more holistic approach in partnership with patients/clients. Professional development recognition programmes provide opportunities for multi-level education that supports learning needs in a transparent manner. There is an explicit expectation that nurses will take personal responsibility for their ongoing professional development and decision making, which aligns with the HPCAA (Pearson, 2005).

\section{Map and compass in the current context}

Maps assist us to develop and maintain context knowledge about the layout and functions of the various landmarks within an environment. The maps of midwifery and of nursing construct the professional grid of significance in this study. The context of the HPCAA (2003), as an instrument for determining nurses and midwives' directions or positions, metaphorically acts as its compass. The previous sections outlined the background for a somewhat uneasy relationship between midwifery and nursing in the areas of education and practice through the century leading up to the current context of the HPCAA. The two professions now have a more collegial relationship as the effort to achieve autonomy is appreciated as self determination for midwifery rather than rejection of nursing (Pairman, 2002).

The HPCAA (2003) now brings all health practitioners under the one regulative statute creating greater consistency for the health care consumer. It mandates the regulatory authority of each profession to ensure its practitioners are competent and don't pose a risk of harm to the public. There are eight key sections prescribed within the HPCAA; they include preliminary and key provisions; registration of practitioners and practicing certificates; competence, fitness to practise, and quality assurance; complaints and discipline; appeals; structures and administration; miscellaneous provisions, consequential amendments, repeals, and transitional provisions; and a guide to the general scheme of the Act (MOH, 2003). Part Two sets out the conditions 
that a health professional must meet in order to practise, and is the most relevant section to this study.

Key provisions of the HPCAA (2003) state that an unqualified person must not claim to be a health practitioner; and those health practitioners must not practise outside their scope of practice. The regulatory authorities are responsible for specifying scopes of practice, prescribing, and maintaining the principles that guide the prescribing of qualifications. The requirements for registration, fitness for registration, and authorisation of scopes of practice are appointed in respect of a health profession by the delegated authority; and applications for APCs are made by the health practitioner to the Registrar of the responsible authority (MOH, 2003).

The Registrar of that authority must take all reasonable steps to ascertain that the applicant meets the required standard of competence. The following criteria outline the possible restrictions on issue of an APC to an applicant; failure to maintain the required standard of competence; or failure to comply with a condition included in the scope of practice; not holding an APC within the previous three years; or an inability to perform the functions required for the profession because of some mental or physical condition; and/or if the applicant has not lawfully practised the profession to which the application applies within three years preceding the date of application (MOH, 2003).

The Nursing Council sets the requirements for nurses, and the Midwifery Council respectively for midwives. Both professions require practitioners to sign statutory declarations to apply for an APC in good faith. For individual practitioners this means that their APC will be linked to a scope of practice which will describe the required competencies for each scope, and they must be able to demonstrate that they meet the current competencies. It is possible to hold an APC as a midwife, or as a nurse, or both. To be more specific; to work as a midwife, demonstration of competency within the midwifery scope of practice, as defined by the Midwifery Council, is required. To work as a nurse, demonstration of competency in one of the nursing scopes of practice, as defined by the Nursing Council, is required. To hold both APCs competency requirements for midwifery must be met, as defined by the Midwifery Council; in 
addition, demonstration of nursing competencies that fit the defined scope of nursing practice, as defined by the Nursing Council must be met (MCNZ, 2004).

According to the Midwifery Council (2004) midwives must take part in the Midwifery Council's Recertification Programme; this involves demonstrating that practitioners have worked across all areas of the midwifery scope of practice; antenatal, labour, birth, and postnatal, the evidence of which is provided in a practice portfolio; attendance at a minimum of three days of compulsory education in three years; and attendance at a Midwifery Standards Review (MSR), annually as a caseload midwife, or once in each three year recertification cycle as a core midwife (Campbell, 2005, Campbell, 2006).

The Nursing Council's Continuing Competency Framework (NCNZ, 2004) provides a mechanism to monitor competency through the application process for APCs, and through audit. Five percent of nurses applying for APCs annually will be randomly selected from the register, and will need to provide the following: evidence of practice (a minimum of 60 days, or 450 hours in the last three years); evidence of professional development hours; and two of the following methods of assessment- senior nurse assessment or performance appraisal; peer review, or evidence of involvement in peer review activities. A competence review process, still in its infancy, is designed to support nurses whose competence has been called into question, to continue practicing while their competence issues are addressed (Dawbin, 2005/2006; Keenan, 2006; NCNZ, 2004).

The possibilities of investigating this current phenomenon of professional change may shed a greater understanding of how practitioners deal with shifting meaning, values, awareness, choices, and relationships. Such insights can shed light onto the factors that influence agency with a group, personal and professional issues of identity, professional decision making, negotiating change, influences on staff retention, and therefore the stability of the professional workforce. There are already early indications that the HPCAA (2003) is having an impact on workforce numbers. The problems that result from a transitory workforce have already been demonstrated in the first midwifery workforce profile, involving NZCOM, Midwifery Council, Statistics New Zealand, and the New Zealand Health Information Service. The effects 
of the past shortfall in midwifery graduates is apparent and has highlighted for the Ministry of Health that urgent recruitment and retention strategies need to be explored and developed for midwifery. The data revealed that 1473 dually registered practitioners renewed their midwifery APCs in 2004, even though they were not working in midwifery, however, only 192 of this number re-applied in 2005 (NZHIS, 2005; Hendry, 2005). A crude workforce measure, obtained from the increased birth rate numbers per caseload midwife for 2004, revealed a rate of 14 more births per midwife than the NZNO recommended caseload of 50 births per year (Hendry, 2005).

The obvious repercussions of increased workload are stress and burnout. A nurse/midwife member of the Multi-employer Collective Agreement (MECA) states that there was some anecdotal evidence in the Waikato that the MECA may draw independent midwives back to hospital-based employment; "many independent midwives are very tired and many are burning out faster than hospital staff. The pay increase, combined with fixed working hours could well tempt some independent midwives back to hospitals" (Black, as quoted by O’Connor, 2005, p 11).

Professional identity is central to a profession's strength and success. Group membership of a profession means taking on the philosophy, role attributes, and standards that prescribe practice, and in doing so defines who we are, what we do, and how we are different (Dawley, 2005). Because the average age for both the nursing and midwifery workforce is 45-49 years of age, practitioners will have acquired several layers of life experience and education, no matter what the path to registration was (Guilliland, 2006). Given these age parameters the decision to create a regulatory separation between the two professions is likely to have an effect on workforce configurations and the ability to recruit and retain workforce, in the short term at least. The dramatic drop in numbers of midwives training and registering in New Zealand from 1981 to 1987 is still being felt in New Zealand's midwifery shortages today (Donley, 1986; Pairman, 2005). Empirical evidence supporting the concepts of mentoring, preceptorship and supervision require an experienced and stable workforce to be successful, and so will be compromised by the consequences of mobility. Statistics reveal the rate at which practitioners leave the professions annually, but not the reasons for doing so. In a small way the experiences of these research participants will contribute to an understanding of how practitioners negotiate the shifting ground 
of professional practice, and how they situate their individual experience within a new social context.

With similar concerns, safe levels of staffing are the focus for this year's International Nurses Day. There is the obvious link between unsafe staffing and patient outcomes, but in addition it provides evidence of a negative effect on nurses' health and leads to nurses feeling morally and ethically compromised when there is not enough staff. When moral distress is not alleviated at an individual level practitioners are more likely to suffer ill health and burn out. According to Bickley Asher (2006) the significant consequence is that staff will leave the job, and leave nursing. It is one of the explanations for the nursing shortage both here and overseas. This lends weight to understanding what issues prompt practitioners to depart, or shift their allegiance.

\section{Navigating the external and the internal landscape}

The HPCAA (2003) has created a unique moment in the history of New Zealand nursing and midwifery, as practitioners who hold dual registration must decide which profession to commit to. It is no longer acceptable to automatically renew and retain an APC without evidence of competency. The 'self' in the context of this study, is answerable to the regulatory authority and its standards of practice and principles, but what the self is responsible for is the authorship of its responses. The nature of the change being experienced in people's careers is not initially the question of a route, but of maintaining ones balance.

The cultural nature of nursing and midwifery's history has been demonstrated as binding dual practitioners past experience and social reform together. By discussing a macro-cultural perspective I have looked at the cultural origins, characteristics, and functions of each discipline. As social institutions they provide the basis of form and content for individual practitioners who have worked in both professions. The more deeply that an individual psychology is embedded in one culture or the other, the more profoundly the culture is embodied in their psychology. This makes understanding both cultures important to understanding how practitioners might negotiate the passage from one social status to another. The notion of liminal space, holding 
paradox in-between stories, explores and challenges the status of subjective professional knowledge, and surfaces tensions experienced in occupying an interstitial position. This interstitial position becomes the context for the research question and comprises the central shaded area in Figure 1: A macro-cultural perspective.

Continuing the metaphor of geographical landscapes, theorists distant from the action, might only be able to offer a Richter scale, or yesterdays solutions. As career cartographers, the presently affected practitioners are involved, not in mapping the changing terrain, but in finding routes through it. They are the Columbus's and Magellan's collecting the data to revise our maps. To identify and navigate these routes collaboration between theorists, researchers, and practitioners may be required. Such map-making will require two qualities of practitioners: a keen eye for understanding the current lay of the road, and the ability to see what previous cartographers have not seen. The maps and compass are merely the tools providing possibilities, but they are not the reality or the journeys themselves. The central thesis question concerning this path-taking experience will demonstrate the creation of new maps that reveal new places of settlement and growth, new routes linking parts hitherto unconnected, and newly discovered resources and features.

As I try to visualise these new maps and destinations I imagine a set of overlay maps. The mental image I have in my head is a series of maps, each transparent, yet with its own unique shape and form. They are maps for the same passage, but depending on how you overlay them one on another, you see the area you are traversing in different ways. This study will make visible the subjective experience of three dually registered nurses and midwives renegotiating arrangements of family, community, and professional practice. As the three maps are overlaid on the professional grid we might get a better sense of alternative routes toward eventual destinations.

The political understanding and reforming of the macro-cultural context contributes to the scientific goal of understanding its relationship to individual work role transition. The material that results from this study will describe what occurred for the participants during their process of decision making, and draws upon the world view of the Unitary Transformative Paradigm, conducive to the application of collective storytelling or myth (Smith, 2002). Encapsulated within the macro-cultural context, 
the researcher, the audience, and the participant are seen occupying the central space between the two professions. The interaction and activity that occurs between these parties comprises the micro-cultural context, and is explored in Chapter three. Social role theory will aid exploration of psychological processes and transition from one role to another. As this role behaviour is contextually bound then the study data will make essential, unobservable principles of work role transition explanatory, and will highlight the relationship between these processes and culture.

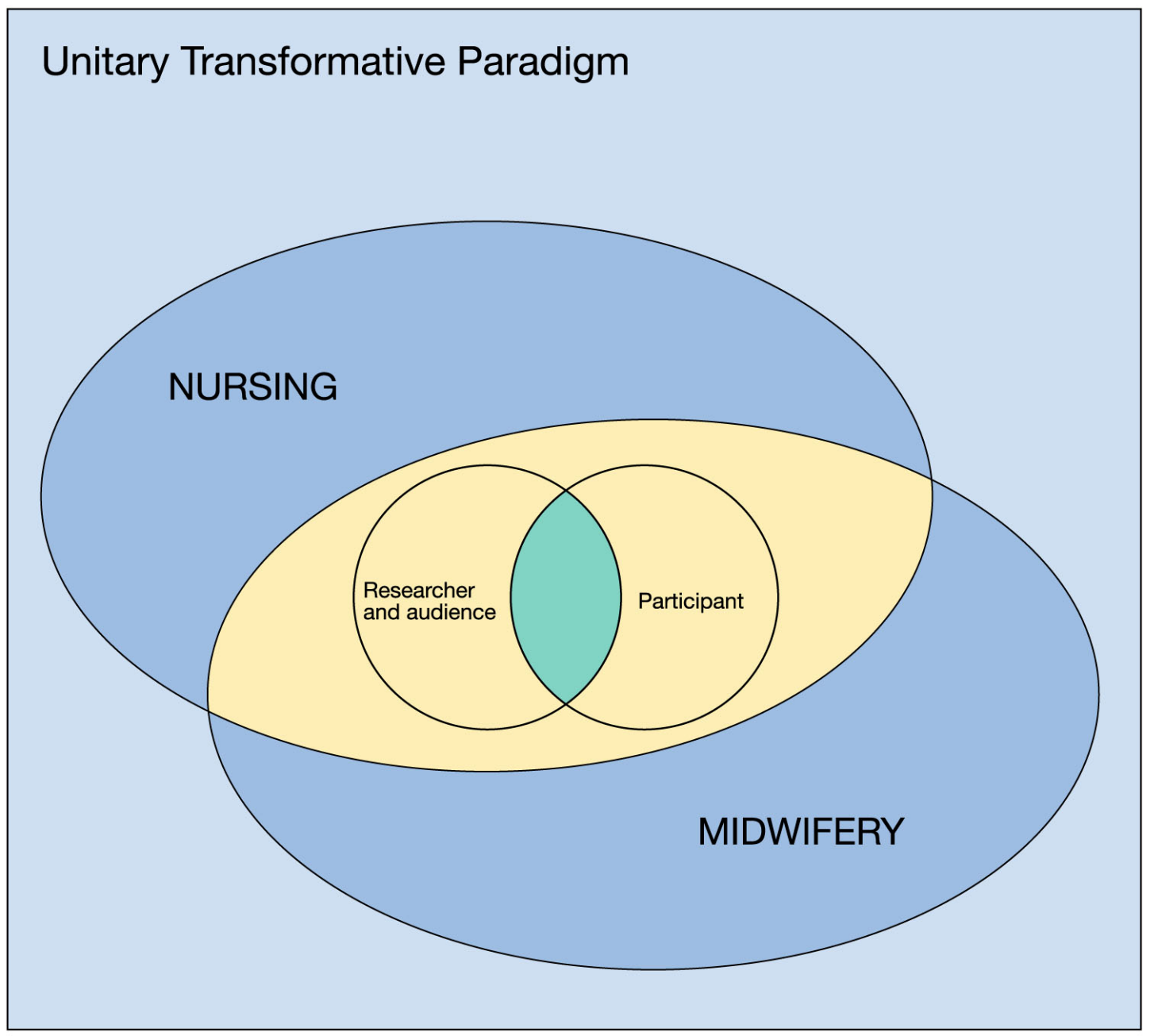

Figure 1: A macro-cultural study perspective 
What are the experiences of nurses and midwives who must choose a path following separation of the professions? Against the historically specific context, practitioner's claims to particular forms of knowledge and expertise being recognised are affected. As practitioners migrate between the professions the notion of hybridity leads analogously to the difficulty of defining culture in a 'pure' way (Bhabha, 1994). Following adjustment to the new legislative requirements, however, hybridity will be a transitory concept. The emerging future for the professions is commitment to one path, with mechanisms in existence for suitably qualified practitioners to be able to make a transition if they so desire.

This study utilises the insight generated in transition research to create a bridge between movements from one zone to another and to recognise transition as a phase of change. This includes work based on role theory (Murray, 1998; Nicholson, 1984); status passage (Glaser \& Strauss, 1971; Bradby, 1990; Bradby \& Soothill, 1993; Holland, 1999; MacNeill, 1997), and personal rites of passage and identity reconstruction (Van Gennep, 1960; Nortier, 1995; Schouten, 1991).

Understanding the maps and destinations that dually registered nurses and midwives create for themselves is an important inquiry. The literature presented in this chapter on the historical background of nursing and midwifery in New Zealand, acknowledges how, as practitioners of either professional discourse, we have been affected by each other. If we wish to learn from the lessons of the past, then our interactions might best avoid clumsily trampling over another's map, or even attempting to rewrite it for them. As we grow to understand each others reality we might be able to avoid misunderstandings and conflict. There are new features to be added to the maps that we have been using to navigate our future professional territories. Rather than make assumptions about the maps of others, and thereby risk creating conflict, we need to listen to what others have to say to build up our model of reality.

Symbolic adaptation to the process of self choice and change, and a synthesis of anthropological and psychological perspectives will aid understanding of these interrelationships next in Chapter Three. 


\section{Chapter Three Preparing for the Journey: Validating the Circle of Inquiry}

\section{Introduction}

For the purposes of this study 'a journey' is a concrete thing. It consists of the people on the journey, the vehicle, the destination, and the path. A humanistic approach of individual journeys following the HPCAA (2003), acknowledges both the world without and the world within. Landscapes approached from the macro-scale to the micro-scale, when viewed as a whole, constitute a context within a context. In Chapter Two we visualised the macro cultural context as a landscape having two dimensions; a horizontal (nursing), and a vertical (midwifery). As a pedagogical device it sets up the landmarks of the grid, whether it is optical, cartographic, or conceptual. To do justice to reality in its many aspects, a finer resolution is needed to consider now the micro scale; the individual affected by the changes that will reshape their professional landscape.

\section{The map is not the territory}

We tend to form a sense of identity from many different levels; i.e. an individual identity, a family identity, a community identity, a national identity, and a planetary identity (Campbell, 1968, 1988; Houston, 1987, 1996). Through our interactions and experiences within these worlds we construct conceptual maps, hence we are map makers. We use these conceptual maps to navigate and act in the world by filtering information for patterns that match our culture, interests, language, values, beliefs, understanding of past and present contexts; in fact everything we have learned in our lives. Each person's map of the territory will thus be unique, and risks becoming outdated if it is not kept updated. The perceived territory via sensory input, processed by comparison with stored experience and projected back out to the territory, show us the constructed nature of reality (Swallow \& Sullivan, 2004). This will help to explain the geographical difference in maps and the meanings that they hold for their readers.

An established personal identity has been demonstrated as being the most important factor before a person can focus on occupational role identity (Bradby, 1990). It is 
important to uncover the attitudinal attributes that foster professional status in nurses and midwives and incorporate them into education and service. As practitioners we respond to situations from within our existing knowledge base which has been accrued through reflection on our experiences over time. In addition to skill acquisition we develop a process of self inquiry as we reflect in the context of defining and understanding our practice. This involves a process of personal deconstruction and reconstruction which Johns (1994) describes as a threefold process of enlightenment, in other words, who I am in a practice context; empowerment, which involves the courage and commitment to take necessary action to change who I am; and, emancipation to liberate myself from previous ways of being to become who I need to be to achieve effective, desirable practice. These attributes will become important in adapting to meet environmental requirements.

\section{The journey as status passage}

Discussion about organisational or institutional change is likely to generate public debate about passages; past, present, and predicted. A status passage is the transition from one social status to another, and for the purpose of this study concentrates on the period of passage between midwifery and nursing. Although an example of early literature, Van Gennep's (1960) model of rites of passage has remained a common source for transition theory, alongside Glaser and Strauss' (1971) work on status passage. Both these works have influenced later role theory and adaptation models (Chudzikowski, 2005; Bradby, 1990; Bradby \& Soothill, 1993; Holland, 1999; MacNeil, 1997; Nicholson, 1984; Nortier, 1995; Schouten, 1991).

As I reflect on the impact of the HPCAA (2003) in the context of a collective nursing and midwifery passage, it could be seen to contain within it, solo passages. Common contingencies may become apparent when we examine what happens to people and how they work through them. As members of a cohort, that is, one of a large number of practitioners faced with this dilemma, it is quite possible that individuals will be unaware of all aspects of the similar passages of their colleagues. Glaser and Strauss (1971) argue that the centrality of the passage to the person, more specifically, how much difference it makes to them, will provide the motivational basis for actions that 
shape the passage. It may be considered in some measure desirable or undesirable by the person marking the passage, or by other relevant parties. This theory demonstrates that when the status passage is considered desirable only for the agent then recalcitrance and conflict are likely to dominate it. In studying the shape of the passage, it becomes important to determine the means of its control. If we consider this explanation in light of the changes in nursing and midwifery, it is possible to argue that a dynamic interplay probably exists between these forces, as the power of the law now insists on compliance and cooperation. As agents of the law, the respective Councils clearly hold the balance of power as practitioners must decide upon their course of action in order to apply for a functional APC. The choice for the practitioner is in its degree i.e. voluntarily, or a feeling of no choice. Hypothetically then, without undergoing the transition process the individual will not belong to either group.

The process of adjustment to transition relies upon change being absorbed through a person's frame of reference, values, and other identity related attributes. Nicholson's (1984) theory of work role transitions proposed a conceptual framework that linked personal and situational causes with individual and organisational outcomes. It demonstrated how transitions, according to their characteristics, are able to sustain continuity, or engender evolutionary or revolutionary change in personal and social situations. Nicholson discusses the construct of discretion as a predictor of work role transition. The usage of this term has parallels with the concept of choice in realising goals, and the pattern of interpersonal communications, influence, and evaluation surrounding them. Discretion seems to be directly related to occupational status, and can be differentiated between high and low extremes. This means that the predominant prior occupation, in terms of higher or lower discretion, plays an important part in shaping a person's adjustment strategy toward the role he or she is entering. It could be argued then, that role transition, as a model, warrants some understanding to maximise the evolutionary potential of individuals and organisations. Aspects of Nicholson's model will aid reflection on the analysed data.

Considering these ideas I believe it is likely that the imposition of the culture of work role transition with its associated status passage generates a shift in the focus of inquiry. Instead of simply making meaning, i.e. what does this mean; a more 
compelling concept becomes, how do meanings change? The modified geography will be perceived individually by mind through the medium of the senses. This renders 'geography of the mind' as the unique lens that affords clarity to nurses and midwives faced with this dilemma, but it remains largely invisible to the observer. The mental being and the moods that correspond to it will give us information about constructing new maps and new journeys. How could I then begin to portray the fullness and context of nurses and midwives lives creatively, respectfully, and expressively? To capture this information as it changes this research required the appropriate methodology, method, and design.

\section{Narrative as both methodology and method}

I consider narrative to be an appropriate methodology and method for several reasons. First, it is congruent with the research aims and its questions - that is, each participant narrates their experience of choice and change through story, in contexts of shared language, common social practice, and shared beliefs and traditions that are given historical meaning in light of the HPCAA. Second, I was interested in how nurses and midwives would react to such an approach. The literature suggests that the act of writing converts our emotions and images into words, so I wondered then whether conversation following this written exercise would assist them to reveal areas of importance previously unrecognised. The act of constructing stories is a natural human process that helps us to understand our experiences and ourselves by allowing us to organise and remember events in a coherent fashion (Pennebaker \& Seagal, 1999). Third, in the process of writing and relating their stories participants reveal their lives embedded in historical, social, and political contexts. I recognised that it would be vital that, as researcher, I distinguish between my own map and others' maps. I would become steeped in the research topic with the participants and would therefore need some mechanism to fore structure my own understanding, in order to ensure that my personal experiences did not determine the shape of the data analysis.

As I thought about the relations of narrative as text, and narrative as conversation, it was possible to see how a written story would become a 'third person' in relation to the participant and I discussing it in a later conversation. Fourth, I believed that 
narrative as methodology would surface the possibility of the use of metaphor. Anthropological studies from our earliest existence demonstrate how humans have received and structured information in the form of stories. Since the beginning of storytelling the basic motif of the universal hero journey has crossed cultures and traditions, and is central to the language of boundary crossing (Campbell, 1968a). As a journey it might show us where the highway is clear for speedy progress, where it might be washed out by the debris from political storms, and where lurk the dragons and trolls? Finally, I believe that making these experiences audible is our ethical responsibility to fellow colleagues, and in a small way contributes to national and international research on work role transition between the cultures of nursing and midwifery.

Based on these rationale for a narrative choice as methodology and method, I further position and support the relevance of a symbolic framework for discovering what lies at the ontological core of our being. The metaphor of maps and destinations within narrative creates the impression of idealised destinations as purpose, and discernible paths become maps. In this text I use my pedagogic interest in the life world, as a nurse and a midwife, for discussing the human science methods of phenomenology and hermeneutics. It is because I am interested in the relationship of a work role transition between nursing and midwifery that I orient myself pedagogically to the participants, through narrative, with underlying symbolic, unitary and phenomenological hermeneutic modalities.

According to Koch (1998) researchers' accounts are framed within a specific storytelling tradition, often described as a paradigm. Narratives have been studied from a variety of perspectives, and can be descriptive and explanatory (Polkinghorne, 1995). A narrative may be oral or written, and may be elucidated or heard during fieldwork, an interview, or a naturally occurring conversation (Chase, 2005). Generally, and in these contexts, narrative then is understood as storytelling. A further provocative image is that instead of signifying, writing is surveying, mapping realms that are yet to come. Thus, the post-modern critique of interpretivism, and the linguistic turn open up the concept of writing as a method of inquiry. The use of narrative as methodology and method, therefore, not only provides a pragmatic basis on which to explore paths and maps that dually registered practitioners create in their 
lives, but, in human science terms, draws on symbolic meaning and hermeneutic expression.

\section{Symbolic considerations}

van Manen (1997) discusses the notion of textuality for analysing meaning but cautions against forgetting the metaphoric origins of ones methodology. By being attentive to the linguistic origins of words, and the use of symbol and metaphor we conceptualise language as "a huge reservoir in which the incredible variety of richness of human experience is deposited. The problem often is that these deposits have silted, crusted, or fossilised in such a way that the original contact with our primordial experiences is broken" (van Manen, 1997, p 61). As a point of reference that delves below our conventional sight level, myth allows us to recover the veins of memory that lie below the surface (Campbell, 1988; Houston, 1987, 1996; van Manen, 1997).

Within each story nests another great story - the hero journey. Drawing on Campbell (1968a) the language of the hero journey authentically speaks the world - it hearkens back to the silence from which the worlds emanate. Seeing the whole present in every part acknowledges our connection to each other and nature, emphasising the lack of boundary. In this sense the universe isn't something out there, it is within. The narrative project of a phenomenology of life and transition in nursing and midwifery is, therefore, not to translate the primordial relations between them into clearly defined concepts so as to dispel its mystery, but rather the object is to bring the mystery more fully into our presence.

Building upon the work of Joseph Campbell (1968a; 1968b; 1988), Jean Houston $(1987,1996)$ author and psychologist, shows how to discover mythic qualities present in our lives and demonstrates how these mythic patterns are repeated across cultures and time. As major organs of the psyche, archetypes such as the heroic journey offer us essential connections and without them the gossamer bridge joining mind, body, spirit, and universe, would be lost. As such they frustrate analysis because they can only be known by direct experience, but they offer a possibility for mediating and refocussing the issue. Since myth contains inner solutions in storied form it suggests pathways into the future (Houston, 1996). Thinking about this in relation to nursing 
and midwifery journeys, if our pattern is the essence of our human uniqueness, then from a unitary way of thinking, rather than seeking after wholeness, knowing and appreciating pattern recognises the already inherent wholeness in each of us. Rather than being random and meaningless, social role behaviour tends to be patterned, rendering habit or patterns of response as conscious or unconscious. Each practitioner makes their decision based on their own inner wisdom and once we understand the pattern and stages of the hero journey we are invited to discover the parallel paths tread by others. As a dynamic perspective the different narrative accounts illuminated a range of variability among individuals enacting or anticipating the same role transition. The career transition literature seems to focus on role transition as a boundary crossing; this thesis will discuss it as crossing a divide.

\section{Creating a bridge}

The early discussion in this chapter so far, has demonstrated my reflections for constructing and validating the circle of inquiry for this research study. I have highlighted how the map is not necessarily the territory, and the significance of journeying in relation to status passage. This might entail recognising different processes of adjustment. I then positioned and argued the basis of using narrative as both methodology and method to surface these aspects of personal and professional life transitions and shifts in identity. In the section on symbolic considerations I have argued the placement of myth, and other symbolic constructs such as the parallel journey of the hero that offers an alternative lens on transition and journeys, and may find expression in and through narrative connection. Building on these as design choice and rationale, it is important to construct a framework of inquiry that could accommodate notions of the hero within the narrative methodology with its underlying unitary framing and hermeneutic modalities. The exploration of myth as knowing is appropriate within the world view of the Unitary Transformative Paradigm. It points to our coexistence with all humanity and describes and explores the landscape of phenomena relevant to nursing and midwifery, such as courage, nurturance, transitions, birth, death, suffering, imperfection, struggle, and triumph (Smith, 2002). 
In this section I highlight the development of the hero journey as a conceptual metaphor for transformation and change which emerges as a central construct from the stories. The concepts presented in Figure Two: An Archetypal Framework of Inquiry are modelled on Joseph Campbell's original symbol 'pedagogical stunt', whereby the ego, that conscious part of ourselves that we tend to position centrally, is positioned as very 'off centre' (Campbell, 1988). When ego takes a less than central position the potential is for greater connection.

As previously discussed, narrative as method, houses the symbolic and therefore the unitary aspects of our humanity. This then creates consistency with epistemology and methodology.

I seek to distinguish pattern in the form of participants' experiences, perceptions, and expressions, as the focus of appreciation. The areas of interest to support investigation of the research purpose were; what was the effect of this period of choice and change on their lives? What factors assisted in dealing with the choice and changes? Did the process of this decision making resemble the process required for other contextual or historical life changes? What was their relationship with other health professionals throughout his time? What were useful strategies for making a decision, and dealing with this change?

If we were to consider the current environment rendered by the HPCAA (2003) as changing pattern, it follows that continual change brings along with it shifting meaning, values, awareness, choices, and relationships. To knowingly participate in change is the central axiom of this theory, and is what is required of dually registered practitioners as they reflect on their practice wisdom, in order to make the most appropriate choice for themselves (Rogers, 1976, as cited in Barrett, 1989). As a means of apprehending manifestations of pattern, such a methodology recognises pan dimensional modes of awareness, that is, forms of awareness outside the five senses. Thus, intuition, both tacit and mystical/mythological, and all forms of sensory knowing are considered valid. It demonstrates the interconnectedness of human/environment integrality with narrative and hermeneutic principles of inquiry (Cowling, 2004). 


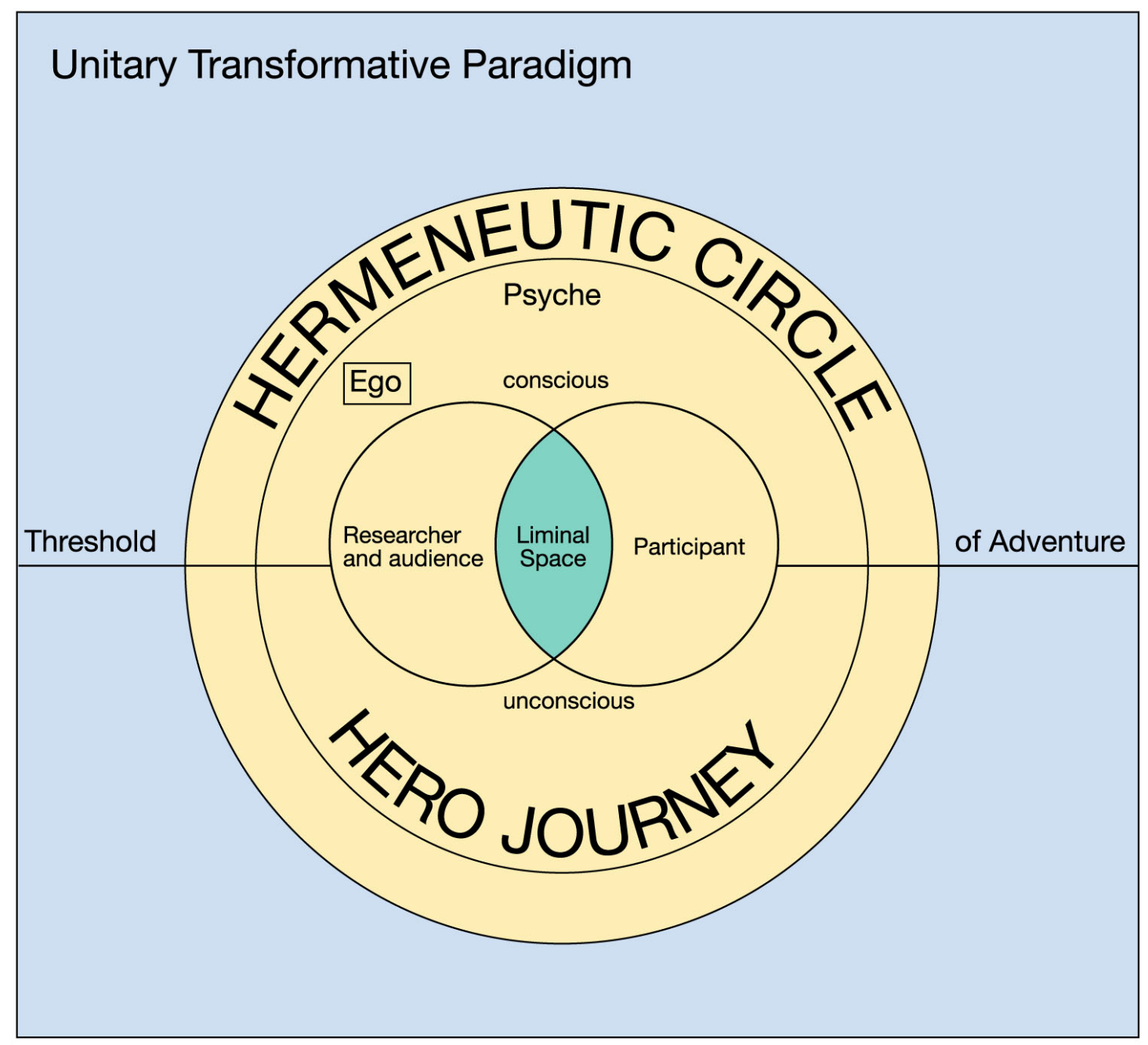

Figure 2: An Archetypal Framework of Inquiry (a micro-cultural perspective)

As people create a range of narrative strategies in relation to their discursive environments, the stories that were shared through voice and text constitute the empirical material that was needed to understand how people created meaning out of this event in their lives.

In Chapter two we imagined a set of overlay maps for the same passage. Depending on how they were overlaid we would see the area traversed differently. If Figure 2: An archetypal framework of inquiry was transparent, individual to each participant, and overlaid on Figure 1: A macro-cultural perspective, then it would occupy the central shaded area and would denote the micro-cultural perspective. Against the background of this paradigm the researcher and the participant are both seen within the 
hermeneutic circle. The image of the circle suggests completeness, wholeness, regularity, order, and indeed disciplined inquiry itself. My values and assumptions as researcher, derived through active and connected engagement with the experience, served as a hermeneutic lens through which to receive the experience of the participants. Gadamer (1976) asserted that we never have a closed horizon, as the nature of human life is its constant motion. By relaxing our preconceptions and through constant dialogue, a fusion of horizons occurs between the researcher and the participant. Rather than being viewed separately, they are depicted on the circumference of a circle; the hermeneutic circle (Anderson, 2000). The word liminal comes from the Latin limen, or threshold and the hermeneutic conversation takes place within this liminal space. Searching, or re-searching from this inside view enabled the essential qualities of the narrative and the dialogue to incubate, settle, and shift in awareness, and animate a subjective response.

What is perceived must be seen in the context of the total field of the perceiver before it can have any existential meaning, and before it can be given any valid interpretation. Situated outside of the research space are the psyche and the ego. Some researchers suggest that this perspective considers that the psyche is involved in shaping our perceptions, not just passively receiving them and contributes to the way we give meaning to experience (Houston, 1987, 1996; Tucakovic, 2005). Aspects of ego, such as levels of anxiety, self esteem, and desire for feedback, have been demonstrated in the work role transition literature as predictor variables for transition adjustment (Bradby, 1990; Murray, 1998; Nicholson, 1983; Nortier, 1995).

As the researcher, I am interested in how people communicate meaning through a range of narrative practices, and how they make sense of personal experience in relation to culturally and historically specific personal meanings and social discourses; and how they draw on, resist, and/or transform those discourses as they narrate their selves, experiences, and realities. In the act of writing we fix our thoughts on paper, and in a sense, externalise what is internal. van Manen (1997) describes the process of staring at what we have written on the paper, and seeing our objectified thinking now staring back at us. The general theoretic attitude of the social sciences, to capture a reflective cognitive stance, is thus captured in writing. According to van Manen (1997), if we are to make our lived world and experience reflectively understandable 
and intelligible, then the object of human science research is essentially a narrative project.

Metaphor is one of the most common literary devices for the communication of cognitive content. Lakoff and Johnson (1980) describe metaphor as understanding and experiencing one kind of thing in terms of another. Churchill and Churchill (1982) offer a description of narrative as a threshold activity that complements the working model for this study Figure 2: An Archetypal Framework of Inquiry (a micro cultural perspective). They situate the narrator's interpretation of events at a fleeting moment in time by linking elements of past, present, and future at a liminal place. The threshold of adventure bisects the model and symbolically represents a response to undertaking a hero journey. From a symbolic perspective, the resultant response depended on whether the individual perceived the choice as a call to adventure or not. As a line of pure potential the options concerning path-taking may be viewed proactively. A three-fold process of departure, initiation, and return is presented as the prototypical action sequence present in the universal story that permeates time and culture (Campbell, 1968).

Drawing together all of the material presented so far in this chapter I could see the relationship between journeying, status passage and professional and personal transition that nurses and midwives might be experiencing as they consider their prospective futures in the wake of the HPCAA. While narrative works as methodology and method for this inquiry, by paying attention to the symbolic considerations that may be present in the narratives of dual practitioners, we might explore these experiences in a theoretically meaningful way. The intersection of Campbell and Houston's work on mythic patterns in narratives, and the parallel journey of the hero, provides a very helpful framework to support this investigation. As I reflected on the notion of the collective story nested within individual stories I wondered whether the three components of the hero journey: departure, initiation, and return, would be discernable in the individual and/or collective accounts given by dual practitioners.

In the next, and final, section of this chapter I cover theoretical material related to the collective story and the three fold processes. 


\section{The collective story of the hero journey}

Richardson (1990) describes how narrative provides a powerful access to the uniquely human experience of time. She details these in five sociologically significant ways; the everyday, the autobiographical, the biographical, the cultural, and the collective. In practice these may overlap and intersect. For the purposes of this investigation the interviewees tell me (as the researcher) their autobiography, which I write up as a biography, but present as part of a collective story. The hero journey is an example of a collective story and displays the individual's story. Such a collective story as the hero journey arose through social movement activity evident in all cultures, across all time. In this way narrative links the universal human experience of time with the past, present, and future. Most significant are the transformative possibilities of the collective story on an individual level, and at the socio-cultural level. In this context incorporating change corresponds to personal and role development, and when viewed symbolically implies transcending and updating patterns of behaviour. In this way narrative gives room for the expression of our individual and our shared fates, our personal and communal worlds. Narrative is thus the best way to understand the human experience because it is the way humans understand their own lives (Richardson, 1990).

There are many interpretations of the hero myth stated in classical and contemporary language (Campbell, 1968; Cousineau, 1999; Flowers, 1998; Houston, 1987, 1996; Johnson, 1992; Noble, 1994; Osbon, 1991; Pearson, 1991; Smith, 2002; Standen, 1987). This summary is a compilation drawn from these sources using language that can be recognised and applied to our contemporary world and current scenario. It is a timeless myth that links us to peoples of all times and places, and in these stories about heroism we find a model for learning how to live. The individual has only to discover her own position, with reference to the general human formula, and let it then assist them past personal limitations. The journey begins when the hero separates self from the ordinary rhythms of life and enters new territory. To achieve initiation into the unknown are a series of trials or obstacles to be confronted. Finally the hero returns to share self and insights with others. The three stages are departure, initiation, and return (Campbell, 1968a; Campbell, 1968b). A summary of the three stages, as depicted by Campbell follows. 


\section{Departure}

The departure begins with the Call to Adventure. Prior to the call the hero is living life in the usual familiar pattern. This call may come from within, an urge to depart from normal existence to the quest for a new life, or it can be thrust upon the hero from some external force; a happening (HPCAA), occurrence, or crisis that compels the hero to embark on the adventure. It is possible to refuse the call or deny the ability to move beyond the status quo; the heralded event may even be ignored. Threshold guardians may impede the hero's crossing into the new realm. Assistance often comes in the form of a guide who knows the path and can offer direction, support, and mentoring. Uncertainty usually accompanies this passage, as in crossing the first threshold a sense of danger as well as opportunity is conveyed. Release here symbolises a relinquishing of attachment to the world left behind.

\section{Initiation}

Having crossed over into the new realm, the hero encounters a series of tests known as The Road of Trials. Each task prepares the hero to pursue the ultimate mythological goal and moves the hero toward self reliance. In classical texts these trials involve several motifs: negotiating the labyrinth, battling monsters or dragons, climbing a mountain, drowning in a storm at sea, or falling into darkness or an abyss. Phases of initiation are: meeting the goddess (expanding consciousness), atonement with the father (discovering one's character and destiny), apotheosis (an awakening to the divine, the union with all that is, a new ability for unconditional love), the ultimate boon (the benefit, favour or blessing bestowed on the hero figure), and the desire to share the boon with mankind.

\section{Return}

On closure of the quest the hero generally returns home. Some heroes do not wish to return. This is the refusal of the return, and is a rejection of any responsibility to renew the community, nation, or planet. For the hero who accepts the need to return, there are two principle scenarios - flight or rescue. Regardless of how the return is accomplished crossing the return threshold now brings the hero full cycle. The 
freedom that came from the glimpse of the eternal with the encouragement to live from the centre of one's truth requires resolving the two worlds, the divine and human; know and unknown; yin and yang. The key to understanding the myth is that the two kingdoms are actually one. The unknown is a forgotten dimension of the world we already know and to explore that dimension is the whole deed of the hero. By crossing the final threshold, the hero recognises that the apparent separation in reality does not exist (no boundary). They then become Master of Two Worlds. The last task is to try and communicate their discoveries and the boon for all humanity. Many are incapable of comprehending beyond their physical world, but inevitably one will hear the message and arise as the next hero. Our hero achieves a Freedom to live, that is, the ability to pass freely between realms. Through their transfiguration, the hero is prepared for at-one-ment.

Reflecting on the examination of journeys in this study three forms have so far been revealed: literal, from one point to another (the macro-cultural perspective); introspective, dealing with the inner self (the micro-cultural perspective); and, imaginative, using the imagination to create an alternative world. Studying the parallel journey of the hero allows us to discover how such an undertaking affects our perceptions of ourselves and our world. Through viewing the individual narrative qualities of each text, which include the personal goals, ambitions, and ways of thinking, through the symbolic lens of the hero journey, we might glimpse how others achieve this passage of change.

\section{Symbolic transitions}

The concept of status passage has also been used in sociological texts as a model for the critical stages of the life cycle beginning with birth, progressing to puberty, marriage, parenthood, and finally death. What becomes noticeable in the early model is that entry and exit from these critical life stages are marked by ritual and ceremony (Van Gennep, 1960). Ritualised transition phases imply symbolic behaviour. In primal cultures unanchored identity, or liminality, was a collective experience mediated by culturally prescribed rituals that afforded shared psychological support through a status passage. In our modern secular world, however, people often experience an 
isolated type of liminality for which there exist few supportive rites of passage, or kindred groups (Turner, 1974). The external change of the HPCAA (2003) presents the new policy as beneficial in all regards; however, the practitioners affected are first going to experience very real effects. These have been described in the transition literature as changes in psychological state, changes in behaviour, relationship with time, way of speaking, perceiving and sorting information, and a changed sense of self as an individual, and in relationship with others (Nortier, 1995). It follows that when a person goes through a passage collectively, or in an aggregate, they may not be aware that they all go through it together, or at least not aware of all aspects of their similar passages. So, by studying individual adjustment to this particular transition, it may tell us more about the evolution, progression, and consequences of traversing the two professions, and provide practitioners with a rite of passage.

French anthropologist Arnold Van Gennep (1960) identified three subdivisions of what he called rites of passage: rites of separation, transition, and incorporation. As a choice of text it has symbolic relevance to the hero journey with similar rites of passage. Detachment, or 'letting go' is analogous to departure whereby the hero disengages from a social role or status. The unclear zone, between the old and the new reality, was described by Van Gennep (1960) as the marginal or liminal period. Later texts describe this phase as 'social limbo' (Turner, 1974, 1982; Holland, 1999). Reflective of the hero's initiation, 'liminars' are subjected to testing feats of endurance which exaggeratedly simulate the components and challenges of their imminent role identity (Prout, 1989). The third stage or phase, incorporation, is analogous to the return of the subjects to a new social status or position within a social group. This may have followed hazardous transitional activities in order to attain this new status. This will be the material revealed in the participants' stories.

\section{Conclusion}

This chapter has explored narrative as a means to examine methods of passage and transition, alongside myth and heroic symbol. The linguistic ordering of experience in narratives transforms a series of events into a unified whole. Within narratives, 
idealised destinations become purposes, discernable paths become maps, and interconnectedness, through the sharing of collective storytelling, generates coherence.

Work role transition theory encompasses three bodies of thought: life span development, organisational change, and occupational socialisation. Through narrative as method and methodology, rich data will be generated that will illuminate the question that we wish to explore. We are likely to appreciate how our memories of the past create expectations that guide our actions in the present generating targets, direction, and purpose for the future. Generalisation is not the aim of such work, reaching a new or better understanding is, so, working with just three people and their narrative accounts serves the level and scope of the project.

This chapter has presented an artful methodological lens for mapping and exploring professional choice and change. Through narrative, change will be seen to emerge organically, that is, from the narrators own process of mapmaking. The theoretical discussion has sought to validate the circle of inquiry to be adopted in the exploration of the phenomenon of choosing a professional path. In Chapter Four I discuss the design and methods for applying, conducting, and analysing the research process. The methods utilised include participant narrative, in depth interview, and textual analysis. The question of interpretive rigour is considered. 


\section{Chapter Four Study Design}

\section{Introduction}

Choosing the appropriate methodology, method, and design underpins any research project. As outlined in the previous chapter, narrative as both methodology and method is justified in capturing the 'hows', 'whats', and 'whys' of storytelling. People will create a range of narrative strategies in relation to their discursive environments, and so the complexity and diversity within each participant's voice draws attention to the various subject positions. On one hand is the narrators' active construction of self, and on the other hand are the social, cultural, and historical circumstances that enable, and/or constrain the narrator. This juxtaposition is what makes each narrative interesting, not only to the researcher and the audience, but to the participants themselves.

I previously argued the key facets of the approach and aspects of the study in Chapter three, and I now present the practical elements of the study. These are the things that I needed to take notice of in order to explore and explain the data.

\section{Research principles and approach}

To understand how nurses and midwives created meaning out of the events in their lives at that time was to appreciate the interviewees as narrators. Their narrative accounts, both written and oral, would provide the reader with an opportunity to engage and reflect on the varied experiences of dually registered practitioners who had to choose a professional path following separation of the professions. The issues involved in making this decision, and the impact of this choice on practitioners would serve to illuminate the scope and effect of the change as a feature of the participant's experience; the factors and forces that assisted in dealing with the changes, and the strategies employed to understand the change introduced and integrate it into their personal and professional lives.

For the purpose of this study the historical act and the narrative are cut from the same cloth. The universality of story as a reflection on experience will also act as a vehicle 
for understanding the conduct of others. The story presented will be held together by recognisable patterns of events, or 'plots'. Central to the plot structure in this study are the shared predicaments posed by the HPCAA (2003) and attempted resolutions by practitioners to adapt appropriately.

The selection of participants was an important aspect if I were to represent a range of possible viewpoints that, in turn would lead to a more in-depth understanding of the phenomena under study. My entry into their lives as participants was to orient to the particularity of each narrators voice and biographical story, by an initial invitation to provide a written narrative on this experience of choice and change. This account afforded enough data to enable preparation for framing the following interview, and set the scene for a conversation to unfold.

\section{Study design and considerations}

The humble road map shows us countless destinations and endless ways to get there in meaningful patterns that show us a path. Within a vast array of paradigms, theories, and approaches to practice, studies that stem from a unitary perspective illustrate the relevance of patterning as the dimension that provides a comprehensive theoretical guide (Butcher, 1998, 2004; Cowling, 1997, 2000; Litchfield, 1999; Newman, 2002).

A design was needed that concentrated on evolving pattern and acknowledgment of the symbolic component of identity, as identity is constantly in progress. To do justice to the fullness and ambiguity of the experience of the life world, a methodology that allowed for a dialectical going back and forth among various levels of questioning would suit a phenomenological inquiry. Rather than a containment of meaning, the focus would have to shift from questions aimed simply at making meaning, i.e. what does this or that mean? To, how do meanings change?

Here I present a design that attempts to incorporate these constructs and reveals the journey of three such travellers as they negotiate the milestones on such a path. The design of the study is summarised in Table One. 
Table One: Study design considerations

\begin{tabular}{|c|c|}
\hline Research question & $\begin{array}{l}\text { What are dually registered nurses and midwives experiences of } \\
\text { choosing a path following the regulatory separation of the } \\
\text { professions? }\end{array}$ \\
\hline Approach & $\begin{array}{l}\text { Qualitative descriptive study. } \\
\text { Theoretical lens utilises: personal narrative, status passage, transition, } \\
\text { symbolic transitions - hero journey. }\end{array}$ \\
\hline Participants & $\begin{array}{l}\text { Three practitioners with dual registration in nursing and midwifery } \\
\text { who need to decide their new professional location. } \\
\text { Any of the following scenarios are possible i.e. retaining midwifery } \\
\text { APC; retaining nursing APC; retaining both midwifery and nursing } \\
\text { APC. }\end{array}$ \\
\hline Data collection & $\begin{array}{l}\text { Participants provide a written narrative account of their journey. } \\
\text { After construction of a pattern profile a follow up individual and in } \\
\text { depth interview explores the material further. } \\
\text { Interview is digitally recorded and transcribed, and theoretically } \\
\text { explored in relation to relevant theoretical literature and method. }\end{array}$ \\
\hline Data analysis & $\begin{array}{l}\text { Orienting to the particularity of each narrators voice by immersion, } \\
\text { attention, and concentration on written and narrative strategies. } \\
\text { Synthesis of patterns connecting emerging themes. } \\
\text { Witness to the hero, as a narrator's device, links the symbolic to the } \\
\text { narrative and separates the narrator's voice from the researcher's. }\end{array}$ \\
\hline Rigour and congruence & $\begin{array}{l}\text { Careful attention paid to: } \\
\text { Trustworthiness } \\
\text { Credibility } \\
\text { Comfirmability } \\
\text { Dependability } \\
\text { Transferability } \\
\text { Authenticity }\end{array}$ \\
\hline Ethics & $\begin{array}{l}\text { Key constructs: } \\
\text { Minimising identifiability } \\
\text { Providing a safe space for interview and discussion } \\
\text { Obtaining informed consent from participants through a signed } \\
\text { consent form. } \\
\text { Obtaining Victoria University of Wellington Human Ethics } \\
\text { Committee approval. }\end{array}$ \\
\hline Treaty of Waitangi & $\begin{array}{l}\text { This study reflects a specific historical period of nursing and } \\
\text { midwifery in Aotearoa/New Zealand. The principles of the Treaty of } \\
\text { Waitangi are therefore acknowledged and inform all aspects of the } \\
\text { research. }\end{array}$ \\
\hline
\end{tabular}




\section{Ethical approval and considerations for the research project}

Application to the Human Ethics Committee (HEC) at Victoria University of Wellington (VUW) was made for ethical approval to undertake the research. Any activity involving participants or data collection did not commence until HEC approval had been obtained (refer Appendix 1) and participants had read the supporting material (refer Appendix 2 and 3) and signed the appropriate consent forms (refer Appendix 4). Responding to my application, the HEC sought assurances on recruitment and selection of participants. Two methods of recruitment were used, an open advertisement and snowballing. An open advertisement inviting expressions of interest was placed in staff areas of a local Maternity facility. Ideally the three practitioners sought would cover a range of possible experiences; for example, a practitioner retaining a nursing APC, a practitioner retaining a Midwifery APC, and a practitioner retaining both nursing and midwifery APCs. Word of mouth facilitated further interest as a snow-balling method of recruitment.

In the ethics application for this qualitative research I stated the inclusion criteria to be three practitioners with dual registration in nursing and midwifery, who have an open minded understanding of their experience, and a willingness and ability to articulate it. This would require that volunteers be competent in written and spoken English, as it was primarily a narrative inquiry. It was also considered a practical requirement that participants would reside within a 50 kilometre radius of the researcher's residence. Information was provided on the research question and the purpose of the study, the time commitment and involvement of subjects, and the option to withdraw from the study. Confidentiality was assured and potential subjects were informed that if the descriptions were published, that no names would be associated with the data. Signed consent implied that the data and portions of the audio taped interview would appear as part of the thesis text. At all times efforts would be made to maintain confidentiality and to protect the participants' identity. The transcribing agent signed a confidentiality agreement (refer Appendix 5) and participants received a copy of the transcribed material. All written material and electronic information was kept in a locked file and access was restricted to the investigator. 
Participation and partnership, as key characteristics of the Treaty of Waitangi, were primary modes for the inquiry process. Inherent in this is the assumption that participants had engaged freely in a study whose topic was of mutual interest, with a shared understanding of the process being used, and were open to emergent discovery. The participants were each respected as the source of expertise, power, and knowledge relevant to their own unique lives.

\section{Negotiating the field of inquiry}

The design strategies, therefore, are aimed at interweaving the richness of the imaginal and the expressive, with the wider world of knowing participation in professional change. The process of conscious decision making required of practitioners affected by the HPCAA (2003) affords an opportunity to renew our choice of profession, or refresh our calling. I will now offer the theoretical rationale, and practical applications for the study design.

Sandelowski (1991) points out that a qualitative method of design is guided by prior interest in overarching worldviews. The macro-cultural and micro-cultural perspectives were presented in Figure One and Two against the backdrop of the Unitary Transformative Paradigm, which is based upon Rogers (1992) Science of Unitary Human Beings. Research methods specific to this paradigm have been developed by Butcher's (1998) unitary field pattern portrait, and Cowling's (1997) pattern appreciation case study method. This study design was derived from investigation and understanding of these perspectives and the details inherent in them for ensuring scientific rigour.

Expressive writing is an innovative health patterning strategy with the potential to facilitate knowing participation in change (Butcher, 1998, 2004). Writing one's own 'portrait', as written expression, is pattern work. Pattern has been described as relevant in the fields of mathematics, physics, theology, psychology, research, nursing theory, art, and behavioural therapy (Barrett, 1998; Braud, 1998; Butcher, 1998, 2001, 2004; Csikszentmihalyi, 1975, 1990; Doane \& Varcoe, 2005; Gueldner et al, 2005; Hall, 1997; Litchfield, 1999; Mahoney, 2003; McNiff, 2004; Newman, 2002, 2003; 
Parse, Coyne \& Smith, 1985; Smith, 2002; Tucakovic, 2005). Each person's experiences, perceptions, and expressions are unitary manifestations of pattern and provide a focus for appreciation. The attention on pattern required an exploration of professional change on the larger aspects of human existence.

For heuristic purposes throughout this study the term narrative is analogous to story. This involves the reflective exploring of experiences, perceptions, expressions and their meanings and connections before story construction. As we consider personal and professional identities, the story becomes a form of self presentation, as personal social identity is being claimed. Everything said, or written, functions to express, confirm, and validate this claimed identity. This directs us to the story content and the way it is expressed through various particulars of the account. The participants would be the storytellers and I, as researcher, would be the listener. Listening, to the interpretive process, meant discerning the voices within each narrative, and remaining mindful of the connection between the varying constructions of self within each story.

\section{Beginning the journey with the research participants}

The three participants who met the inclusion criteria are known in the thesis by their pseudonyms: Mary, Susan, and Jo. Mary currently holds an APC in midwifery and has relinquished nursing; Susan has just relinquished her midwifery APC and holds a nursing APC and position; and Jo holds both midwifery and a nursing APC and works between the two professions. They selected their own pseudonym and each pattern portrait presented has a title that reflects an important comment made by them during our conversation, or a theme relevant to their story. The stories that they had to tell depended on their social location in their specific institutional, organisational, and/or discursive settings.

\section{Data collection methods}

Each participant was firstly asked to write a story about their experience of change or realignment of their professional career, and of its effects. To be included in their story was the scope and effect of the change experience, the barriers and enablers to 
change, and their strategies for dealing with the changes. The information sheet given to them, following expressions of interest, framed the subject of the story as 'describe your experience of deciding which professional pathway to pursue; share all your thoughts, perceptions, and feelings you can recall, until you have no more to say about the situation' (refer Appendix 3).

Once the stories had been read they were collated and summarised into a narrative profile, using the participant's language, and shared with them for validation and revision at a later interview (Butcher, 1998, 2004). The participants, as narrators, used their own narrative strategies for making sense of their experience, such as metaphors, or subjugated storylines as linguistic features. These are taken for granted practices and processes made visible and audible through narrative as methodology (Chase, 2005).

The interview was digitally recorded and later transcribed. I carefully reviewed the text to identify key meaningful segments, and each participant received a copy of the transcript for confirmation of its authenticity at which stage they had the opportunity to choose to omit material if they so desired. In a partnership approach participants had three opportunities to receive feedback throughout the process. They also had the option of receiving a summary of the completed thesis which will also be available in the Victoria University of Wellington library.

Following the interview, as the researcher, I made observational notes which included objective descriptions of what was observed, such as non verbal expressions. I also maintained a reflexive journal whereby I examined my own beliefs, values, and interests ensuring that I engaged critically with my own experience in relation to the stories of others. This increased awareness is well documented as a hermeneutic principle that lessens the possibility of projecting the researchers pre-understanding onto the process of investigation (Braud, 1998; Heidegger, 1962; Jones, 2002; Koch, 1994; Packer \& Addison, 1989). 


\section{Data analysis}

To begin interpretation, the story profiles, the transcribed interview texts, and the observational field notes, gathered throughout the course of the investigation, were collected. According to Butcher (1998) the researcher immerses into and dwells with each narrative profile, identifying key phrases, themes, and words. Butcher describes an immersion/crystallization process of data synthesis that fosters intimate contact with the text, and is most appropriate when the goal is exploration of a new concept in the absence of significant literature about the question (Miller \& Crabtree, 1994; Butcher, 1998). Crystallization is described as a process of giving definition, precision, and distinctiveness of form (Butcher, 1998).

Analogously, a term borrowed from heuristic research, indwelling, describes the process entered into with the material of the participants' stories. To seek a deeper comprehension of the nature of the meaning conveyed in the story, an unwavering attention and concentration on the expressive qualities was required. This process was conscious and deliberate in an attempt to become at one with the storyteller and reveal the wholeness of each experience (Moustakas, 1990). The resonating themes are then combined and synthesized.

As in any story, the ending is foreshadowed in the beginning, so, paying attention to how participants chose to title or begin their accounts might give some clues to their positioning. The narrative linkages between what each storyteller had to say about her biographical particulars, on the one hand, and her perceived resources and constraints on the other, might also provide some evidence of each participants construed reality. To keep the flow of their stories I use quotation marks around the words given to me during written and oral narrative, and meld them with my commentary. Extensive verbatim script has been referenced, but where occasional words interrupt the flow of commentary the reference has been omitted.

A narrative device was used at the end of each storied account that clarified issues of voice, interpretive authority, and representation. Witness to the Hero connects and separates the researchers and the narrators' voice. This entailed attending to the what and how questions that might open up further ways of understanding what was being 
communicated through each story. The use of the hero journey, as a narrative analogue, promotes discussion of a predicament and provides a natural basis for raising questions about causal relations and alternative actions. It is itself a narrative structure of emplotment as well as a means of representation.

As witness to the hero, I, as researcher, take narrative responsibility for speaking differently, yet, at the same time, respectfully and supportively. By presenting extensive quotations from the stories there is room made for the readers alternative interpretation. As a post modern representational practice, witness to the hero is designed to portray the contradiction and truth of human experience in a manner that recognises the transformative potential, and emphasises the multivocality of human experience.

\section{Rigour and congruence}

There were certain tensions and discomfort in positioning this study at the edge of political boundaries. This boundary is the result of many years of determined strategy and effort by the midwifery profession to clarify its identity as separate from nursing and align itself with women. The HPCAA as legislation, now provides this regulatory separation and allows both midwifery and nursing to be completely in charge of its own destiny. According to Guba and Lincoln (2005) border activities show the most promise for projecting where qualitative methods will be in the future. If communities' desire is to take control of their futures, then members are encouraged to take an increasingly active role in nominating inquiry interest and participation. This fosters emancipation and discovery and serves to redress power imbalances by offering the marginalised a voice. The empirical literature exploring work role transition reflects critical stages of the life cycle linked by a rite of passage to status passage, and ritualised transition as traditionally assisting passage from one state to another. The response from the participants indicated that the act of taking part in the study fulfilled a symbolic need to explore and record this passage. The question of interpretive rigour, however, is difficult to prove when issues such as the single experience, the individual crisis, the epiphany, or the moment of discovery threaten conventional objectivity (Guba \& Lincoln, 2005). 
The expansion of social data in this inquiry relies on the narrative quality of life, which in itself includes aspects of the experiential, the embodied, and the emotive qualities of human experiences in order to capture the elements of the conflict involved in professional choice. In such a case, applying only a series of illegitimate questions from the researcher's frame of reference, might serve a quest for objective knowledge, but deny the participants a meaning-making mechanism that expresses their tacit or subjective knowledge. Participatory research methods allow research participants to speak for themselves, either in text form, or oral performance and are a key feature that sustains congruence. This resides in the social, mental, and linguistic designation of their worlds, and in this study was allowed expression through their first written narrative exercise. This content then fuelled further active exploration through conversation and contributed to a degree of congruence between the specific assumption of the research question, and the processes of the research method. Such a design allowed the participants' expression first and thus reduced human bias or contamination. The resultant narrative summary or profile was authenticated by the participant before further inquiry progressed, and in total, three opportunities were provided for participant feedback.

The relationship between words, and what those words might signify, provided the zest for social and theoretical exploration of this experience of decision making. The richness of these social, mental, and linguistic worlds being situated within participants' texts provided the field for fertile inquiry. Rather than locating truth and knowledge in some extraordinary reality, the participants are seen through their stories as actors in historical reality. This analysis ties social change to social critique by raising consciousness of all perspectives (Guba \& Lincoln, 2005). The resultant dialogue, and any agreement of what constitutes valid knowledge, arises from the individual participants.

Argument about truth claims cannot be made by a study with three participants, but by demonstrating the fluid nature of identity of the self and the partiality of truth, claims that purport to an objective stance on social construction of reality may be seen to be, at best, controversial. Rigor and validity though are separate to what might be 
construed as objective truth claims. The general criteria of trustworthiness and authenticity are applied here to frame this interpretive study.

\section{Trustworthiness}

Trustworthiness rests on the methodological decisions made throughout the pattern synthesis process and includes criteria for judging credibility, confirmability, dependability, and transferability (Guba \& Lincoln, 2005; Butcher, 1998). Credibility or truth value is the equivalent of internal validity and reflects an effort to establish confidence that the data had been understood as the narrator had intended. It is met through prolonged engagement and extended immersion in the data, persistent observation, multiple sources of data, participant checks for validation and revision, and peer debriefing with my supervisor.

Confirmability assures that all steps of the process derive from the mutual understanding of the material received and discussed, and not in the researcher's imagination. All original sources of data were catalogued, and the processes of pattern synthesis can be traced by an audit trail of carefully maintained records.

Dependability is the equivalent of reliability and is concerned with the stability of the data over time. Methodological changes are documented so that the reader can understand the context of the design. For example; the narrative segment separating the narrator's and the researcher's voice, witness to the hero, has been discussed as a methodological change to the emergent design contributing to rigor. Rather than threats to dependability, Butcher (1998) describes methodological changes as hallmarks of a maturing and successful inquiry. Transferability or external validity is determined by the reader from the detailed descriptions rendered.

\section{Authenticity}

Reflection on lived experience is always recollective. In other words there exists a systematic attempt to uncover and describe the internal meaning structures of lived experience. van Manen (1997) maintains that the essence or nature of an experience 
has been adequately described in language if the description reawakens or shows us the lived quality and significance of the experience in a fuller or deeper manner. Authenticity includes criteria for descriptive vividness and unitary integrity. The description of the data should reveal the flow, spirit, and life inherent in the participants' experiences, perceptions, and expression. They should reflect an unbroken wholeness and undivided flowing movement that resonates with the audience and reflects multiple and dynamic potentials. The utilisation of the hero journey as a narrative device draws upon a deeper underlying archetype. The coded matrices of new steps and pattern that are portrayed in myth bear amplified pattern of certain rhythms and cadences that we recognise in our own stories. This dimension symbolises the rites of passage that mark our lives, and seeks to yield a universal and interactive sense of resonance that extends beyond the written words on the page. As Sarbin (1984) reminds us the pageantry of rites of passage are storied actions.

\section{Reflexivity}

Reflexivity is the process of reflecting critically on the self as researcher, the 'human as instrument' (Guba \& Lincoln, 2005, p 210). The centrality of my history to the interpretive stance I take in this study means that at times this transition phase is framed from a perspective of what was relinquished. My personal construction of reality, therefore, afforded a pre-understanding of the experience of dual practitioners that was subjective. By concentrating on the material provided, the memory of my own transition process was generated. Thus, an externalised inquiry focussing on others, at times transferred in the process to an internalised focus of inquiry for me. This has been described in the literature as an 'E-inquiry' transferring to an 'I-inquiry' through the research process (Atkinson, 2000; Chomsky, 1986; McNiff, 1993). My conscious experience as both inquirer and respondent, coming to know myself within the processes of the research, is detailed in Chapters Eight and Nine. Guba and Lincoln (2005) account for how an interrogation of the multiple identities that represent the fluid self in the research setting, questions how the research efforts are shaped around the binaries, contradictions, and paradoxes that form our own lives. Such efforts contribute, and bring to a closing, the discussion on validity. 


\section{Conclusion}

In the last two chapters I have examined the methodological underpinning of this research and the method and design used to complete it. Communities of scholars have advanced the science of unitary human beings and evolved research methods that encapsulate the necessary academic rigour. These have been referenced throughout. I sought, and was granted ethical approval, and I have sought to create a design that communicates a nexus of ideas, meanings, and symbols. The dark abyss, the journeys, and the unending cycles are captured in the hero journey and balance the interplay and connection between all the ways of knowing.

The discussions concerning the imperatives of the research have been explored, and any further discussion will involve the findings inherent in the storied actions of the participants. The strengths of the research detail the dialogic efforts within this inquiry that become a form of moral discourse, or in Reason and Heron's words, examples of 'human flourishing' (Heron \& Reason, 1997). The following three chapters present the rites of passage chosen by Mary, Susan, and Jo as they negotiated this period of professional decision making. 


\section{$\underline{\text { Part Two }}$}

\section{Departure}

Initiation, and

$\underline{\text { Return }}$ 


\section{Departure, Initiation, and Return}

The first step, detachment and withdrawal, consists in a radical transfer of emphasis from the external to the internal world, macro - to microcosm, a retreat from the desperations of the wasteland to the peace of the everlasting realm that is within. It is the realm that we enter in sleep. We carry it within ourselves forever. All the ogres and secret helpers of our nursery are there, all the magic of childhood. And, more important, all the life potentialities that we never managed to bring to adult realisation, those other portions of ourself, are there; for such golden seeds do not die.

(Campbell, as cited in Osbon, 1991, p 77). 


\section{Chapter Five Mary's Story: Finding a Path with Heart}

Mary has relinquished her nursing APC and practices and stands pedagogically as a midwife. If personal biographies are organised and understood to explain and justify life experience through the stories that we create, then Mary provided a very clear and purposeful written narrative that constructed her sense of self as motivated and supportive of the divide between the professions of nursing and midwifery. She describes her political stance very clearly, believing that nursing is not a necessary pre-requisite to being a good midwife. The requirements for professional development, and conscientiousness decision making, she believes, are important for both professions, and is wholeheartedly in favour of them. Mary was relatively unconcerned with choosing to forfeit her nursing APC as during this period she states "I work as a midwife and have no desire to return to nursing" (Story, line 126-127). Time and external circumstances, however, can intervene to provide the possibility of different ways of being.

To aid reflection on the data that Mary and the other participants' provide, there are certain existential themes, described by van Manen (1997) that, regardless of the diversity of historical, cultural, or social situatedness, is present within the narrative research process. In unity, four essentials are seen to constitute our lived world; lived space (spatiality); lived body, (corporeality); lived time, (temporality); and lived human relation, (relationality). As a temporal way of being in the world, Mary positions herself to other practitioners, whose common age group is in their forties. Mary describes her lived space currently, as "being at a crossroads" (Story, line 127128). As a category, the lived space of a 'crossroads' provides a narrative clue, or metaphor, for understanding the way that Mary is experiencing her current position in relation to the personal divide. Crossroads are generally not places where we can feel at rest. They are liminal points at which we make a decision about the direction we are going to take. Mary defined her then options as "I can choose to continue to work as a midwife, or as an employee, or, I can take the somewhat radical step of re-entering nursing” (Story, line 131-134). A return to nursing type programme, she believes, is "easily achievable if I truly decide that midwifery is no longer an option for me" (Story, line 139-141). 
When we first meet someone in their landscape we meet them first of all through their body (corporeality). Mary, throughout the research interview, was relaxed and self assured, providing evidence of a life lived with clear and purposeful goals in mind. In a relational sense her responses were reflective and considered, and her easy conversational manner revealed the issues, or factors, now affecting her social sense of purpose in life. As opposed to clock time, lived time speeds up when we are enjoying ourselves, and slows down when deliberate decision making is taking place, drawing on the dimensions of the past, present, and future horizons. The mystery of what lies ahead for Mary will be shaped by her present recollection of the past, in light of her current circumstances. To better understand the divide from Mary's personal life perspective, we will examine what created continuity in the form of a sense of identity for her, and what took her down certain paths.

\section{A journey to becoming: Status passage into nursing and midwifery}

Mary recounts her career history with great zeal and enthusiasm. Her determination to enter nursing was set in childhood, which was a common expectation for young women in that era. Very quickly she identified a passion for the area of women's health and babies. She recalls: "I vividly remember being part of a woman's labour and birth and the immense satisfaction I received when she thanked me "I couldn't have done it without you" - wow! I must be good at this stuff! It was there that I heard about midwifery as separate or adjunct to nursing” (Story, line 26-30).

This powerful moment of conscious self awareness propelled Mary toward the profession of midwifery. She encountered several people who meaningfully encouraged a passage from nursing to midwifery and she opted to train overseas as she did not feel that the midwifery training at that time in New Zealand was very well managed. Despite the hierarchical system that she encountered through this training period, Mary describes her prior nursing education as assisting her through this period.

The social process and hierarchical notion of midwifery training during those years would have resembled the apprenticeship system already experienced as a student nurse, and would likely have assisted Mary's internal adaptation to this new external 
environment. The theoretical frameworks that utilise the concept of status passage identify the three main processes of separation, transition, and reincorporation (Bradby, 1990; Glaser \& Strauss, 1968; Hart, 1976; Holland, 1999; MacNeil, 1997; Turner, 1974). Performances of ritual are therein described as distinct phases in the social process of adjustment. It could be argued then, that strict hierarchies establish a 'rite of passage', the principle being that if students are capable of overcoming this difficulty of training, then they deserve to be integrated into the whole.

On the threshold of the status Mary was about to enter, the socio-political environment of midwifery in New Zealand was poised for change. Although Mary had already undergone a status passage from lay person to student nurse, to nurse, and subsequently to student midwife to midwife, the following transition after the Nurses Amendment Act (1990) was to be highly significant to her sense of identity. The new legislation assigned an image of midwifery as an autonomous profession in its own right, and corresponded to the notion that identities are socially bestowed and socially sustained. Mary described this transition: "I was young, single, and worked hard. I quickly built a reputation as being OK amongst colleagues, both medical and midwifery. I also earned quite a lot of money rapidly! This was a heady time for many midwives" (Story, line 83-85).

According to Bradby (1990) status passage is effected with more ease if the individual has higher self esteem and lower anxiety. A strong personal identity is considered an important factor before refocussing on occupational role identity. As Mary crossed the threshold into independent practice she acknowledged the assistance from supportive mentors and the opportune job experiences that seemed to arise readily:

"I've been very lucky that things have just opened up, and that I haven't had to work particularly hard, that I have been given opportunities quite easily” (Interview, line 135-137).

"I've never had to think about what I was going to do next, which maybe makes where I am now a little tricky because this is the first time I've really had to think what's next"(Interview, line 220-222 ). 
Identity as a midwife was fostered over many active years of experience. In Mary's life, at this point, her identity as self-as-nurse is a past identity. She describes the experience of moving from novice to expert practitioner as:

"The nursing part of me grew smaller and the midwife in me increased" (Story, line 92-93).

Passage through to the role of being a midwife entailed movement into a different social structure, and a gain of privilege, influence and power. This status as expert means that she now spends longer making professional visits. She recognises issues that require greater attention, earlier; and she now provides more information on health initiatives, such as HIV screening, hearing screening, smoke change, and the immunisation register. Her self assurance grew with experience, and:

"I began to see myself as that real advocate for women working with families, rather than providing nursing care" (Interview, line 271-272).

The process of divestiture, discussed in Chapter One as a sub passage of a status passage, is recognisable in these last words of Mary's. These words impart a realisation that her identity as nurse was in her past. For many years Mary was absorbed with her professional activities and although she "worked hard", she enjoyed her work. The exhilaration in her story shone through.

\section{A liminal place}

Narrative functions at the autobiographical level to mark off ones own individual existence from all others. Mary was socially positioned to tell her story at this given biographical and historical moment, more-so because she was in the process of identifying with the experience of 'burnout' and reflecting on life goals and available workforce options. Hence, she felt positioned at a 'crossroads'. 
Nicholson (1984) documents early success in a job as a powerful catalyst for heightened achievement motivation, and career development. Mary established clear goals and foreshadows the efforts that she went to achieve them. Work role transition theory discusses changes to motivational orientation that arise through influences external to the workplace. Life events and the aging process itself will bring changes in personal disposition and work related motives. As I reflected on Mary's written and oral narrative I detected a combination of internal symptoms related to burnout and a corresponding midlife passage. I looked for the narrative strategy that she used to integrate the stories related to her past with her current positioning. She responded first with an affirmative professional stance before critically reflecting on her observations of the profession with which she currently identifies.

"I don't feel disadvantaged or cheated by having 'lost' my practicing certificate, as I know I can return to nursing. I do not feel that I would be safe to work as a RN at present, even though some of my midwifery care could be defined as nursing care. I feel that we can move between the two professions - perhaps not easily, as there would always be a catch-up time. There are midwives who also work as nurses, and while there may be a separate philosophy for each, we are surely all working for the health and well-being, and self determination of people? I think that as long as you can be aware of which hat you are wearing, the two situations could coexist" (Story, line 134-147).

Mary views the latest legislation that separates the two professions as positive. She believes that providing evidence of competency and conscientiousness decision making around professional practice is important for our professions. She recognises that there are colleagues who:

"that's what they've done for so many years and they're sick to death of it and they fulfill their contract with the employer or whatever, but haven't got the heart for it anymore... and that's sad for them as women, and for the women we care for (Interview, line 421-431). 
It was these last comments that provided the emphasis for the title of Mary's story. She spoke about being out of compassion that hinted at a loss of heart. Kornfield (1994) emphasises the simple importance that our path be connected with our hearts otherwise any actions without that connection become dried up, meaningless, and barren. Mary is concerned at these attitudes expressed by other practitioners and is anxious that they recognise these signs so that we can continue to feel:

"Proud of what women having babies in New Zealand get and I don't want anyone to let the side down. And when you see that happening you, I think that's not good enough women deserve more than this" (Interview, line 328$331)$.

She describes the postnatal area as the "Cinderella of Maternity Care" whereby practice is effected when practitioners take on too much work. The increased demands of the profession have led to a personal awareness of some symptoms of burnout. These have manifested physically as neck stiffness and muscle spasm, and mentally and emotionally as having used up the "allotment of compassion", feelings of "I can't be bothered, I don't want to do this anymore", and "I've just run out of energy". Such confessions convey the sense of a loss of heart, and hence, her arrival at a crossroads.

Where do personal needs and growth blur into political critique and social change? Barnett (2006) contends that we ethically and productively examine emotion to afford the hope for material change to occur for individuals and society. By focussing on individual's concrete experience we utilise emotion productively; if we ignore the personal in our search, then social change will be compromised. The flow of discourse within Mary's story proceeds to the point where she carefully considers the reality of remaining in a profession that she has given to tirelessly to. She details the steps she takes in making a decision:

"I think there's always a fair bit of soul searching and a fair bit of umming and ahhing; and I would describe myself as being quite a worrier, or quite neurotic; and that it takes quite a lot of energy to 
get to a decision, but once the decision is made, I'm usually happy" (Interview, line 144-147).

Other useful strategies that Mary has discovered assist her decision making are; writing down dilemmas, including a plus and minus list for any big decision. She values the opinion of a trusted partner, colleague, mentor, or friend, and is keen to read and research around the topic. It would be unusual to jump to any conclusion without “quite a lot of soul searching and thinking” (Interview, line 144-147).

No longer laying claim to being a midwife causes Mary to wonder "what else am I trained to do" (Interview, line 62), and how she might be able to change or "re-hone those skills that I have learned into something that's not quite so demanding" (Interview, line 67). She is clear that she has arrived at this point of her own volition and doesn't feel pushed or forced out of either profession. Mary begins to imagine ways of maintaining the passion she feels for midwifery "one step removed" from being a Lead Maternity Carer, and considers the options of nursing, or even something completely different. In thinking through how change would be perceived by others Mary had this to say:

"I would like the safety net that an employer gives you. And it's funny because there's this little part of me that thinks being an $L M C$, in a lot of peoples minds, maybe this is just my insecurities, is like the way Midwifery should be held; it's sort of like the pinnacle and you step back from that; is there a thought that Oh you can't hack it; or you, you're taking a retrograde step, so if you work in the hospital you go back to another aspect of nursing; it's like well, is, is that considered that retrograde, and I guess we all like to be held in high regard, or our status is important; whereas if you have a job that's seen as a complete change, or if I got a job teaching, then that's almost a promotion or it's something so different, that it's more acceptable. Does that make sense?" (Interview, line 583-592). 
I sense here the anxiety that Mary will experience a sense of failure, or doubt the nature of the visibility of her work in a parallel setting. It hints, perhaps, at a role ambiguity within the profession of midwifery. If the perception exists that the cultural mores of that group perceives that the LMC role or its set of behaviours are superior, then any adjustment is likely to cause confusion. Not knowing how others will behave towards her creates the possibility of mixed messages, and role ambiguity. The resultant anxiety might well create a struggle in a search for personal and role identity that would be acceptable to the greater team (Bradby \& Soothill, 1993).

Nortier (1995) speaks of resistance to change as being more about resistance and apprehension, with regard to the transition process, that will have to be made to cope with the change i.e. the fear of having to give something up and face the unknown.

A sense of 'social limbo' is recorded as preceding the first stage of a rite of passage, and Turner (1974) suggests this phase as a source of social change. My senses intuit in Mary an air of preparedness to let go, or at least consider change that will allow her to replenish her energy and reconnect wholly with the sense of passion that was conveyed early in her story. She currently dwells in the mystery of "what else am I trained to do" (Interview, line 62), accompanied by a sense of trust that the answer will eventually come.

\section{Witness to the hero}

The heroic quest is a cyclic process fuelled by curiosity, courage, and capacity for growth; qualities that propelled Mary from her early nursing days on an overseas adventure to complete her midwifery training and travel, and return to independent midwifery practice. Symbolically, this history represents two cycles with Mary currently on the threshold of a new adventure.

Mary linked narrative, as storytelling, in construction of the postnatal aspect of her practice. Embedded within Mary's narrative was the metaphorical image of Cinderella, used to portray the relationship of the part of postnatal care to the whole of maternity care. From a narrative perspective this allows us to consider the thematic 
connections between the universal story as a story of transformation, with that of the task affecting Mary and other practitioners. Considering the symbolic Cinderella framework we might consider such questions as: Are we trying to squeeze into the offered shoe, but wearing it painfully, or, are we looking for a way to massage the structure of the shoe to make it more comfortable? (Kovach, 2005, p 9).

Cinderella offers medical writers a rich tapestry of metaphors as judged by a Pub Med search in 2005 citing 163 papers dating from 1954 to 2005 (Cameron, 2005). Sub themes of relevance are neglect, identity, transformation, and exhaustion. The themes of overwork and under appreciation link the threat of burnout to this fable too. "The fragmented nature of life in the twenty first century sometimes causes us to lose ourselves and to relegate the soul, like Cinderella, to some dark forgotten cellar" (Cammock, 2003, p 143). Threshold guides and guardians abound as Cinderella overcomes adversity gracefully, determined to see what life has to offer. If only it were as easy as a magic spell, the stroke of midnight, and a glass slipper to make effective change, and live happily ever after.

Viewed symbolically, the birth of the hero in myth is accompanied by signs of coincidence, or serendipitous events and wonders. Mary acknowledges the synchronous patterns of experience that have facilitated her working passage. "I've often thought that I have [met people at the right time] especially where work has been concerned I feel like I have been very lucky" (Interview, line 211). When viewed symbolically coincidence begins to take on a much more respectable appearance describing, rather than denying connection. Rather than finding obscure meanings and patterns in unrelated events, which might be viewed as pathological, Johnson (1992) proffers the process of 'mythologization' as tying together details of life experience to "reveal the intentionality that structures the world of experience and to direct that power toward integrating the life" (Johnson, 1992, p 115). In practice, the call to adventure often emerges as an interaction of the external and the internal origins. Mary's realisation that she is ready for change is representative of the internal call that alerts her to the signs of burnout at a midlife phase in her life, and effects a response to the external call of the HPCAA (2003). 
There is no easy answer to Mary's question “What is next?"(Interview, line 222). Campbell (1988) responded to essentially the same question by noting:

My general formula for my students is 'Follow your bliss' Find where it is, and don't be afraid to follow it. If the work that you're doing is the work that you chose to do because you're enjoying it, that's it. But if you think, "Oh, no! I couldn't do that!" that's the dragon locking you in. (Campbell, 1988, p 148).

Mary's sense of vitality and passion has waned to the extent that she has arrived at a 'crossroads'. Being positioned in such a liminal space is ripe with possibility highlighting again the constantly evolving nature of identity. While some practitioners will be open-minded toward a new way of life, others may at first be unwilling or unconvinced about embracing the unfamiliar. Forces lurk at thresholds, and it is not surprising that the call is often resisted, or in some cases, never heard.

Mary's own unique past, present, and future became part of an integrated whole through her writing. By reconstructing her biography first, Mary reconnected and evaluated her early experiences with the larger whole, better enabling her to clarify personal goals, and imagine the future direction of a path with heart. 


\section{Chapter Six Susan's Story: Dragons of Initiation}

Susan has just relinquished, with great difficulty, her midwifery APC. Her participation within the profession of midwifery was described as "lived and breathed" (Interview, line 690-691). Just like the air we breathe we rarely discuss it, or question it, or marvel at what is so natural and yet for others may be difficult. With her extensive experience in midwifery, it strikes me as significant that Susan would title her written narrative with the question: What is a midwife? It is as if she questions her knowledge of the past, the present, and her future when she titled her written narrative in such a way.

The obvious social aspect of writing a story is that it is told to someone, so, the shape of the telling is moulded by the rhetorical and internalised expectations and perspectives of the storyteller. Susan portrays herself in both written and oral narrative as disappointed and disillusioned. It was difficult to establish a cohesive order to relate her story chronologically. As a narrative construct, critical moments were displayed by reversals in story lines, and steep up and down slopes that Sandelowski (1991) describes are indicators of the intensity with which events are experienced. Her recollections, however, represent most fully the phases of transition and loss as she 'let go' of a profession that still obviously held great value and treasured memories. So by examining the literature on transition, in conjunction with the experiential material of Susan's narrative, we might arrive at a clearer understanding of this important process. The way that Susan chooses to re-enact her life through story will be revealed in the links between where she itemizes relevance and exposes her evaluative responses to elements of the past, present, and future. I was interested to see where Susan would place the greatest emphasis on traversing this change, as there were several layers to Susan's written story that were contextually embedded. 


\section{A journey to becoming: Status passage into nursing and midwifery}

Soon after starting her nursing training Susan was attracted to midwifery. Biographical detail about her years of training, or her years spent in the profession of nursing, did not occupy much of Susan's commentary, nevertheless her intense satisfaction with the profession of midwifery was conveyed. She missed the camaraderie of the workplace when on days off or annual leave.

Impelled by a movement toward greater autonomy Susan had entered domiciliary practice early in her career. Although she states that "I'm not an especially brave person", with good support and encouragement by colleagues she discovered the process "a really easy thing to do". Memories mingled from the precious to the profound:

"The experience I had with so many strong women was magical" (Story, line 7-8).

"We were a pioneering group of women spurred on by our passion for mothers and babies" (Story, line 15-16).

Involvement in a critical professional incident, and personal health issues intervened early in Susan's written narrative. Their strong presence served to contribute to a sense of regret about the past, united with a certain lack of clarity about the future. These were sufficiently powerful to be exerting an influence on her story in the present. She applied metaphor as an abstract image in describing the power of this incident. Susan's description of a critical incident as "it rocked the foundations of my beliefs about my practice" (Story, line 21-22) was a phrase that highlighted a previous painful transition, and as such, was having an ongoing impact on the current dilemma being faced. As I read and listened to Susan's description, I wondered just how many nurses and midwives had experienced the foundations of their practice being rocked.

Nortier (1995) explains that it is not unusual for people to use very strong expressions and metaphor to describe what they are living through at these times. Empirically, if a person has experienced incomplete or painful transitions, the individual may have real difficulty in dealing with any new transition. In such a scenario a resonance phenomenon may then occur whereby feelings and moments similar to past 
experiences are re-experienced. These echoes of the past thereby amplify the characteristics of the present situation (Nortier, 1995). This resonance phenomenon goes some way to explaining Susan's strong reactions when faced with change. These explanations do not include any further triggers that the individual may have experienced in her personal, family, and private life.

As a narrator, there were times when Susan's individual voice seemed constrained by her family responsibilities and strained against the mediating aspect of social and cultural expectations. It is likely then, that using the same rationale of resonance phenomenon in reverse, personal transitions will also have an impact on professional lives. Changes in external family and community involvements can also influence work role motives and opportunities.

Susan organised her written biography in such a way as to explain and justify her life experiences, and this allowed extension in our later conversation. The repercussions from this period of time began to affect the joy that Susan had previously experienced in her profession, and she feared a repetition. Continuing in independent practice following this critical incident was difficult, and Susan stated "I just felt like I needed more protecting. I felt very vulnerable as an independent midwife" (Interview, line 359-360). From a narrative perspective, time was represented as somewhat discordant, as these personal factors were impinging on the publicly altering socio-political context. The effects were being felt in her personal and family life, and were factors that caused her to consider further employment options. It was in these circumstances that the introduction of the HPCAA (2003) began to gain momentum.

Susan related a desire for somebody from the Midwifery Council to "race in and say wow you're such a great midwife, lets set up a system so that we can keep you in the system" (Interview, line 73-75). This suggests an attachment to the role of being a midwife. She is expressing a desire for some form of acknowledgement of value from the Midwifery Council for all her years of dedicated service. A lack of recognition corresponds to what van Manen (1997) describes as indifference, or a crisis of the 'we'. It is possible that being allowed to leave without any recognition could have been perceived as indifference on the part of the group; and so exit became a functional alternative to 'voice'. 
Whilst still retaining a small midwifery caseload Susan commenced alternative nursing work that she found challenging in its unfamiliarity, and she enjoyed the experience. Although she thrived in a new academic environment, she discovered that the associated financial cost did not guarantee greater employment options, and sought employer funded education schemes in the future. The distance continued to grow from midwifery, and was furthered throughout this period by a withdrawal of membership from the professional body, leading even further to a feeling of isolation.

Susan reveals her feelings in the statement:

\begin{abstract}
"I feel angry and sad that I am being pushed from midwifery. It may be that I am ready to make the move, but why then do I grieve so much over what is going? I am still searching for the job that will inspire me as midwifery has done" (Story, line 90-93).
\end{abstract}

Susan acknowledges that she no longer has the family support to stay with midwifery and further opportunities within the profession of midwifery can only offer her shift work. If the hospital had turned around and expressed appreciation of her experience, and a willingness to be adaptable Susan admits that this is the way she would have gone. But because the only openings included full shift work, she disregarded these.

"I probably would have made the changes anyway, but it would have been over a longer period of time. So the HPCAA has actually hastened it, and quickened the process. It's probably made it much harder because I'm not ready to go" (Interview, line 97-99).

\footnotetext{
A liminal place

The process toward an eventual decision had been anything other than lineal for Susan as she acknowledges that her personal pattern of decision making in life generally, is one of avoidance.
} 
"I avoid decisions. That's probably an easier way to put it. I kind of drift and, whatever seems the strongest, or seems right, I will make" (Interview, line 127-128).

By her admission the process of deciding has fluctuated. For example:

"I miss midwifery so much that some days I think I will just take the plunge. Such an occasion happened recently and I announced to my daughters with great excitement that I had finally decided to return to midwifery. Their reaction changed my mind" (Story, line 73-75).

In response to a former client's request for midwifery services Susan had at first responded positively and then her response changed:

"I think that woman ringing up was quite a good catalyst because I said yes, and then, when I thought through the reality of actually putting it in place, I thought I don't want to do this. So, suddenly I had a choice and I decided it wasn't what I wanted" (Interview, line 715-717).

These fluctuating mind-sets meant avoidance of decision making for some time, and were not conducive to Susan feeling in control. Eventually, paying attention to her families wishes became the motivating factor for her. The steps of alternately focussing attention on the self and then on the family were necessary for Susan to build up a complex meaning system. She described the factors of disillusionment leading up to this point as the increasing loneliness of independent practice; the expense of maintaining practice; the requirements of maintaining two professional portfolios when she considered that the competencies overlapped; the persistent effects of being on call; the poor pay in comparison to the demands and responsibilities; the effects on family life; and the limited support network of midwives who were also mothers. These factors became most evident once she was employed in a nursing position: 
"Within about the first month it was really obvious, the difference in pay rate, the amount of time off, and the sense of freedom of not having the phone by you all the time" (Interview, line 377-379).

"It was such an amazing feeling, to leave the phone in my locker, walk away, and not have to carry it" (Interview, line 391-392).

And so it was in hindsight that Susan recognised the physical and emotional signs of burnout that had been manifesting. There have been some necessary adaptations:

"I'm desperately seeking new adventures and new paths. It's how many are actually going to open up because one of the things that concerns me about nursing was that it was a subordinate type role; and I struggle with that at times, and I know I've had to bite my tongue at times. I see people doing things that I would snap about as a midwife, but I'm not in a position to do so. But, I've learned how to deal with things more tactfully" (Interview, line 728-733).

This encounter provides an interesting window into the contradictory and shifting nature of hegemonic discourse. Susan's individual experience of this encounter draws us to consider the lived experience as nurse, as opposed to the lived experience as midwife, and to theorise about the distinctions between different forms of knowledge. Knowledge speaks through our lived experience, and for Susan this was predominantly experience as a midwife. In this role, contact with the medical profession occurred mainly when referral was required, particularly when a situation deviated from the normative experience. Here, outspokenness was considered essential, but as this scenario suggested, was inappropriate in her role as a nurse. Experiencing transition, as previously discussed in Chapter two, echoes the question: where am I, and relates to the daily impact of choice and change. Transition to the role of nurse saw a relative change-over from one set of expected positional behaviour to another. If we were to apply the three phases of a rite of passage to this scenario the theoretical material on status passage becomes apparent. Having relinquished a role of higher discretion in the phase of separation, Susan encounters hazardous transitional activities in order to fit her new social status as nurse in the phase of incorporation. 
A person's adjustment to role transition, according to work role transition theory, can be considered as personal development whereby change is absorbed through the person altering her frame of reference, values, or other identity-related attributes (Nicholson, 1984). Alternatively, depending on the constraints and opportunities of the role, and the needs and expectations of the person, a proactive strategy may be applied. Role development then becomes a form of organisational development. The novelty of the role demands persist until the limits of the learning are reached and adjustment stabilises.

Susan's journey to resume practice as a nurse does not deter her continued attraction to midwifery, albeit incompatible now with her family's current needs. She remains sceptical, however, about the cost of a return to midwifery course in the future. In addition to the rising cost of an APC, a return to work as an LMC would involve delayed payment several months into practice, so therefore, she would be "out of pocket for a period of time until the money starts coming in" (Interview, line 561-562).

Susan is appreciative of the skills learned as a midwife and sees the relevance to her current work setting. As she establishes her new work practice she states that colleagues and clients come to trust her practice, and, as she gains credibility, it makes her job easier and more enjoyable. With these varying commitments, and orientations in mind Susan chose to relinquish her midwifery APC, and completed her personal traverse of this professional divide.

\section{Witness to the hero}

Susan's narrative allows us to grapple with the ambiguity, diversity, mystery, and discontinuity that come with the reality of a professional being in the world. As a narrative there are tensions of order and chaos. Disequilibrium and discontinuity, though, are as much about the order of the world as equilibrium and continuity. With no power to control the rhythms and movements of the world, we might consider how the universality of the human journey resembles the journey of the hero. We are as much of the world as the world is within us. Once past the threshold, the symbolic 
hero begins the journey into the unknown. It might be outward into a physical unknown, or inward to a psychological unknown. Whichever direction the journey takes, our adventure seems to put us more at risk as we face a series of challenges or temptations.

If there is any stage of the journey that is more demanding than the others, it is surely the initiation. This seemed an appropriate title for Susan's story. Believing that they have answered the call and that all will now become better, Noble (1994) answers: Not so. It is a period of profound change, challenge, and tribulation. These may reflect our needs and fears; for it is only in facing and acknowledging them that we can transform the 'dragons'. The symbolic pattern of descent and renewal, death and rebirth, are of mythic proportions. The purpose of the hero's initiation is to release the capacities and hidden strengths by being presented with a series of formidable obstacles. These 'dragons' or obstacles are said to break the hold of a personal past, shatter the chains binding an outworn image, and free the reluctant hero for transformation (Noble, 1994). By being open to the possibilities inherent within the myth of the hero journey, it is possible that inner solutions, in storied form, will suggest alternative pathways into the future. The collective story can be found nested within the individual story and the stages infer rites of passage as thresholds are crossed. This provides a sense of danger, and a sense of opportunity.

Dr. Kathleen Noble (1994) charts the contemporary woman's hero path through the dynamic stories of women she has studied over the years. From their rich stories she has fashioned a framework for understanding life events, and shows how to devise new archetypes of heroism out of their own experiences. Each woman begins her heroic journey with the call to an awakening, a summons to realise her own potential. Each one battles with her dragons of initiation that guard the path to transcendence. And at crucial moments she encounters allies, from without and within, who strengthen her heroic self and prepare her for the transformation. She offers this alternative framework to show how the call to adventure, to a leap across the chasm (or divide) of personal and social change, can lead to new creativity, spirituality, and achievement. Excerpts from her framework will be applied to shed a new light on the complexity and diversity within Susan's narrative. 
Noble (1994) regards six symbolic dragons of initiation of specific challenge to the female hero path. Susan stated in her story "as a good girl, approval was very important to me" (Story, line 24-25). Noble warns the female hero of the first and most formidable dragon, that of her own self. It may present in the guise of the soul stunting pattern of the 'good girl' who conforms to the needs of everyone else. Analogously, Hochschild (1983) describes how women, who are more likely to be in service jobs than men, specialise in the 'flight attendant' side of emotional labour, requiring one to master anger and aggression in the service of 'being nice'. In the service industry of nursing and midwifery, practice involves affirming, enhancing, and celebrating the wellbeing and status of others, and provides a link to issues of burnout. Fear of this dragon can find us running from one place, person, or distraction to another, to find the value we seek, in others. The weapons in Susan's armoury against this dragon became her hope, perseverance, and indomitable will.

Noble uncovers the second dragon experience common to women, as the legacy of depression or despair that results from the attempt to live life according to the dictates of others. The emotional labour of remaining a seriously 'good girl', according to Hochschild (1983), is that the worker can become estranged from an aspect of the self. This might compromise the ability to form intimate friendships and compound feelings of isolation and loneliness (Noble, 1994). A general resilience factor across the lifespan, and a basic human need essential to wellbeing, is relatedness. Susan described strategies that helped her to deal with change as:

"support, education; the more you know the easier it is. The more support you've got to do it, the easier it is" (Interview, line 266-267) and,

"any change is painful to some degree, but if you have support from those that are important in that change, then it makes it much easier" (Interview, line 275-276).

The third dragon symbolises the dragon of dependence and enclosure, a dragon that socialises us to drift until someone else provides a solution (Noble, 1994). An exchange of vitality and independence might be made for a life of safety or passivity. Often at the symbolic threshold, or 'jumping off point' for the adventure, our doubts 
and our ineffective thought and behaviour patterns may become threshold guardians. These threshold guardians have two functions. They protect us by preventing us from taking journeys for which we are unready or unprepared. However, once we make a commitment, to say: 'I'm ready, I can do this' they symbolically step aside and point the way (Harris, 2006). Susan encounters the cultural stereotype of this dragon with these words:

\begin{abstract}
"One of the things that I was thinking about was that it is almost like wanting to be rescued. That I want somebody from Midwifery Council to race in and say "Wow, you're such a great midwife. Let's set up a system so that we can keep you in the system" (Interview, line 73-75).
\end{abstract}

However much we desire the relief of being rescued, it denies the female hero the possibility of transformation that self expression entails, according to Noble (1994). She describes 'rescue' as another wily dragon, cunning and seductive in its promise of transformation, but failing utterly to deliver on its word. Susan met this symbolic dragon when she recognised and asserted the validity and primacy of her own needs, and integrated these into her personal and professional life.

A fourth symbolic dragon along the heroic path reveals itself as prejudice. Noble (1994) contends that if women do not conform to stereotypical criteria such as age, attractiveness, size, colour, or sexual orientation, they risk being excluded from the challenge of the heroic quest.

Saying 'yes' to too many expectations and demands, often at the expense of our own physical, psychological, and spiritual well being, is the tendency of the fifth symbolic dragon (Noble, 1994). Despair, hopelessness, burnout, and a radical experience of impotence can strike many who are most committed to offering alternatives (Houston, 1987). In tracing the genealogy of midwifery, Brown (2003) using a Foucauldian perspective, theorises that following investment power can find itself exposed and therefore retreat to reshape itself. In effort to maintain autonomy, and meet recommendations, midwives begin to suffer burnout at the cost of their personal lives 
(Brown, 2003). Susan confronted this symbolic dragon by altering the demands and complexities of her daily life to meet her personal needs.

Noble (1994) suggests it a rarity that the sixth dragon, of unexpected hardship and loss, does not roar with sudden and devastating force into the fabric of a woman's life at least once. Illness, the death or collapse of an important relationship or the disintegration of a way of life might challenge physical, emotional, and spiritual resources to the utmost. Susan summoned resources of inner resolve, and identified where the greater meaning in her life was in her current context:

"Finally I have decided I have to put my family first for a time, while I still have them, and work the hours that suit family life" (Story, line 76-77).

The process of confronting the dragons in our path and slowly subduing them becomes the symbolic tasks of initiation. The Grail of wholeness may indeed 'rock our foundations' and our sense of wholeness may be hard won. 


\section{Chapter Seven Jo's Story: The Portal of Transformation}

Jo currently holds practicing certificates in both the nursing and midwifery professions. She works predominately in a nursing role, and maintains her competencies as a midwife by working on a casual basis. A narrative framework obviously offered Jo access to ordering her experience and indulged her impulse to tell a tale. She provided a delightfully evocative story of her early captivation with nursing, knowing implicitly at the age of five where her future path lay.

Jo's narrative was biographical in nature, clearly outlining the temporal nature of her working experience over the years. The details were presented succinctly and the issues that influenced her exchange from the predominant occupation of midwifery to nursing were presented as bullet points at the end of her hand-written narrative. These were jotted down between busy life events that were taking place at the data gathering phase of this investigation. It would have been easy for Jo to cancel her participation in this project, but she chose to honour the commitment that she had previously made.

Lived space, as a category for understanding Jo, revealed a person who made efficient use of every moment, and her written and oral narrative portrayed herself as honest, hardworking, and highly principled. As a moral enterprise her story justifies the model for life that she espouses. In an easy, open conversation Jo was happy to expand on her experience of transition from midwifery to a nursing role.

\section{A journey to becoming: Status passage into nursing and midwifery}

Jo indulged in precious early memories that fired her enthusiasm for a future path in nursing leading on to midwifery. At the ripe age of five her future vocation as a nurse was apparent. "I constantly scribbled on my doll so I could put a plaster on her, or a bandage. In later years, probably about ten, I got into trouble for filling up my friends ears with daisy and buttercup flowers, packing them in really well. I was fixing the ear. At twelve, I observed my mother in labour, bearing down between two beds, being absolutely fascinated with the process of labour. In addition, my Dad, a tow truck driver was always attending car accidents. Telling stories to other people - I'd often 
eavesdrop. When my mum had my youngest brother, we visited the maternity ward. That's it! I would be a maternity nurse when I grew up" (Story, line 1-11).

Upon completion of her comprehensive nursing training Jo identified her work preference for the maternity setting, and enjoyed it immensely. Obstetric nurses working in that setting at that time were threatened with being transferred to the general wards unless trained as midwives. The possibility of this happening spurred her on to gain the specialty qualification of midwifery, which she completed, part-time over eighteen months. She accrued much experience after graduating from midwifery, in public and private birthing facilities, and as a Lead Maternity Carer (LMC). She then upgraded her Midwifery Diploma to a Bachelor of Midwifery Degree.

Jo feels a real sense of satisfaction that she personally financed the training that she undertook to become a nurse and a midwife, working seven days a week at times, and through the holidays. This assures her that both qualifications are hard-earned and deserved.

After marrying and having a family, Jo continued to work hard choosing full time night shift to fit with the needs of her family. Protracted shiftwork over many years was adversely affecting her health, however, and she was aware of signs of impending burnout. Her children were growing and communicating a desire that she no longer work the hours that prevented her from being available for family activities.

"I battle a bit between a career and my family. Because when I go to do something, I like to try and do it quite well, and I guess it gives you self esteem and other things that your family don't give you. You can be different person" (Interview, line 223229).

These words convey the tension between maintaining an active working life and a family life, and yet the importance too of maintaining an individual personality and identity, while maintaining close family relationships. Holding Jo's spirit and vision intact was her sense of where deep meaning lay. Personal life circumstances had convinced her of the importance of attending to her children's needs having: 
“...experience to ground you and make you realise what's most important in life; rather than get to the end of your life and look back and think, well actually, I should have spent more time with my family" (Interview, line 241-243).

It was about this time that the proposed HPCAA (2003) was impending. Her viewpoint of that time was:

"I didn't want to lose my nursing registration. I have a really firm belief that I see myself as a Nurse/Midwife. I find it really hard to separate them both, and, because there wasn't a lot of information around as to once we do let go one of the registrations, or as to how we get back on board...it's more of a security thing for me; when you have both then you can apply for different positions" (Interview, line 97-105).

As a harbinger of things to come Jo had already completed some post graduate papers to improve her chance of promotion within her current work environment. Attaining a management post would provide an opportunity to find working hours that would be more conducive to her family's needs. The reality proved more difficult when she was overlooked for an eligible position by an internal process of promotion that offered no opportunity for application. Jo described her dismayed reaction as to the unfairness and inequality of the process. In not being considered for the position Jo felt “overlooked, invisible, and devalued" (Interview, line 400). Previously held beliefs and values were suddenly shattered. The sense of inequity and the perceived lack of honesty and openness meant that she no longer foresaw relevant opportunities within that organisation, and her career path was about to veer in an unexpected direction. A nursing position arose that included an education package that would extend her skills. 


\section{A liminal place}

Jo's exit from this previous role exhibits characteristics of the crisis/confusion stage of transition outlined by Nortier (1995). It is the 'last straw' which may trigger off some action. Although equilibrium has not been present for some time "it is the small piece of information which suddenly and fully gives meaning to all those pieces of information, which until now, had been minimised; the consequences of which people had not wanted, or been unable to see, and which have been pushed aside without attaching any importance to them" (Nortier, 1995, p 40). The entire system that Jo had built up to sort and decide information collapsed and became questionable, creating conditions indispensable for real change to occur. Jo revealed "I just felt that I can't work for people who are not honest and open, and don't treat everyone as an equal" (Interview, line 422). Here Jo uses narrative to identify her ethical and moral identity. These controls are internalized in the body's own responses, rather than in external authorities. To continue to participate actively in this environment has been demonstrated to slowly erode a nurse's identity as moral agent (Hartrick-Doane, 2002).

Research supports confusion as conducive to assimilating new behaviour. The literature points to three types of response to a crisis phase. In an attempt to find a state close to the initial equilibrium, an individual might hand in her notice in an attempt to find a job like the original one. This often results in disillusionment, or evolution that stagnates, as what they have experienced has changed them, and assimilating a new context itself calls forward a new transition. Alternatively, if the crisis persists without providing a possible way out, or gleam of hope, a state of depression may result; the degree of severity related to the context of the person i.e. history, previous transitions, family support etc. Most often the individual decides to take the initiative (the hero path) even though she does not always know the paths eventual destination (Nortier, 1995).

The phase generally continues with a growing acceptance of the situation. Once the first clues of a new response are felt, surprisingly, there may be a burst of new creative energy. The situation then becomes an opportunity for a large-scale 'tidying up' operation of personal ways of acting and organising. Thus apathy moves to hope, or even enthusiasm. This stage starts to trigger then, new meaning and direction which is 
an essential feature of transition. It is, at the same time, a fragile phase in which elements of doubt may still be present. While being on a new path it is still necessary, according to Nortier (1995) to generate the types of behaviour, reasoning, and resources which will enable this increased sense of meaning to fit with the new daily reality. This final phase Nortier coined as 'rebirth' which is often wrongly associated with the end of the transition. As new reference points are considered, behaviour will generally reflect change as being more complete, moving the transition from the before to the after.

Also influential in the process of deciding to undertake this status passage Jo listed the increasing cost of APCs and continuing education, and the increasing disparity she was observing between the work practices of other practitioners and her own. This meant an increasing level of responsibility she was encountering in the workplace. Combining all of these factors together Jo's pattern of decision making was methodical and thorough. When her husband and children are unable to clarify a direction she will:

"Sit down and go through each scenario; and I also look at the pay” (Interview, line 151).

"I think things through. I write them down, and then I throw them out, so no-one finds them" (Interview, line 175-176).

I find this last line particularly intriguing as it points in some way to Jo's moment of awareness, and how she chose to deal with it by denying its existence and impact.

She states that friends provided "fantastic support" having noted the tiredness and gradual decline in her health due to shift work. Lived other (relationality) has been discussed previously as the lived relation we maintain with others in the interpersonal space that we share with them. van Manen (1997) describes how transcending ourselves, as we meet and develop a conversational relation with colleagues and friends, helps to develop a social sense of purpose in life. These relationships provided Jo with enduring support and assisted her individual adjustment through the experience of change. 
The central premise of adjustment, according to work role transition theory, is mediated by individual differences in the characteristics of people. Jo's own attitude toward potential change is very philosophical:

"Things happen for a reason. I'm a great believer in things happening for reasons. Sometimes it's more of a blessing in disguise" (Interview, line 1260-1262).

Such a relaxed approach to living prompts two commonly asked questions in the area of social science. What types of people are likely to be well or happy? And, are there people who can be characterised as being happy or well? The relation of emotions to well-being deals to some extent with the meaning of well-being itself. As such, the hedonic and eudaimonic perspectives have quite different views, and will be explored.

According to Ryan and Deci (2001) well being is a complex construct and current research has been derived from two perspectives: the hedonic approach, which focuses on happiness and defines well-being in terms of pleasure attainment and pain avoidance; and the eudaimonic approach, which focuses on meaning and self realization and defines well-being in terms of the degree to which a person is fully functioning. This perspective derives from realising ones daimon or true self. In other words, pursuing personal goals, and feeling happy doing so, may be disconnected from finding meaning and acting with integrity. Jo's life activities are shown to be most congruent with her deeply held values, and are therefore congruent with a eudaimonic sense of well-being.

The diversity of attitudes and responses to change demonstrates the swirling levels of competing responsibility and personal experience that connect the personal to the political. There is further social science research that demonstrates a correlation between attributional styles that are more self enhancing, or enabling. Extraversion, conscientiousness, and low neuroticism were linked with the eudaimonic dimensions of self acceptance, mastery, and life purpose. Openness to experience was linked to personal growth; agreeableness and extraversion were linked to positive relationships; and low neuroticism was linked to autonomy. People were most likely to depart from their general characteristic traits when they were engaged in life roles in which they were least able to express their true self (Ryan \& Deci, 2001). 
Self determination theory is another perspective that embraces the concept of eudaimonia, or self realisation. According to Ryan and Deci (2001) it posits that there are different types of positive experience and that there are some conditions that foster subjective well-being, but do not promote eudaimonic well-being. For example succeeding at an activity while feeling pressured might result in happiness (aligned with subjective well-being) but it did not result in vitality (a positive effect of eudaimonic well-being). On the other hand succeeding at an activity while feeling autonomous, resulted in both happiness and vitality. These are relevant concepts involved as practitioners weigh up roles that have greater, or lesser discretionary value. A sense of autonomy it seems is most relevant.

Jo discussed her declining health status as related to prolonged shift work. Physical health has an association with well-being increasing displeasure or pain, and so, the presence of poor health was likely to increase the negative effects of her work role. Empirical results assessing subjective levels of vitality, that is having energy available for the self, were used as indicators of eudaimonic well-being. Correlations were found with psychological factors such as personal autonomy, and relatedness, but also covaried with physical symptoms (Ryan \& Deci, 2001).

Since relinquishing shiftwork Jo feels more mentally alert:

"I feel like my brain's a lot sharper. I wouldn't be able to talk properly, or talk in this matter. I probably would have wanted to say something, and something else would have come out because you feel like your pathways all crisscross" (Interview, line 464-466).

She is consoled by the newly perceived improvement in her physical health, the reduction in absent minded behaviour i.e. remembering where she puts items; and no longer having "to be in a state of readiness carrying a pager"(Interview, line 1074). She remembers "getting palpitations every time the pager went off" (Interview, line, 1083). She has noticed the rising rate of medical conditions, such as hypertension, in her midwifery colleagues and: 
"then they're saying 'what else can I do? I'm in my fifties. I want to work, but what else can I do' and they don't know what else to do, so, some of them do keep doing it" (Interview, line 10401046).

Regaining a sense of personal power was one of the immediate benefits. When asked whether the thought of no longer laying claim to being a midwife bothered her, Jo's response was a rapid 'Yes';

"I always thought, as a midwife, you're a little more prestigious"

"And that's one of the battles for me, because I felt like I was a nurse, then I was in part too, a midwife, and I feel like I've slipped back, but I haven't”' (Interview, line 664-672).

From a eudaimonic view, goals such as fame or image will not in themselves satisfy basic psychological needs. Despite perhaps a partial satisfaction, they potentially distract from factors that might yield need fulfilment and detract from a sense of authenticity. The unanimous opinion from the participants was that a level of value must exist between the level of effort and responsibility, and the level of remuneration. Examination of the impact of impoverishment on eudaimonic outcomes revealed that socio-economic status was linked to the dimension of self acceptance, purpose, mastery, and growth. There were identifiable risks to poverty, but few benefits to wealth when it came to well-being (Ryan \& Deci, 2001).

There has been increasing appreciation of the fundamental importance of attachment, relatedness, and well-being. Jo had extensive experience in both professions, and her response to whether nursing felt like a separate profession was:

"I feel like it's an extension of what we're doing. I don't think there's separation at all" (Interview, line 1161-1165).

Jo feels that she has settled in to nursing "quite quickly and easily because I was doing a lot of nursing” 
“I think nursing's got a lot more options. They're more likely to do eight hour shifts" (Interview, line 1091-1092).

A general resilience factor across the lifespan, and a basic human need essential for well-being, is relatedness, Warm, trusting, and supportive interpersonal relationships had been fostered over the years. As I reflected on Jo's attitude of a collective experience of the professions of nursing and midwifery, in addition to another example of a "prestigious" attitude toward group perception, I speculated on whether the divide would foster or encourage attitudes of superiority, or competition between the professions. The quality of relatedness between the professions is important for collective professional well-being and flourishing. The well-being of cultures in the current social context will be directly related to between- person, and within-person influences. From the perspective of collective well-being then, the way that we pursue our goals in terms of hedonic or eudaimonic outcomes, create conditions that may make the attainment of well-being of others more formidable.

Jo struggles to get used to saying 'nurse' as a form of identification, and has detected strains of reticence in extended family member's reactions to her new position. She describes a typical reaction as;

"She went silent and she couldn't say anything" (Interview, line, 795).

"I interpret that as she probably thought that I was slipping backwards" (Interview, line 802-803).

This only bothers her "to a degree, but I think once I get settled it won't; it's for a reason" (Interview, line 815-819).

The workplace scenario that scuttled future plans for more suitable hours provided sufficient threat to Jo's self interest that it provoked and initiated an empowering process. Only when the immediate and physical violation of a sense of integrity has sufficient force will a response be evoked (Kieffer, as cited in Gibson, 1991). Jo intends to complete her midwifery portfolio, and participate in a Midwifery Standards 
Review process in anticipation of the possibility that she leaves midwifery for a few years;

"and then I feel happy then to probably leave it, because then I'll have a baseline of what I left on, if I ever want to go back" (Interview, line 973-974).

The concept of discretion was discussed in Chapter two as a characteristic affecting mode of adjustment to a new role. A typical dimension of discretion is the capacity to choose goals (Nicholson, 1984). Jo works between the two roles in order to maximise her choice of occupation, until she is ready to commit to one or the other. Jo recognises that her previous predominant role as a midwife does not offer very conducive working hours, being comprised of shift work, or on call. These constraints motivated her to exercise choice over adjustment outcomes. This issue of will or motive has a directive influence, and affects and contributes to a positive role transition.

Two constructs have been identified that distinguish positive orientation to experience and environment. Nicholson (1984) describes the first of these as the desire for control, which is related to the causal axis of discretion already explained; and secondly, is the desire for feedback. The theoretical proposal is that individual differences in modes of adjustment will depend on how strong a person's desire for control or feedback is at the time of transition. Affective responses to transition are more likely to result in tension if mismatches between ego requirements and role development exist.

In terms of Jo's journey she has yet to commit to crossing the divide in its fullest extent, and perhaps exists in a virtual state of 'social limbo'. This has been previously discussed as a sub passage of a status passage (Holland, 1999). She has, however, in her distinct methodical style, put in place alternative routes to maximise her options. 


\section{Witness to the hero}

The title of Jo's story is significant as a departure point from one stage of self development to the next. The portal of transformation is literally the brink of transformation. A precipitous leap would be as chaotic and counterproductive, as not leaping at all.

Like the awakening, the timing of a new adventure and opportunity for transformation is unpredictable. There is often a sense of disbelief about awakenings, and according to Noble (1994), a feeling that whatever is happening could not possibly be happening. It was as if the issues of shiftwork, ailing health, the changing needs of the family, the workplace scenario, the HPCAA with its prompt to deciding on a path, and the possibility of a new nursing role, would all be mitigated by responding to a call to adventure. They seemed to provide an initiation that acquired and strengthened Jo's inner muscles ready to catapult her from the self that she had been into the self that she was becoming. As she stood at this portal, her family and friends served as allies reinforcing and encouraging her to accept the challenge of awakening, and to leave her old way of living behind.

Jo's values, ethics, and sense of integrity which had not been consulted, rose in rebellion, refusing to allow her to continue on the existing path. One possibility is to view the dragon of her workplace scenario as an ally too. It led her deeper into herself identifying the importance to her that people be treated fairly and honestly. It escorted her to a portal for transformation as she made the decision that she would not remain in the same environment. Her friends, as precursors, had already helped to plant the seeds of concern about her health and well-being and introduced hope and possibility that germinated when time, circumstances, and Jo's own determination and inner strength enabled her to make the leap. In leaping through this portal Jo gives the impression of arriving at the centre of herself. The difference of the hero path is that the hero gives because she chooses to, a heroine gives because she is required to; and therein lays the difference (Noble, 1994).

Noble (1994) discusses how adhering to our own transformational timetable is crucial because, more often than not, whatever we feel we can least afford to part with, is 
precisely that which binds us to an outgrown self. And that part can only be dislodged slowly, gently, and with compassion. To refuse the call would have meant passivity, possible boredom, powerlessness, a sense of being victimised, and resentment. Jo's used the words "invisible and devalued". The situation had become constraining and the call to leadership meant taking responsibility for her life. Jo had provided evidence of a hard-won belief in her ability to manage change, having survived painful life events that assured her of her courage derived from experience, and she provided the willingness to let go of an outmoded sense of self.

Within her own sphere of influence Jo experienced a revitalisation, as she took personal responsibility and responded to the call. Her sense of mental alertness and physical health improved. Embracing identity and character in small private steps, if multiplied by all of us, would transform the world (Cammock, 2003, Kabat-Zinn, 2005, Noble, 1994). The primary boon of the hero's journey then multiplies to become a collective creation for a compelling future. By aligning our future vision with a deeper sense of calling and faith there exists a potent platform for change.

\section{Conclusion}

These comments draw to a close the articulation and illumination of the three participants' narrative accounts. The key message of the last three chapters has been that professional practice takes place amidst uncertainty and constant change within society, and within our practice. Change imposed from the outside can be difficult. In the midst of imposed change we can choose paths that see us immersed in chaos, either being reactive, or being proactive as agents or reframers of change.

Framing reactions to change as a positive force has been facilitated by the creative language of the hero journey. This framework teaches us to persevere with the anxiety, turbulence, and discomfort of the unknown, and to start on a journey with an unknown path and destination. Learning to trust the process will increase our confidence as we seek to be creative in our practice and in our relationships with clients and colleagues in order to bring about change and transformation (Higgs \& Titchen, 2001). The three narratives now bring the symbolic hero's full cycle. What is 
the result of the journey and return? The last task of the hero is to communicate her discoveries and the boon for those who care to listen.

In the next chapter we cross the final threshold and enter Part Three: The master of two worlds. The essence of the return is the new level of awareness that the participants have to share with the community. In examining the experience of professional choice and change I will focus on a synthesis of insights and ideas expressed through the participant's stories and interviews. Having an appreciative response is a different process from that of critical comprehension as a way of knowing. The unitary response to viewing change requires placing choice and change in the context of the life patterning of the practitioners affected by the legislation, rather than seeing it as a problem that needs management. How choice is made becomes the window through which the larger life patterning and wholeness is seen to exist. The exploration and understanding of the way in which this process took place may then be used to inform us about professional decision making in the future. 


\section{Part Three}

The Master of Two Worlds 


\section{The Master of Two Worlds}

The two worlds, the divine and the human, can be pictured only as distinct from each other - different as life and death, as day and night. The hero adventures out of the land we know into darkness; there he accomplishes his adventure, or again is simply lost to us, imprisoned, or in danger; and his return is described as coming back out of that yonder zone. Nevertheless - and here is a great key to the understanding of myth and symbol - the two kingdoms are actually one. The realm of the gods is a forgotten dimension of the world we know.

(Campbell, as cited in Osbon, 1991, p 80). 


\section{Chapter Eight Discovering the Boon}

\section{Introduction}

In Chapter two I posed as an imaginative exploration a set of overlay maps, each transparent, yet with its own unique shape and form. Depending on how they were overlaid, the geography would assume a new perspective. Mapping or graphing a particular status passage such as the nursing/midwifery divide from a macro-cultural perspective i.e. the cultural origins and social institutions of the disciplines, the direction and timing can be considered as the two axes exerting influence over the shape, direction and schedule of the passage. The HPCAA (2003) heralded the prescribed schedule at which time dually registered practitioners were made aware of the change and its imminent choices. A principle property of measuring the shape of this status passage is the distance that the passagees (the individual practitioners) have travelled. The distance travelled was marked by anticipation, entry, exit or 'letting go' of previous roles, and taking on new ones. The storied accounts that were shared charted individual passage across the divide between the professions.

The research, through argument and through the participants' accounts, generates recognition that crossing the divide is not (just) a metaphor, it is a paradigm shift. Crossing the divide is a new paradigm for thinking about the two knowledge spaces of nursing and midwifery, as shifting the paradigm changes the way we think about things. Instead of automatic renewal of a practicing certificate, service delivery now occurs based on proven competency. It is possible now to consider midwifery and nursing as two separate discourse activities. Such an approach from a critical scientific discourse analysis would empty the 'divide' of its metaphorical meaning so that 'real' meaning could emerge. Asking nurses and midwives about the image of activities such as workplace/lifestyle mix however, supported description of people as inside a profession, in a social environment surrounded by personal and social factors that enable or constrain functionality within either given profession. It is this change from seeing the person from outside of the personal-professional space, to seeing the person inside the personal-professional space, an 'inside-out' view that is the important change of viewpoint. From this perspective I asked the participants whether they had any advice for practitioners currently in the dilemma of making this choice. The 
answers they gave were interesting and typified by the following quotes from Susan and Jo. "I think it's actually a very personal choice, and it's not one that you can necessarily make easily. There are a lot of contributing factors. I think I would have straddled both for probably several more years and either decided 'Yes', I really wanted to keep going with midwifery and would have picked it up again, or I would have found a world for myself in nursing and been happy to let midwifery go. So, if other midwives are standing between both, they will have their own personal information on whether they particularly want to be a nurse in the future" (Susan, Interview, line 793-797).

"No, it depends on them. I couldn't make that [decision] for them, I couldn't even advise them. It's very personal” (Jo, Interview, line 932-933).

At the time of gathering the study material from the participants their adaptation to transition status was seen to be related to other situations and conditions inherent in their lives. As a whole the above responses indicate that practitioners recognise the individuality and complexity of the issues involved, and would suggest that the fruition of any path lies in working from these reference points. The process generated by the HPCAA has required a firm point of self reference and the ability to perceive, interpret, and decisively integrate varied possibilities.

For the remainder of this chapter the research reveals the phenomenon of choosing a path following the separation of the professions, viewed through the participants' journeys. It is important to note the story themes that emerged from the synthesis of insights and ideas expressed through written and oral narrative. The main themes were narrative functions of thinking and reasoning in decision making, factors affecting individual and group identity, the juxtaposition of esteem to the dominant discourse, reconciliation of work pattern and life stage/Midlife, and stress and Burnout 


\section{Narrative functions of thinking and reasoning in decision making}

Negotiating the passage of the HPCAA, by telling it from the point of view of three dually registered practitioners, generates a shift in our conscious awareness and expands the perspective from the familiar basis of our own experience. Through language the participants conveyed their relationship to the research question. They each discussed strategies of decision making that included writing lists of pros and cons (written narrative), and talking with family and colleagues that helped to clarify the issues (oral narrative).

Histories first provided a comfortable opening to storytelling by exploring how participants got to this particular place and position; what the environment looked like when they arrived; and how it changed. It showed what was lost, and what was found, or improved. The response from the participants indicated that the act of taking part in the study fulfilled a symbolic need to explore and record this passage. Mary stated: "this has been an interesting exercise to really make me consider my options and look at what is important to me" (Story, line 168-169), and, "I found it quite cathartic in a lot of ways, it was a good exercise to help me find where I was" (Interview, line 1011).

Susan stated: "when you first write it out, you write it out superficially and then you go back and there's just layers and layers of it. It's something that I feel you could write and write about forever" (Interview, line 10-12),

and in Jo's opinion: "I found it really helpful. I was able to reflect back on and try and work out some pathway, and what direction I was heading in life. It just sort of reaffirmed where I came from and what I actually did want to do in life" (Interview, line 14-16).

Mary, Susan, and Jo's responses to the healing feature of narrative expression shifted the focus from analysis of the material to the creative energy of using this method for self reflection and empirical research. Sharing their stories of experience of choosing a path circulated the energy that resonated from the writing and the speaking, and by their admission, influenced their wellbeing. Responding creatively and imaginatively 
was closely tied to reading, listening, and appreciating the expressive structures inherent in the participants' written and oral narrative as they attempted to understand their own experience. This required a process of aesthetic contemplation, or immersion in the material. This reflective process was followed by imagining how the writing or speaking affected the narrator, how it would influence people who read it, and what its ability would be for stimulating further creative expression. An approach that was open to the unexpected or the unique responses that readers of the text might have avoided reducing the images conveyed to that of linear narrative only. Exploration of central themes was facilitated through an additional interview and illuminated areas of the written narrative.

The pattern profile that was shared during the interview was constructed by the researcher from the written narrative using the narrators own language but displaying a more objective account of the written narrative detail. It was confirmed as a fair and accurate summary by each participant before dialogue commenced. Susan reacted in the following manner:

“when I wrote the first one [story], there's all my emotion, and my interpretation of some of the words, and my feelings in the words. Whereas when you read how you've written it, it seems less emotive, or less stressed might be a better way to put it. So when it comes from that third person it doesn't come across as strongly to me and yet it's still the same feeling" (Interview, line 38-43).

Agreement of the fair representation of the story content was the starting point for the conversation to begin. With different wording and diluted emotion, participants recognised the story objects differently. The potential of viewing the same themes as spectators from a distance was that story objects became the concrete issues to be considered, rather than constricting in their subjectivity. This distance became significant to understanding better those things that were limiting or constraining.

Generative words are words laden with meaning and become so ingrained in our lives that we fail to examine them critically. Openness to the refinements of perspective takes shape through the exchange with others. Mary unconsciously used a new version of the old story of Cinderella to illustrate the unlikely alliance between postnatal care 
and abandonment. It allowed access to creative energy that encouraged real engagement with what she wished to convey. Susan's active metaphor of 'rocking the foundations' lent her story of passage the image of seeking to maintain her balance. Contemplation of such spontaneous and generative language engendered a primary and visceral response from me as researcher as I contemplated what this period meant for them. Cognitive and narrative therapies work in similar ways by encouraging creative problem solving. When the controlling mind releases its grip and allows spontaneous expression, fresh structures are formed (McNiff, 2004).

Understanding the perspectives of others cultivates empathy and compassion within an organisational setting by appreciating the different ways that people can perceive the same thing. What we value or dislike in others often says more about who we are than a direct attempt to describe ourselves. Through the language of storytelling Jo's testimony portrayed how feeling unappreciated by ones employer is a source of suffering in the workplace and brought to light a situation that is typically ignored. Practical benefits accrue from establishing empathy with positions contrary to our own. By stepping out of fixed roles and expectations it helps to envision what other people need. This is often easier by reading the narrative accounts of characters than evoking empathy in the workplace or in our daily lives. Symbolic consideration provided a safe anonymity at times and was a powerful way to explore and understand interpersonal situations. Paradoxically it can bring the audience closer to the facts and the atmosphere of the situation than theoretical explanations, as it is easier to identify with a characterisation or a metaphor that aggregates qualities shared by many different people (Campbell, 1968a; Houston, 1987, 1996; McNiff, 2004).

Functions of thinking and reasoning are evident in behavioural responses and are conveyed through language. The study material revealed a variety of behavioural responses from the three participants indicating that individual characteristics and the transitions being experienced mediate situational adjustment. Work role transition theories seek to understand how change and stability interrelate, and how the interaction between individuals and social systems affect either. The predictor variables that existed between the three accounts, and accord with Nicholson's (1984) study of transition, were role requirements, motivational orientation, prior occupational socialisation, and current organisational induction processes. 
Regulatory requirements now mandate role requirements. Professional portfolios must now be compiled and provide evidence of professional competency. This was revealed in the findings as a source of confusion and of calls for a review of Nursing Council procedure concerning dual registration, where it was believed that competencies overlapped.

Motivational orientation was evident in each of the narrative accounts. These ranged from changing family responsibilities and commitments, to work related symptoms of stress and the stated phenomenon of burnout. Symptoms of burnout increase displeasure or pain thereby increasing the negative effects of employment. The option of on call and shift working hours were seen as unattractive facets of future employment. Viewed positively, altering identity or frame of reference is a transition strategy that pursues personal development by changing role requirements to better align with life needs.

Prior socialisations for practitioners bear similarities when the majority of the affected workforce is aged 45-49 years. Midlife, as a rite of passage itself, encourages examination of lifestyle and work mix, and is reflected in the alteration to workforce numbers. Critical stages of the life cycle have been linked by a rite of passage to status passage, and ritualised transition has traditionally assisted passage from one state to another. The indecision, or lack of clarity about future paths occupied a significant portion of time for the participants before full incorporation into a new social status or position occurred. Bradby and Soothill (1993) estimate the average time for effecting a status transition as six-ten months. This period of social limbo is important to the task of departure, or 'letting go'. Susan discovered how incorporating change involved a personal sense of loss, or divestiture, and was directly anticipated and experienced as past identity.

The current organisational induction process for Mary was unchanged but anticipated, and Susan and Jo were experiencing the passage to a new social status. There was little or no preparation of what this passage would entail and contributed to feelings of anxiety and insecurity. Paradoxically, the anxiety is also likely to be higher when the knowledge base is greater (Bradby \& Soothill, 1993). 
Nicholson's (1984) model discusses four possible modes of adjustment: replication, absorption, determination, and exploration. Rather than being categorical they are viewed as dimensional forms of development that incorporate affective reactions that are positive, negative, or from a midpoint that is affective neutrality. At the time of the data collection, the predominant characteristic of role learning in Susan's account of her new social status fits the description of absorption. Without modifying the parameters of the new role, the burden of adjustment was almost exclusively her own. Her energies at the time of her account were devoted to the task of assimilating new skills, social behaviours, and frames of reference to meet the requirements of the new situation. Positive sentiments of the absorption mode are associated with satisfaction from learning and the enlargement of personal capacities. Negative counterparts might incur feelings of skill degeneration, and disconfirmation of valued self images (Nicholson, 1984). This partly resembles Jo's transition, although her description of a relatively easy passage at the time, and her opinion that there was little differentiation between her prior and existing role steers her adjustment outcome toward replication. Few adjustments to identity or behaviour are required to fit the new role. Positive feelings in the mode of replication are associated with preservation and stability, and valued skills and experiences are maintained throughout the transition. Associations of restriction, helplessness, or of being stuck 'in a rut' without any scope for change, would determine negative feelings from replication (Nicholson, 1984).

Mary, in her desire to capitalise on her previous experience seeks a similar role with different parameters, and fits the cell defined as exploration. She currently experiences the negative counterparts of exploration, which are confusion and anxiety. These are experienced by the person who has lost her internal and external bearings that then gives way to turmoil of experience and behaviour. The positive experience of the exploration mode that she has to look forward to, are the pleasures of sensing her growth through cycles of thoughtful experimentation, feedback, and change (Nicholson, 1984).

The outcome dimensions that I have suggested here can be expected to shift from one adjustment mode to another over time and in response to greater personal development. No category is necessarily more desirous than another as transition is, above all else, responsive to individual circumstance and a process through time. 
Changes in interpersonal influences and trust between the individual and significant others at work is likely to influence whether stabilisation occurs, or role development increases. Susan echoes this rationale in her written story: "While my skills are no longer applied to midwifery they are relevant in my current work settings. As I establish myself I gain the credibility that makes my job easier and more enjoyable as colleagues and clients trust my practice” (Story, line 101-104).

Mismatches, according to Nicholson (1984), between the kind of adjustment demanded by the situation and by the person, may become the catalyst for lasting change. In such a case there are four possible scenarios; the resulting mismatch could represent the first step toward personality change if the shift becomes established through long term practice and adaptation. Alternatively, a person may radically alter the role requirements, or exit for a better fit elsewhere; or, a person may remain fixed in a person-role mismatch and endure negative psychological consequences. Exit, within the framework of the theory, can be seen as a kind of determination, and was the path taken by two of the participants. This provides a practical example of the categorical shift in modes of adjustment to career choice and change, whether or not the source was internal or external. It is also possible that in response to time and changing circumstances, the participants have moved again from the stance that they occupied at the time that the research data was collected. This lends weight to a follow up investigation of the participants' career course over an extended period of time.

\section{Factors affecting individual and group identity}

One of the elements of status passage previously discussed is the phenomenon of 'letting go' of the old role to become integrated into the new. A real possibility is that the fear and insecurity of this position of letting go of previous aspects of identity can have us tenaciously clinging to fixed perspectives making it impossible to entertain the view of others. The resultant loss of equilibrium evident in the participants' accounts following the introduction of the new regulation was seen to provide the tension and conflict that were necessary for renewal. Transforming tensions into affirmations of life is the basis of making whole, and is in sync with the larger movements of nature, characteristic of the integral approach of Unitary Science. In 
keeping with the self regulating functions of natural systems, we too go through experiences of disintegration in order to refashion ourselves. The same realisation applies to the process of work role transition, with its sub-passages of divestiture and 'letting go'. These phases are part of the process toward achieving renewal. This realisation of greater purpose reinterprets the energy of chaos or confusion.

All of the narratives emphasised elements of literacy, power, and identity. The personal and emotional were seen as critical elements of the analytical through examining narrative. Although our power may feel limited whilst traversing this passage, there still exists real power to define ourselves in the face of social forces whose definitions of us seem absolute. Mary, Susan, and Jo did so by active participation in this inquiry. The dissonance between the different voices and tones were highlighted in Chapters Five, Six and Seven as analysing private activities in the public forum.

Susan provided a provocative account of the process of role socialisation that caused me to consider how our identities depend on our relationships to individuals and groups and to understand how emotionally complicated that analysis is. She identified in her narrative that she functioned more 'tactfully' in her role as a nurse. Her words were "I see people doing things that I would snap about as a midwife, but I'm not in a position to do so. I've learned how to deal with things more tactfully" (Interview, line 731-733). As a process of role socialisation we see Susan internalising the behavioural expectations associated with her new given role, as well as learning the patterned resolution that minimised and managed unavoidable role conflict. It caused me to wonder whether she was learning more about her previous role as a midwife through an exploration of nursing. It exemplified a practitioner geared toward autonomy, accountability, and self regulation, constrained by a bureaucratic form of controlling work. Whilst experiencing transition through status passage, Susan's shift in identity was seen as relational and accountable, at least in part, to the historical dynamics of power. Relational understanding of identity is not only how we see ourselves in relation to others (especially those who have more power), but also how others see us in relation to themselves (Barnett, 2006). This added layers and complexity to her account. 
According to Ellemers et al (2002) the term social identity refers to the nature of content of a particular identity, and commitment indicates the strength of people's ties with that particular group. The first line of Mary's written narrative states "I have been a midwife for seventeen years. I'd describe myself as a midwife, not that it is my job" (Story, line 1-2). These words confer her sense of social identity and her attitude toward midwifery's political positioning, and is compliant with the level of commitment to what she perceives is the dominant social group.

When commitment to group identity is increased Ellemers et al (2002) contend that social perception now acquires a self relevance at the group level. In relation to group membership, uncertainty may provide people with motivation to define the situation and their relation to it, in a display of group affirming responses. Empirical work confirms that people were more inclined to identify as group members when group status was unstable, promoting inter-group competition and social change. Namely, the permeability of group boundaries tended to promote social change between groups. This led to an individual level of self-definition, as opposed to the group determining characteristics, norms, or outcomes that influence perceptual, affective, and behavioural responses of individual group members (Ellemers, 1993). Thus, it is the social context, rather than the specific group features, that determine the evaluative flavour of a given group's membership. The context provides the feedback about ones social position in the group, and the social position of the group in relation to other groups.

Mary displayed a sense of group or collective self and agreed with midwifery's political position, and yet, circumstances still prepared her to consider alternative employment options. In thinking about the development of a group or collective self I was drawn to consider the attitudinal and structural features that distinguish a profession. The attitudinal or behavioural component conditions how individuals think and act toward their profession. Literature suggests that belonging to a professional organisation, reading its journals, and attending meetings, workshops, and conferences develops a level of professional consciousness and socialisation (Hampton \& Hampton, 2000). Susan stated that she experienced a greater sense of isolation once she withdrew membership from the NZCOM. As a form of professional consciousness 
then, belonging to the professional body as a part of the socialisation process would serve to enhance the meaningfulness of a collective sense of self.

Reassessment of professionalism in nursing was conducted in response to serious nursing shortages. A series of statistical analyses revealed that professionalism was related significantly to years of experience as a registered nurse, membership in organisations, service as an officer in the organisation, and specialty certification (Wynd, 2003). These findings indicated that organisational culture predicted a greater level of professionalism than personal attributes. These are important considerations for professional leaders promoting group agency as many experienced practitioners leave the field. In a symbiotic form of relationship, nurses and midwives who join professional organisations begin to perceive themselves as more professional, and the organisations begin to grow based on the support of their members. Positive aspects of nursing and midwifery professionalism must be recognised and implemented to retain experienced practitioners in the professions and attract people to the professions as a viable career choice.

\section{The juxtaposition of esteem to the dominant discourse}

Social identity in different group contexts has implications for the individual and the collective sense of self. In terms of motivational implications, such as autonomy or self determination, group status as a midwife generated comments of superiority from all of the participants. It is included in Mary's concern about a work role transition from status as an LMC, to midwife employee or to nursing, and contributes to understanding Susan and Jo's reluctance to renounce midwifery with its higher discretionary group status. The possibility of exclusion from the group can act as a source of threat too, and legitimises Susan's desire for acknowledgement or validation from the collective group.

Discourses may remain largely undisputed because we come to take them for granted as the 'truth' over time. Power and knowledge then become connected to the idea of truth and this further informs the discourse. According to Higgs and Titchen (2001) in everyday social practice this truth, power, and knowledge produces our identities and 
roles. It is fair to say that practitioners progressed through nursing to midwifery, and so this might have led an individual to feel that they had transcended the previous level.

Troublesome duality is a category that has been derived from anthropological literature and applied to discussion about the role ambiguity, and dual role status experienced by nurse teachers. Nurse teacher respondents confirmed that whilst not initially a problem, after a period of time commitment to the clinical role component diminished. The rhetoric of practice as dual practitioner does not always match the reality (MacNeil, 1997). It seems reasonable to compare the same concept to the dual status of being a nurse and a midwife, if practiced concurrently. This constant shift, or blurring of focus, provides a possible rationale for why some opinions would regard shifting from one role to another as unfavourable. As practitioners move from one regime of truth to a different context, then adherence to the previous dominant regime may challenge their new work status. Critical reflection on the permeability of boundaries related to practice experience, may then construe truth as becoming more permeable too.

What was interesting was that the participants only became consciously aware of this perspective once a competing discourse became a possible new reality. This raises an interesting set of questions. Do these attitudes permeate language systems and social practices shaping our current healthcare environment, and how does this position the power dynamics between the two professions? What are the effects of such patterns of thinking and behaviour, on individuals, personally and professionally? What are the effects of this pattern of thinking and behaviour on the perceptions, or status as a group, within the interprofessional team? And, do we comply with social practice consciously, or unconsciously?

Co-creating the culture of nursing and midwifery has meant adhering to tribal values and beliefs. Myss (1996) presents tribal power as an archetype that describes group identity, group force, group willpower, and group belief patterns. Analysis of the data would suggest that negotiating the passage of choice and change following the HPCAA (2003) has meant that practitioners sought personal truth versus tribal truth. Reflection on personal belief patterns and ways of being required a conscious 
understanding of personal power and how to use it. It is a great deal more than change; it is a matter and a process of becoming. Our attention to one profession may have been intense for a period of time, but can change in response to changing rhythms and responsibilities.

Reflective thinking about the cultural and social layers that influence the relationship between the professions will contribute to a richer interpersonal understanding, and foster collegial relationships. Practitioners who shift their allegiance at this time have the opportunity to examine the power dynamics of belonging to one or both professions, and investigate the different strengths of the two disciplines. By subscribing to an empowerment model, nurses and midwives legitimise the belief that both parties are equal partners and share the responsibility of supporting and strengthening individual and community functioning in different contexts.

\section{Reconciliation of work pattern and life stage/Midlife}

We can respond to challenges from the outside, or we can respond to the challenges that come from within; often this emerges as an interaction of the two. My hunch on entry into this research was that the context of the HPCAA might portray professional choice and change as being externally derived, but it would appear from the data that practitioners were inwardly constructing their past-present-and future place in the world. Through autobiographical reconstruction of their life experience, and its meaning for them, they explored their past and present, for possibilities for the future. Although diversely situated there were similarities in the process and timing of the plotlines in their stories. They situated the HPCAA as new knowledge in their present experience and continued to construct meaning as the research proceeded. Reconstruction included participants as a nurse, and a midwife, and as a person in daily life in a social context. Each professional knowledge landscape and sense of identity constituted an intersection of biographies and histories and was the product of how each story was constructed and reflected upon.

Uncertain ground creates an image of a shifting focus, and whilst this is characteristic of the external legislation and its consequences, it was indicative of the internal 
landscape of practitioners too, as mothers thinking about the consequences of choice on their families and their professional identity. In Jo's story, liminal space was the place to hold paradox and uncertainty. Rather than choosing one side over the other, it was how to hold both while considering possible actions and their consequences in the context of her relationships.

The participants were poised upon another threshold or rite of passage too, in addition to the professional one. The physiological reality of midlife constituted a common element of each journey, and age statistics confirm that it currently affects the majority of the nursing and midwifery workforce. It is comprised of its own set of life characteristics and tasks. The first half of life involves completing the task of building a solid sense of identity. Being positioned in the middle of life allows us to look back and evaluate what has been accomplished, and to look ahead to determine what comes next, or remains to be done. Batten (2000) suggests that there is something about midlife that invites us toward deeper layers of being, more into our essence.

Susan related the experience of writing her story as being, at first superficial, then multi-layered "You go back and there's just layers and layers of it. It's something that I feel I could write, and write about, forever" (Interview, line 10-12). Like an onion, peeling back the layers can bring a stinging tear to the eye. Any experienced practitioner will have layers and layers of experience that hint at submerged stories. Incremental change thus accrues a gradual building up of experience and confidence. Whether it was the space offered by the HPCAA, or whether it was the drumbeat of midlife, old patterns that were no longer suitable were being reassessed. Batten (2000) believes that midlife calls us to our soul work. She describes this as being beckoned or lured which are adjectives used by Campbell to describe the Call to Adventure.

Gauthier (2003) explored transformative change at midlife, including the rebalancing of masculine and feminine qualities within the psyche and described a process marked by withdrawal from the world, a death of the identity the individual has known, and rebirth and return to the world. Using an organic research methodology, Gauthier interviewed ten men and eight women between the ages of 42-63, to obtain their experience of midlife change. The study determined that all participants made a descent, and many made multiple descents in the service of healthy ego development 
and expanded self awareness, as a result of meeting aspects of the shadow i.e. the darker, less conscious elements of the psyche (Gauthier, 2003).

Polarities of masculine and feminine qualities, according to Schaefer (1986), are not only the exclusive attributes of men and women respectively, but are archetypal forces or principles that exist in men and women. It is possible for principles such as individualisation, analysis, and objectivity to go overboard, becoming extreme and decadent, and so we become surrounded by selfishness, exploitation, and anonymity (Schaefer, 1986). Must the forces of masculine and feminine merely surge through us, or can we learn to use these different qualities with growing consciousness and responsibility?

Midlife, as a rite of passage similar to puberty, sees a dawning of a new capacity of thinking, and a whole new self consciousness and movement toward independence. Dr. Rudolph Steiner (1861-1925), the Austrian philosopher, scientist, and founder of Anthroposophy and of Waldorf education, saw that bringing the forces of feminine and masculine into harmony, as an essential aspect on developing human consciousness (Schaefer, 1986). Any alchemical process relies on an awareness of the need to work with these polarities if a truly creative process is to occur.

Susan, and Jo exposed a generally unseen balancing thread, a positive feminine force of caring for the needs of their families as a priority for consideration in the decision making leading up to choosing a path. Mary described how her role as a LMC “actually balances quite well, because most of my job I can do between nine and three. It does work quite well and that's a bit of a dilemma because if I become an employee, I will have to work the hours that they tell me to work. But when I get home at night that will be it. Whereas, at the moment I have a lot of paperwork, a lot of phone calls that I still need to make from home, a lot of stuff for the review, and I can get called out at a moments notice" (Interview, line 545-550). Susan and Jo's children were verbalising their desire that their mothers be home at nights and in the weekend. These are relational aspects which include the age of the children and their own adaptation to parental work role demands. These narrative examples illustrate how individuals respond creatively and reconcile work pattern with life stage. Susan desired working conditions that would allow her the opportunity to "appreciate her children while she 
still had them" (Story, line 76). Jo stated that "it makes you realise what's most important in life, rather than getting to the end of life and look back and think, well actually I should have spent more time with my family" (Interview, line 241-243). These comments express the inner battle we all experience between our detached, observing, masculine side, which wants clear cut answers, and that more elusive, evolving, feminine side which seeks to trust in the unknown, and gently receive what it barely begins to intuit (Schaefer, 1986).

The participants were trying to balance their feelings and needs of being true to themselves and their families, against the struggle to overcome the fear of rejection or perceived ridicule. This perception was attributed to deviating from the accepted norms of the dominant group status. And so, we come again to the need to renew the feminine as a balancing force in individuals and in society.

In the process of re-evaluating Mary explored other options that were "one step removed" (Interview, line 360) from being an LMC; and Jo realised that to remain in her then current employment would not offer an opportunity to work Monday-Friday, so she would have to seek this opportunity elsewhere. Susan anticipated travelling overseas for work in the future and stated; "I have concerns about my range of employment options if I am not a registered nurse. To have to choose whether I am nurse or a midwife is not fair when I clearly identify with both. It is like asking whether I am a woman and a human. They are not mutually exclusive" (Story, line 6972). All of the participants demonstrated a sense of loss no matter what choice they made but were motivated to seek redress. They brought their focus from the outside to the inside as they storied their experience of seeking to achieve a balance of work and family with personal interests and health needs. The extra push of the HPCAA (2003) may have precipitated movement in participants' lives; however there were already signs of an impending shift. Statements reveal a chasm between public and private life, such that the political order was seen as detached from the values, needs, and realities of individual life. In reading these we recognise aspects of being and self that is relational. Decisions are influenced by, and affect significant others, family members, friends, and acquaintances. Actions based on, or motivated by these experiences, have political and social consequence and affect society at large. 
Each story was responsive to the context in its own unique fashion. As though in response to an internal compass, each individual was brought to that path that was most in harmony with their personal and family needs. For some of the participants the trajectory of their path was affected by the greater need of/for relationship, whereby they were prepared to exchange or amend their sense of identity for the greater good of the many. This acknowledged response was seen by all of the participants as synchronous with the changing legislation, not necessarily as a result of it. This transition meant a creative reorientation of their world views, sense of self and life purpose and offered potential for a new hero journey.

\section{Stress and Burnout}

The reported frequency of work place stress became an abiding theme/pattern. With our cell phones and wireless palm devices, we are now able to be so connected that we can be in touch with anyone and everyone at any time. In the process, we run the risk of never being in touch with ourselves. As participants recovered their experience in light of the social context, and re-evaluated meaning from their current life positioning, they each relayed physical and emotional symptoms indicative of burnout. These symptoms were signposts on their internal road map that signified to them that the time was ripe for change. Mary reflected; "I don't want to be a midwife unless I can be compassionate, and I think you start to lose that. You have to lose that a little bit, you can't love and hurt for every woman" (Interview, line 361-363), and “when you start to think, oh God, I can't be bothered, you know, I know that its time to think hmmm, maybe its time for a change" (Interview, line 366-367). "I Think that's when you need to leave in some ways, when you are still feeling satisfied, before you feel completely empty, when you've still got something to give to the women you are caring for, when you start to notice, oh ow, I'm not quite as keen on this as I used to be. For me, I don't want to get to the point where it's just a job, where I'm just going through the motions" (Interview, line 393-401).

Kabat-Zinn (2005) discovered from listening to why clients attended a stress reduction clinic, that in the end, there was really just one reason, to be whole again, to recapture a spark they once felt they had, or felt they never had but always wanted. 
The effects of a mindfulness based stress reduction programme on nurse stress and burnout were studied and presented in a three part series of studies. Analyses of the data revealed benefits including significant reductions in emotional exhaustion and depersonalisation, and a trend toward significance in their improvement in sense of personal accomplishment (Cohen-Katz et al, 2004; Cohen-Katz et al, 2005a, 2005b).

This raises some questions. Could this be an area of professional practice that we need to think about? How can we develop positive ways to sit with uncertainty? Perhaps future practitioners could be provided with a tool for balancing practice and developing a sense of attention and awareness to the whole domain of professional practice that involves the personal demands of on call and shift work.

Both Susan and Jo recounted workplace scenarios that resulted in a sense of wrongdoing that left them feeling disillusioned. Hocschild's (1983) work on the managed heart shows us that emotions can be symbols that signal how to manage and express ourselves in social interaction. Our ability to manage them are dependent on our expectations of others and the expectations of others toward us. The analysis was extended further to introduce the idea of control or management of emotion by others resulting in tension between what the employee actually feels and what the employee is to portray to the public. As workforce resources, and/or staffing levels become constrained, disillusionment and burnout may result from competing demands.

Susan indicated the difficulty in calling for support "Given midwifery is a woman centred profession it seems to care little about the women that provide the service and their needs. Midwives are poorly paid considering the demands of the job and the responsibility taken. It is not family friendly when mothers miss birthday parties and are interrupted in their family life to take phone calls from clients. There is a limited support network, as all midwives are busy mothers, and to impose on their time is to impact on their family also" (Story, line 80-86).

Similarly Mary feels that"some of the changes seem to have heaped a lot more work onto midwives, many who are already feeling overwhelmed by our lot. We work in a rather 'greedy' occupation, where our own needs or our family's needs can be superseded by another woman's needs" (Story, line 116-119). 
These words convey the consequences of the intensive emotional labour of providing continuous care. Sharing these practice stories is about sharing practice wisdom. Patterns of practice and strategies that alleviate or reduce stress will benefit colleagues and contribute to the longevity of the workforce. It is time for practitioners affected by on call demands to debate how they make choices concerning competing demands between home and work. As the resources for maternity care have become more constrained, both personally and institutionally, an adaptation of professional outlook has become necessary.

There are different ways of segmenting home and working life. Working in a partnership model means that some practitioners involve an element of integration of work and home. Alternatively, there are those that choose to be employed and work pre-determined hours. They wear a work uniform, have many friends not associated with the work environment, and are involved in other regular non-work activities. These are practitioners who segment aspects of home and work. Managing the physical and emotional demands safely is, according to McLardy (2002), vital if midwifery and nursing are to retain its workforce, otherwise, as these study examples indicate, practitioners are likely to opt out of the workforce at best briefly, at worst permanently.

\section{Conclusion}

The findings confirm that role theory does not provide a rigid or static view of social behaviour. Role socialisation is seen as a dynamic perspective as individuals forged behavioural patterns or adaptations in response to personal life circumstances, and in accordance with patterned and predictable methods of decision making. The level of intensity of the strain produced by role transition will vary from person to person depending on the presence or absence of certain moderating factors, including attributional styles, social support systems, and centrality of role to self.

The aim of contemplating stories has been to gain alternative understandings that will positively influence similar situations in the future, either our own transitions or those 
of our colleagues. Collective wisdom was made apparent, when what appeared unspeakable or ineffable moments for one participant, was often amazingly conveyed in the words or metaphors issued by another participant. Reflecting on the process of sorting and contemplating the data, I had some comprehension of the underground, 'rhizomatic' experience of thought happening in the writing. St.Pierre (2005) discusses writing as a method of inquiry, and the possibility of accidental and fortuitous connections being made through the process of writing. This happened for the participants through the process of this inquiry and for me as the researcher. Key personal reflections and implications that unfold from the data will be included in Chapter Nine as a new mythology for the future is considered. 


\section{Chapter Nine Back to the Future: Toward a New Mythology}

\section{Introduction}

This research project has been part of a significant journey for me and the end point of an academic qualification. As stated in Chapter one the motivating factor for the initial research question derived from my own experience of traversing the shifting terrain following the introduction of the HPCAA (2003). After many years of identifying with midwifery I made a decision to re-enter nursing. This significant decision caused me to wonder whether other dually registered practitioners regarded this period similarly.

This study brings to attention the internal process of transition that accompanies the passage constituted by the divide. The data suggests that this process of transition is more prolonged than objective statistics would indicate. Mary, Susan, and Jo participated in the culture of nursing and midwifery by sharing their narratives as cultural stories, making narrative sociologically significant. The three narrative examples confirm the continually changing nature of identity and demonstrate that, as passagees, we are in constant movement over time. Although narrative, as storytelling, is relevant only for the period of time that it is written, it nevertheless provides a snapshot of what constitutes professional decision making. This snapshot indicates some of the factors that influence how people develop a 'cognitive map' of the environment which enables them to find their way to a specific location. What became apparent was that the environment was not just a physical structure, but a space that individuals conceived of through their activities and practice. Consideration was then given to the social construction and ideological impact of individual cognitive geographies. It is these differences which are ignored by the objectivist tradition of analysing what is the nursing/midwifery divide.

\section{The journey is a map}

The two activities of theoretical and methodological processes were designed to support and serve a joint purpose i.e. to make known the experiences of practitioners affected by the historical legislation of the HPCAA (2003). The career transition literature seemed to focus on role transition as boundary crossing, a role shift, or a 
status transformation. Myth is compatible with boundary crossing, and so the metaphorical concept of navigation with notions of the hero journey was applied to the question of how human beings have interacted with the experienced world and effected discovery, exchange, organisation, and transformation. This perceptual level provides a view port onto the underling structure that connects an individual's story to the broader story of a marginalised group. Perhaps most importantly, though, the journey is the pattern that we follow in our lives as we face challenges, opening us to knowledge and understanding.

A shared understanding of space constituted the context of the 'divide', and needed to be communicated, negotiated, and understood, as practitioners decided what their place would be. As the data would suggest, people produce or construct their places at different times and there was a flow on effect from one place to another. This led to thinking about the various ways that people navigate through places or situations in the course of this investigation. Clearly navigation styles were unique, but they tended to resemble previous distinctive patterns individuals had for negotiating other life events. There are different conceptions of landmarks depending on previous experiences, age, gender, and/or social group; and for some the navigation is more of a conscious activity. It seems that navigation can be relatively unconscious too.

The knowledge that we accrue at the end of our journey will have been filtered through the background, culture, and preferences of each traveller. This resultant knowledge is one of the pleasures of either undertaking a journey ourselves, or following the journeys of others. So, to appreciate the depiction of journeys given, we need to appreciate the individual qualities that lent it subjectivity. Sooner or later the hero was presented with a challenge, or adventure to undertake. The call to adventure established the stakes of the game, or the competencies to be met, and made the hero's goals clear.

Anxiety or fear makes for a reluctant hero and this has to do with confronting unknown territory. The call may be refused unless the encouragement of a mentor enables the hero past the turning point of fear. As a common theme in most stories, and of rich symbolic value, the function of a mentor prepares the hero to face the unknown. These were shown liberally throughout the participant's stories, and were 
seen to fulfil the function of threshold guides. However, the mentor can only go so far with the hero as eventually they must face the unknown alone. By agreeing to face the consequences of dealing with the challenge, or the choices which must be made, the hero finally commits to the adventure and crosses the first threshold. Once across this threshold, the hero naturally encounters new challenges and tests and begins to learn what it is to experience transition, and learn the rules of having a new status.

The final reward, in most cases, is the knowledge and experiences that leads to greater understanding and reconciliation with hostile forces, (or decisions one would prefer not to have to make).

\section{Reflections on the research process}

The period of reflection prior to engaging a final choice of professional direction involved remapping my professional career to date, to consider what my personal goals were for the future. I was not aware of a process or a formula to my decision making at the time. Reading the literature on knowing participation in change triggered an interest in how participants would respond to questions about their own personal strategies for making choices. Even when we desire change there is a powerful comfort in the way things have been.

To consciously uncover our patterns could be an important step toward self awareness, as individuals, and as professions. I believe that participants did discover personal pattern through dialogue and narrative exchange. They each expressed satisfaction with the process of reflecting upon and writing their story. This increased sense of organisation in authoring experience lends weight to the use of storytelling as an opportunity to share our practice wisdom, and there is a large literature support for storytelling as therapeutic. In addition it generated rich data, illuminating the question that was being explored. Generalisation was not the aim of the work, considering the size of the study, and claims must be made with care, as there were only three participants. I believe, however, that the design was responsive to the inquiry, and it opens doors for conversations to take place. 
As the researcher there were many obstacles to grapple with, practical, personal, political, and ethical. At a practice level the choice of a narrative research design needed to be congruent with the reality of the setting, and as a research instrument it needed to be culturally sensitive and suit the participants engaged in busy lives. At a personal level, as a researcher, I held other roles such as colleague, or acquaintance, which interacted with my role as researcher. This made it hard to present findings which might potentially identify participants or comments that were critical of professional practice. Material that was revealed that did not apply to the specific research question, was thus omitted. I found myself identifying with some participants experiences, and it was important to work through these reactions so as to identify with the participants' perceptions. The issue of subjectivity in research was discussed in Chapter four and outlines the measures undertaken to minimise this.

At a political level there were initially issues of discomfort in positioning this study at the hyphen. There was a certain tension in the process that findings might reflect poorly on a service that is close to my heart. In one way the application of the hero journey became a vehicle that facilitated activity as a witness, thereby reducing a sense of discomfort somewhat. With this knowledge I sought to ensure that this framing did not obstruct new knowledge or information. I was unsure how Campbell's (1968) ideas would be accepted, however, I found many references to the hero journey as a central metaphor in mainstream literature such as leadership, education, and management.

At an ethical level are the issues of informed consent. The personal revelations, through storytelling potentially increase the vulnerability of participants who may fear that comments will reveal previous relationships, or working environments on whom they may be dependent upon, or who may exercise power over them in the future. They may also have been deemed vulnerable in relation to their capacity to make an informed decision at a time of crisis. On the other hand, it may be perceived as less intrusive to respond to questions by someone they know and trust.

I have become convinced of attending to the calls and invitations that life presents, at the same time as acknowledging the attachment to old patterns and the emotions accompanying change in life direction. The participants held the tension of uncertainty 
until the connections became clearer and their choices more apparent. What surprised me was that the HPCAA was not the main motivator for consideration of change in work role environments. In response to an internal call the participants were each considering reconstructing identities, removing any notion of a fixed identity or correct knowledge. Because our social environment is always changing and open to interpretation, the data highlighted for me how our internal construction of identity is dynamic and ongoing, and connected to the social landscape. Our actions are shaped in congruence with what we consider to be the greater moral choice in the given context. And this context changes in response to the web of relationships in which we exist.

The opposing forces which influenced my research activities were my knowledge and past experience of identifying and working as a midwife, with my current experience of working as a nurse, and yet still partly identifying as a midwife. This led me to consider the value of accommodating contradictory perspectives in the analysis and interpretation of qualitative data. My own behaviour and motivation reflects the stance that I have taken with regard to the research community in which I wish my voice to be heard.

Presenting the stories on two levels undoes the habit toward the decidability of truth, the inevitability of progress, the triumph of reason, the objectivity of science, the forward march of history, and the existence of the singular autonomous self. These foundational principles are to do with making the world knowable and predictable, and are not compatible with post-modern research inclined toward a new ethic of inquiry (Atkinson, 2000; Denzin \& Lincoln, 1994). The inquiry approach that I chose to adopt fits with the post-modern turn toward acceptance of uncertainty and ambiguity, and reconstructs our concept of validity by seeking 'new imaginations'. According to Atkinson (2000) this takes us beyond established ways of seeing, interpreting and justifying a research activity. Searching my own personal investment in the ideas that arose, and considering its effects on the conclusions reached, I revealed a level of interpretation that acknowledged the legitimacy of both of the disciplines. I realise at the same time how each discourse shapes the production of a perceived interpretation. 
As discussed in Chapter four by conducting an external inquiry into the experiences of dually registered practitioners negotiating a path, what Chomsky (1986) and McNiff (1993) describe as an 'E-inquiry' (externalised inquiry focussing on others), a different dimension of reflective consciousness emerged for me as the researcher. Atkinson (2000) explains the phenomenon of an 'E-inquiry' transferring in the process to an 'I-inquiry' (internalised inquiry focussing on the self). As I read and listened to the participants' accounts, the so called fixed objective reality generated an examination of my own personal construction of reality. My own history determined, perhaps, my own behaviour and motivation toward creating a viewpoint that acknowledged and respected the loss of identity involved in the transition process from one valued discipline to another. By acknowledging the centrality of my personal history to the interpretive approach taken in the study, I am aware that other standpoints may re-interpret my interpretations. Thus, by understanding Atkinson's explanation, the example of the transition from an 'E-inquiry' to an 'I-inquiry' involves the acknowledgement of two factors; first, that my interpretation of any situation is founded on my pre-understanding and is essentially subjective; and second, that each interpretation is provisional, and liable to change in the light of new subjectivities. Understanding self in context in this way recognises the contradictions that will abound in any investigation of this period of nursing and midwifery history, and the premise on which we base our assumptions about truth. This, however, is the principle unique to post-modern thinking; its willingness to embrace 'conflict' without resolution.

If we hold to the belief of tacit knowledge as knowing more than we can tell, then the therapeutic use of narrative by practitioners externalises and makes that tacit knowledge explicit. This tacit level has been demonstrated to have deeper roots, and a longer history. The relative tension between these two forms of knowledge prompts a closer investigation for practitioners involved in such an activity. If we were to apply this same principle of 'harmony in contradiction' to the now separate discourses of nursing and midwifery, by acknowledging the dialectic between the tacit and explicit, we might see how historical energy between the two professions sets up a two-way communication that informs, rather than transforms, each practice discourse. This type of communication has been seen as a necessary dialectical process in the growth of educational knowledge and involves a continuous sequence of question and answer. 
This process allows the possibility for a solution or explanation of an issue that in turn may give rise to a new issue for consideration. Thus, each discourse maintains its original principles without a loss of integrity, but is subject to adjustment and modification in an ongoing exploration of knowledge, and its growth. This has particular relevance when considering the 'superiority' of one group status over another, as revealed by the data. This revelation was made in response to the experience of incorporating conflict and confusion into the decision making process. To treat such revelations with corresponding integrity, we might consider how nursing and midwifery knowledge progresses now, following the historical introduction of the HPCAA (2003).

The example of tacit and explicit knowledge is compatible with an Archetypal Model of Inquiry that acknowledges the communication between the conscious and the unconscious. As participants sought to harmonise the contradictions that existed for them, a balanced tension that arose prompted the search for a new balance state, which in itself sets up a new and productive set of tensions. The view of a static nature of knowledge then becomes the myth, as what is seen to become the new balanced state contains within itself the potential for a new tension, continuing an evolutionary process.

The interchange between the conscious and the unconscious links back to the construction in Chapter one of two research spaces; one at ground level, or above, that describes the political manifestations of the HPCAA (2003); and a second space below ground that links the reverberations of social change on people's personal and individual lives. The use of narrative allowed a deeper understanding of the relationship between tacit and explicit knowledge, and enriched the interpretation of making a work role transition between the two professions. This is as true of the researcher, as it is of the researched, and thus my investigation of my own complexities and contradictions became a vehicle both for my research, and for my personal development. The ensuing constructed nature of reality and revealed data lent weight to the concept that the map is not the territory.

I believe that the participants' accounts opened up a critical space for discussion and exploration of our own understanding and analysis of the discourses to which we 
adhere. This process serves to allay the myth about what is truth, and generates possibilities, or routes for the future that are closed off by epistemologies of certainty (Atkinson, 2000; Stronach \& MacLure, 1997). These are processes that will inform and reform practice for at least as long as there are still dually registered practitioners crossing divides.

\section{Back to the future: Significant findings}

The theoretical framework adopted for use in this investigation can also serve as a lens for viewing self. The theory base furnishing the foundational discourse of the Science of Unitary Beings sees us continuing to evolve toward greater diversity within the context of our current environment. Feminist writers have identified the radical change of world viewpoint undertaken around the seventeenth century when a patriarchal, fragmented worldview replaced an appreciation and understanding of the natural order. Countless midwives were tried and tortured during an era when female consciousness or its characteristics were treated with suspicion. In a new era it will not be the fires of annihilation that count, but fires of transformation. Living in harmony with this natural order, as a goal of science, saw an integration of the unconscious, the subjective, and the emotional within the structural, rational, and intellectual.

Feminism returned awareness to the essential connectedness of all life and the embeddedness of existence in the cyclical process in nature, balancing the masculine/feminine polarities. Paradigms that unite human and environment link female experiential knowledge with spirituality, and the emerging ecological paradigm. Political change from a predetermined and mechanistic universe that sees individuals as helpless cogs returns to a unified flowing universe that sees us as coparticipants and co-creators. This recognises and respects participants as powerful actors with the capacity to shape and alter the course of future experiences. This may at times involve exploring the unfamiliar and uncomfortable landscapes at the edge, which constituted the context for this study. The experience of discomfort, however, served as a point of entry into a deeper inquiry. 
A hermeneutic phenomenological approach expands our understanding of experience as lived along this uncomfortable landscape. The data in this study highlights how practitioners are involved in an ongoing, relational process of valuation and meaning making, incorporating the tension between the interpersonal and the intrapersonal. As they sought to be true to themselves and the people around them, their intentions were toward wholeness and orderliness, improved health, and harmonious family relationships. Although the three participants represented three possible practice scenarios, the larger circumstances of people's lives demonstrate the similarities rather then the differences. At a practical level culture was seen to encompass the web of relationships that individuals exist in, which are continually dynamic and changing. The female hero path requires that a woman be her best compass, using her inner guidance to discern where she needs to be at any given time, and to live authentically. The boon will be different for each individual, and sometimes the most heroic thing a quester can do is stop, turn around, and find another way.

I have to wonder whether professional organisations, in planning for change, adequately prepared members for transition issues. If research supports confusion as conducive to assimilating new behaviours, then educating members about its presence and potential is a key skill for a manager in today's changing health environment. Research in the field of management development has found that there is no point in a manager speaking only of the future, if they have not demystified the process that staff might be experiencing. The individual going through the crisis phase often has the feeling that she is the one who is malfunctioning. Evidence suggests that the simple act of explaining the transition dynamic to people who are going through it, is enough to alleviate the situation. With relief, they then understand that what is happening to them is normal, and not them at fault; moving them from culpability to responsibility.

The use of role theory concepts that include the process of role transition could be included in reorientation and recertification programmes. These programmes need to be highly visible and accessible as each participant experienced difficulty in accessing information that would have facilitated their passage of decision making. It may be that individuals wish to direct their energy toward concrete action in order to restructure their reality. Correctly anticipating a new set of role expectations would help to prevent role shock and strain. Even though the transition is eventually 
forgotten, it is what enabled the change to eventually come about. By acknowledgement then, it potentially remains in reserve for the next experience. Managing transition is an important and essential process for the well being of the professions and the quality of the experience of its members. It would be cogent for professional leaders to discuss the repercussions of transition in their preparation for future planning.

In a narrative mode of inquiry that looks for connections between events, I pondered on Susan's perceived need for affirmation, and how, in its absence, she perceived a sense of indifference. Feeling validated, it would seem, is important to individuals, and in addition might be worth considering for future workforce planning also. A tick box to indicate a reason for not renewing an APC, from an abbreviated list of possibilities, is not an activity that respects a relational form of inquiry.

The reported frequency of burnout certainly issues a caution to all practitioners as to how easily our authentic sense of self may become subsumed by a new role. Over an extended period of time it is possible to become immune to the signs that usually signal a warning. This suggests an important lesson in paying attention, otherwise the light of the warning system becomes dimmed and before we realise it our physical and psychological health is compromised.

A surprising aspect of the narratives was the shared perception that gave a higher order to the discourse of midwifery. This was not a revelation that I had expected, and I paused to wonder about its prevalence from a practice point of view. How we are embracing and embodying a social category, and how does it affect how we position others? Where did this perceived superiority of knowledge derive from? It caused me consider what my own stance had been before my transfer to nursing. I am speculating that for dually registered practitioners, arrival at midwifery as a destination was an evolutionary process. It thus, transcended and included all that had gone before it, which included nursing. As the current midwifery training has changed to direct entry this phenomenon will become less of a feature. A dragon on the path would be belief in the seductive myth that allows us to feel that we have attained the pinnacle. And a lesson in humility to realise that 'arrival' was the myth. 
As diverse practice experience permeates either side of the divide, the personal and professional journeys that merge have the capacity to affect theory development and practice in the future. As practitioners reside in a new discourse they will critically consider their intuitive and emotional responses, existing theories and research, and contextual factors when making practice decisions. Theoretical practice will thus be informed and re-formed. Separate professions now co-author the healthcare environment for new families. Living with one another in responsible community calls for collaborative practice, sharing information, trusting that the information of collaborators is the best and most current, and preserving the knowledge created for re-use. This is hard won I have discovered, and continually re-created, and requires respect for difference and interconnectedness. We could join our voices together to consider how separate 'truths' shape the boundaries of healthcare practice. A cooperative knowledge finding investigation, grounded in local, social, cultural, and political issues, would be conducive to improved inter-professional relationships. This offers further research possibilities.

\section{What might a new mythology imagine?}

As health professions embark now on their separate journeys they need to be clear about their own vision, mission, and goals. As individual practitioners involved in personal and professional journeying we could use our minds, our hearts, and our collective midwifery to bring the female hero to birth in our quest for wholeness. Wherever the hero wanders, it would seem she is in the presence of her own essence. There is no separateness. The myth of the hero journey illustrates our connectedness with all humankind. The willingness of the participants to share their unique path means we might guide each other by sharing our wisdom on taking journeys across divides. Any situation that leads to increased self awareness and self growth, improves our effectiveness as practitioners to act as a resource for others, or as future facilitators of change.

I think what Joseph Campbell was conveying in his seminal works, about the function of myth, went beyond an intellectual exercise in its connection to something beyond 
us. Through story that resonated with his listener's innermost being, he wove a connection to our vital spirit.

When an individual experiences a crisis of midlife, of being out of compassion, of feeling sapped and exhausted from a life of over-service, and wondering about the meaning of it all; that meaning is not in the mind, but precisely in that vital spirit seeking the rapture of being alive. For that is what is meant to be creative, to create meaning and order out of confusion, and to structure our lives intentionally by knowing participation in change. What is especially interesting about some of the translations of his work is the idea that a sense of wonder might lead us to ask incisive questions like: What is it I need to know in order to live my life more fully? These were central themes that practitioners were considering at this time of choosing a path.

The work of the myth draws us to consider the patterns of the clues in each of the stories presented in this study, and whether in response to our own story clues, we respond consciously, or unconsciously. When I asked the participants about the way that went about making decisions, or what they found were useful strategies for dealing with change, they each paused in surprise. Mary even exclaimed "Oh, such thorny questions" (Interview, line 155). It is precisely these patterns which make us who we are, and different from each other. It was the highlighting of some experiences, and the discounting of others that shaped the stories offered by the three practitioners. These are the signs that give direction to our wandering.

I imagine that the leaders of the professions of nursing and midwifery will be investigating and interpreting the patterns of choice and change in practitioners' lives following the HPCAA (2003), in order to make strategic decisions that minimise future workforce repercussions.

\section{Conclusion}

The objective characteristics of the external stimuli of the HPCAA (2003) required that a professional decision be made by dual practitioners. The action of decision making was seen to involve individual practitioners completely as each unique set of considerations mediated between the needs of the person and social demands. Thus, 
the distinction between extrinsic and intrinsic motivation was the placement of value and meaning on integrating actions to concur with these needs. It was the complex interaction of these processes that determined the decision outcome. This text has been a synthesis of ideas and interlinked stories illuminating patterns of learned association to change experience. Motivational elements provided and enriched the pattern of actions, and decision making trends mirrored stored experience. The association with a mythological way of thinking means that sometimes the links have been indirect; through a parallel story, metaphor, and symbol.

We have been discussing a divide. By divide I draw attention to the chasm that now exists between the two professions that hold valuable memories for dually registered practitioners. The HPCAA (2003) required that the individual councils of nursing and midwifery could assure the public of the competency of its members. That meant that a decision about a path was required, and this has involved a personal journey to position their professional lives in the current context. The function of myth has been to make possible, and then facilitate, the jump - by analogy.

As Campbell intended, mindsets and senses are presented in such a way as to suggest a truth or openness beyond. As each individual reflects on the journey involved in crossing the divide, they consider that void, or being, literally and imaginatively in the context of their unique life pattern. The fundamental truth of Campbell's vision was that such symbolic thinking moves and awakens the mind. It provides the language for the signposts which we each place in our lives by our intention to perceive them, and by the selective perception through which our mind filters the experience. What the HPCAA (2003) provided for dually registered practitioners was the realisation that our worldview must change, and through the course of a journey that crossed a divide, we have the power to evoke wonder, as we choose personal and professional direction. 


\section{The Hero Journey}

We have not even to risk the adventure alone, for the heroes of all time have gone before us. The labyrinth is thoroughly known. We have only to follow the thread of the hero path, and where we had thought to find an abomination, we shall find a god. And where we had thought to slay another, we shall slay ourselves. Where we had thought to travel outward, we will come to the centre of our own existence. And where we had thought to be alone, we will be with all the world.

Joseph Campbell, The Power of Myth, 1988, p 123. 


\section{Appendix 1: Ethics Approval}

\section{VICTORIA UNIVERSITY OF WELLINGTON}

Te Whare Wananga o te Upoko o te Ika a Maui

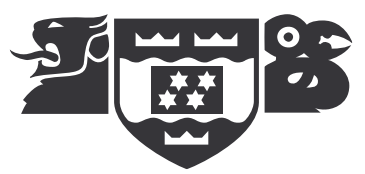

\begin{tabular}{l|l}
\hline TO & Dianne Mulcahy \\
\hline COPY TO & Associate Professor Cheryle Moss \\
\hline FROM & $\begin{array}{l}\text { Dr Allison Kirkman, Convener, Human Ethics } \\
\text { Committee }\end{array}$ \\
\hline
\end{tabular}

\begin{tabular}{l|l}
\hline DATE & June 12, 2006 \\
\hline PAGES & 1 \\
\hline
\end{tabular}

\section{SUBJECT Approval: No 46/2006 - Reclaiming heroism: nurses and midwives' experience of choosing a path following separation of the professions.}

Thank you for your application for ethical approval, which has now been considered by the Standing Committee of the Human Ethics Committee.

Your application has been approved and this approval continues until 28 February 2007. If your data collection is not completed by this date you should apply to the Human Ethics Committee for an extension to this approval.

Best wishes with the research.

Allison Kirkman

Convener 


\section{Appendix 2: Advertisement}

\section{VICTORIA UNIVERSITY OF WELLINGTON \\ Te Whare Wananga o te Upoko o te Ika a Maui

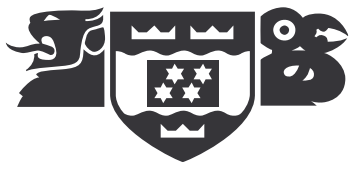

\section{Are you interested in joining a Study?}

In fulfilment of a Masters of Arts (Applied) Nursing, I am seeking expressions of interest from three candidates willing to participate in a research project. I wish to examine the experience of practitioners with dual registration; i.e. both nursing and midwifery, who must decide, (or who have already decided), upon a professional pathway following enactment of the Health Practitioners Competence Assurance Act.

You would be asked to write a narrative account of this experience, followed by a later interview, to clarify and revisit issues in your story.

Ideally, the three practitioners would comprise the range of experience; i.e. a practitioner retaining a nursing Annual Practicing Certificate (APC); a practitioner retaining a Midwifery APC; and a practitioner retaining both nursing and midwifery APC's.

If you are interested I am happy to discuss this with you, and to provide an information sheet for your consideration. Expressions of interest would be appreciated by (date would be approx 3-4 weeks following HEC approval).

I can be contacted most evenings after $7 \mathrm{pm}$ at (07) 8567924 .

Your enquiries will be treated confidentially.

Thankyou, in anticipation, for considering this request.

Dianne Mulcahy 


\section{Appendix 3: Participant Information Sheet \\ VICTORIA UNIVERSITY OF WELLINGTON \\ Te Whare Wananga o te Upoko o te Ika a Maui}

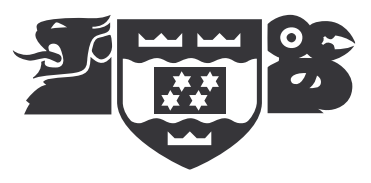

\section{Participant Information Sheet}

I am a Masters student in the Graduate School of Nursing and Midwifery at Victoria University of Wellington. As part of this degree I am undertaking a research project that will examine the experience of three practitioners with dual registration (i.e. both nursing and midwifery), who must decide upon a professional pathway following enactment of the Health Practitioners Competence Assurance Act (HPCA) 2003.

Legislative changes have meant that Midwifery and Nursing are now two separate professions. The two regulatory bodies; The Midwifery Council, and The Nursing Council of New Zealand are each responsible for setting standards for education, registration, competence, disciplinary activities, and for issuing competence based Annual Practising Certificates for its members. Practitioners with dual registration as nurses and midwives are being asked to decide which profession to maintain competence to practise in. This may be one of two possible pathways and there is current debate around securing competencies in both professions. Hence, I am inviting expressions of interest from three dually registered practitioners, who have participated in the conscious decision making required to negotiate the necessary changes in accordance with the HPCA, to participate in this project.

Professional change is inevitable in our careers and it is not arrived at without considerable thought and preparation. It is particularly relevant for dually registered practitioners at this period of time who have elected one pathway over another. It is expected that the data resulting from this study would give fresh insight into the impact of these choices and changes, and their effects on participants' lives.

Participants will be asked to each write their own story about their experience of change or realignment of their professional career, and its effects. This may require a period of reflection and a time commitment that is not expected to exceed three hours. The story writers will be asked to provide information on the process of change; i.e. the scope and effect of the change experience, the barriers and enablers, and their strategies for dealing with the changes. Including the suggestions just made the subject for your story might be framed in the following manner; 'Describe your experience of deciding which professional pathway to pursue; share all your thoughts, 
perceptions, and feelings you can recall, until you have no more to say about the situation'.

The stories will be received respectfully and, using the research analysis framework, the researcher will respond to the narrative by compiling a narrative statement using the participant's own language. This would be sent back to you for us to discuss together at a later interview. A suitable time and location for the interview would be negotiated together, and again this time commitment would not exceed three hours. This is an opportunity for us to clarify and explore the issues that you had identified in your story. Our conversation would be audio taped and a copy of the typed transcript given to you to reflect upon. My contact details would also be left with you as you may wish to amend or make further comment following a period of reflection.

Theoretically, it could be argued that in the act of exploring options and making choices, each participant will have their own unique patterning, but there is likely to be common themes or areas of experience, or perception that will resonate for many readers. These patterns and differences would be explored in the thesis and presented in a manner which honours each participant's unique ability to integrate professional change in to their lives.

If you are interested in participating in this study I will ask you to sign a written consent form. If you choose to discontinue your participation you may do so at any time. Participation would require that volunteers be willing to use a pseudonym, to protect identification and care would be taken that no identifying information would be included. A small sample size will permit a detailed examination of the impact of choice and change, and its subsequent effect on participants lives. The study requires only three participants, so in the event that there are more than three interested candidates, I would communicate this, via letter, to those concerned.

My supervisors, Cheryle Moss and Rose McEldowney, will be reading and critiquing drafts of the thesis as part of the supervision process. You will be entitled to receive a summary of the research results or a full report if you wish. Consent would include permission for the final data to be made available for conference presentation, or publication as a scholarly article in a reputable nursing or midwifery journal. Deposit of the completed thesis would be made in the Victoria University library. I will maintain a reflective journal throughout the research process and I will receive ongoing supervision with Cheryle during this time.

If you have any questions or would like to receive further information about the project, or would like to register an expression of interest following consideration of the information, please contact me at 36 Malcolm St, Hamilton, phone (07) 8567924; or my supervisors, Associate Professor Cheryle Moss and Associate Professor Rose McEldowney, Graduate School of Nursing and Midwifery, Victoria University, PO Box 600, Wellington, phone 0800108005. 


\section{Appendix 4: Consent for participation}

\section{VICTORIA UNIVERSITY OF WELLINGTON \\ Te Whare Wananga o te Upoko o te Ika a Maui}

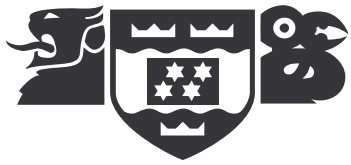

\section{Consent form for participation in the research project}

\section{Title of project: Journeys Cross Divides: Nurses and Midwives experience of choosing a Path following separation of the professions}

I have received and understood the information provided about this research project. I have had an opportunity to ask questions and am satisfied with the response. I understand that there is no personal consequence, in relation to any of the information I provide at any time, nor is there any penalty for withdrawing myself, or any of the information I provide, at any time.

I also understand that:

- Any information or related material I provide will be treated confidentially by the researcher, her supervisors, and the person transcribing the audiotape of our interview

- A pseudonym will be used to safeguard against any identifying information during and after completion of the research

- The length and time of the interview will be negotiated with me prior to its commencement, and if flowing will not exceed 3 hours

- I will keep a copy of the typed transcript of the audio taped interview and the researcher will keep her copy in a locked filing cabinet, and for five years after the completion of the research project

- I will have the opportunity to view and comment on the narrative relating to me before the written thesis is submitted by the researcher 
- The researcher may utilise the data in conference presentations, or in articles for national and international refereed journals

- The completed thesis will be available in the Victoria University Library

- The data I will provide will not be used for other purposes, other than those stipulated in this consent form, without my further consent;

- I have the right to receive a summary of the research results when it is completed

I hereby agree to take part in this research project.

\section{Signed:}

Name of participant:

\section{Date:}

I wish to receive a copy of the research when the project is completed

Yes

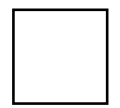

No

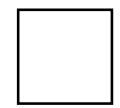




\title{
Appendix 5: Transcriber Confidentiality Form
}

\author{
VICTORIA UNIVERSITY OF WELLINGTON \\ Te Whare Wananga o te Upoko o te Ika a Maui

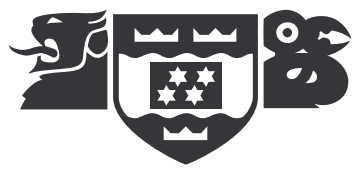

Date:

I agree to maintain confidentiality when transcribing the participants' audiotaped interviews.

I will not disclose any information related to the participants in the research project.

I also understand that the only communication I have related to transcribing the audiotapes will be with the researcher Dianne Mulcahy.

Signed:

Name of Transcriber: 


\section{References}

Anderson, R. (2000). Intuitive inquiry: Interpreting objective and subjective data. Revision: Journal of Consciousness and Transformation, 22 (4), 31-39.

Atkinson, E. (2000). Behind the inquiring mind: Exploring the transition from external to internal inquiry. Reflective Practice, 1 (2), 149-164.

Barnett, T. (2006). Politicising the personal: Frederick Douglass, Richard Wright, and some thoughts on the limits of critical literacy. College English, 68 (4), 356381 .

Barrett, E. (1989). A nursing theory of power for nursing practice: Derivation from Roger's paradigm. In J. E. Riehl-Sisca (Ed.), Conceptual models of nursing practice ( $3^{\text {rd }}$ ed., pp. 207-217). Norwalk: Appleton \& Lange.

Barrett, E. (1998). A Rogerian practice methodology for health patterning. Nursing Science Quarterly, 11 (4), 136-138.

Batten, J. (2000). Growing into wisdom: Change and transformation at midlife. Auckland: Tandem Press.

Benyon, D. (1998). Research and advanced technology for digital libraries. Proceedings from the Second European Conference, ECDL. Crete. [Transcript]. Retrieved December 10, 2006, from http://www.sics.se/humle/projects/persona/web/littsurvey/ch3.pdf.

Bhahba, H. (1994). The location of culture. New York: Routledge.

Bickley-Asher, J. (2006). Ethical staffing-there can be no compromise. Kai Tiaki Nursing New Zealand, 12 (3), 20.

Bradby, M. (1990). Status passage into nursing: Another view of the process of socialisation into nursing. Journal of Advanced Nursing, 15, 1220-1225.

Bradby, M., \& Soothill, K. (1993). From common foundation programme to branch: Recognising a status transition. Nurse Education Today, 13, 362-368.

Braud, W. (1998). Can research be transpersonal? Transpersonal Psychology Review, $2(3), 9-17$.

Brown, A. (2003). Foucauldian perspectives on midwifery practices and education. The Internet Journal of Advanced Nursing Practice, 6 (1), 1-12.

Butcher, H. (1998). Crystallizing the processes of the unitary field pattern portrait research method. Visions, 6 (1), 13-26. 
Butcher, H. (2001). Nursing science in the new millennium: Practice and research within Roger's science of unitary beings. In M. Parker (Ed.), Nursing theories and nursing practice (pp. 205-226). Philadelphia: F. A. Davis.

Butcher, H. (2004). Written expression and the potential to enhance knowing participation in change. Visions, 12 (1), 37-50.

Cameron, S. (2005). Cinderella revisited. British Medical Journal, 331 (Dec), 15431544.

Cammock, P. (2003). The dance of leadership. Auckland: Prentice Education New Zealand Ltd.

Campbell, J. (1968a). The hero with a thousand faces. New York: Princeton University Press.

Campbell, J. (1968b). The masks of god. New York: Viking.

Campbell, J. (1988). The power of myth. New York: Doubleday.

Campbell, N. (2005). Recertification: Cleaning up the confusion. Midwifery News, 37, June, 6 .

Campbell, N. (2006). Forum: Midwifery standards review. Midwifery News, 42, September, 10.

Cassie, F. (2003). The time is right. Midwifery News, 31, 7.

Chase, S. (2005). Narrative inquiry: Multiple lenses, approaches, voices. In N. Denzin., \& Y. Lincoln., (Eds.), The Sage Handbook of Qualitative Research, ( $3^{\text {rd }}$ ed., pp. 651-679). California: Sage Publications.

Cheyne, C., O’Brien, M., \& Belgrave, M. (1997). Health policy reform: Control or responsiveness? In C. Cheyne., \& M. O’Brien., \& Belgrave, M, (Eds), Social policy in Aotearoa New Zealand: A critical introduction, (pp. 218-240). Auckland: Oxford University Press.

Chomsky, N. (1986). Knowledge of language: Its nature, origin and use. New York:

Praeger Publications.

Chudzikowski, K. (2005). Career transitions in a post organisational context. Paper presented at the EDAMBA Summer Academy, Soreze, France. [Transcript]. Retrieved December 13, 2006, from http://edamba.wuwien.ac.at/Paper\%20Katharina\%20Chudzikowski.pdf.

Churchill, L., \& Churchill, S. (1982). Storytelling in medical arenas: The art of self determination. Literature and Medicine, 1, 73-79. 
Cohen-Katz, J., Wiley, S., Capuano, T., Baker, D., \& Shapiro, S. (2004). The effects of mindfulness based stress reduction on nurse stress and burnout. Holistic Nursing Practice, 18 (6), 302-308.

Cohen-Katz, J., Wiley, S., Capuano, T., Baker, D., \& Shapiro, S. (2005a). The effects of mindfulness based stress reduction on nurse stress and burnout, Part II: A quantitative and qualitative study. Holistic Nursing Practice, 19 (1), 26-36.

Cohen-Katz, J., Wiley, S., Capuano, T., Baker, D., Deitrick, L., \& Shapiro, S. (2005b). The effects of mindfulness based stress reduction on nurse stress and burnout: A qualitative and quantitative study, Part III. Holistic Nursing Practice, 19 (2), 78-86).

Coney, S. (1988). The unfortunate experiment. Auckland: Penguin books Ltd.

Cousineau, P. (Ed.). (1999). The hero's journey: Joseph Campbell on his life and work. New York: Element Books.

Cowling, W. (1997). Pattern appreciation: The unitary science/practice of reaching essence. In M. Madrid (Ed.), Patterns of Rogerian knowing (pp. 129-142). New York: National League for Nursing.

Cowling, W. R. (2000). Healing as appreciating wholeness. Advances in Nursing Science, 27 (3), 16-32.

Cowling, W.R. (2004). Pattern, praxis, and power in unitary appreciative inquiry. Advances in Nursing Science, 27 (3), 202-215.

Csikszentmihalyi, M. (1975). Beyond boredom and anxiety: Experiencing flow in work and play. San Francisco: Jossey-Bass Publishers.

Csikszentmihalyi, M. (1990). Flow: The psychology of optimal experience. New York: Harper \& Row.

Davies, E. (2006). Call to review dual registration. Kai Tiaki Nursing New Zealand, $12(1), 5$.

Dawbin, A. (2005/2006). Are you able to prove your competence? Kai Tiaki Nursing New Zealand, 11 (11), 24.

Dawley, K. (2005). American nurse-midwifery: A hyphenated profession with a conflicted identity. Nursing History Review, 13, 147-171.

de Bock, C. (2006). Midwifery and nursing closely linked. Kai Tiaki Nursing New Zealand, 12 (1), 5-6.

Denzin, N. K., \& Lincoln, Y. S. (Eds.). (1994). Handbook of Qualitative Research. Thousand Oaks: Sage. 
Department of Health. (1998). Report of the ministerial taskforce on nursing. Wellington: Ministry of Health. Retrieved December 10, 2006, from www.moh.govt.nz/moh.nsf/0/226311 fa843649ba4c256671007e0530/\$FILE/ nursing4.pdf

Diekelmann, N. (2001). Narrative pedagogy: Heideggarian hermeneutical analyses of the lived experiences of students, teachers and clinicians. Advances in Nursing Science, 23 (3), 53-71.

Doane, G., \& Varcoe, C. (2005). Toward compassionate action: Pragmatism and the inseparability of theory/practice. Advances in Nursing Science, 28 (1), 81-91.

Dobbie, M. (1990). The trouble with women. The story of Parents Centre New Zealand. Whatamongo Bay: Cape Catley Ltd.

Donley, J. (1986). Save the midwife. Auckland: New Women's Press.

Ellemers, N. (1993). Influence of socio-structural variables on identity enhancement strategies. European Review of Social Psychology, 10, 41-74.

Ellemers, N., Spears, R., \& Doosje, B. (2002). Self and social identity. Annual Review of Psychology, 53, 161-186.

Flowers, B, S. (Ed.). (1988). The power of myth: Joseph Campbell with Bill Moyer's. New York: Doubleday.

Gadamer, H. (1976). Philosophical hermeneutics. London: University of California Press.

Gauthier, J. (2003). Midlife Journeys of transvaluation and meeting the feminine through heroic descent: An organic inquiry with 10 men and 8 women. Unpublished doctoral dissertation. Pacifica Graduate Institute, Carpinteria, California.

Gibson, C. (1991). A concept analysis of empowerment. Journal of Advanced Nursing, $16,354-361$.

Gilmer, S. (2006). Gaining dual registration an ordeal. Kai Tiaki Nursing New Zealand, 12 (3), 3.

Glaser, B., \& Strauss, A. (1971). Status passage. London: Routledge \& Kegan Paul Ltd.

Guba, E., \& Lincoln, Y. (2005). Paradigmatic controversies, contradictions, and emerging confluences. In N., Denzin., \& Y., Lincoln (Eds.), The Sage Handbook of Qualitative Research (pp 191-217). California: Sage Publications Inc. 
Gueldner, S., Michel, Y., Bramlett, M., Liu, C., Johnston, L., Endo, E., Minegishi, H., \& Carlyle, M. (2005). The well-being picture scale: A revision of the index of field energy. Nursing Science Quarterly, 18 (1), 42-50.

Guilliland, K. (2003). A separate reality. Midwifery News, 31, 4-6.

Guilliland, K. (2004). A hundred years of midwifery and what have we learnt about ourselves? Midwifery News, 37, October, 4-6.

Guilliland, K. (2006, February). The media can make up the story but prejudice fuels it. Midwifery News, 40, 6-7.

Hall, J. (1997). Nurses as wounded healers. The Australian Journal of Holistic Nursing, 4 (1), 11-16.

Hampton, D., \& Hampton, G. (2000). Professionalism and the nurse-midwife practitioner: An exploratory study. Journal of the American Academy of Nurse Practitioners, 12 (6), 218-225.

Harris, R. (2006). The hero's journey: Life's great adventure. Retrieved June 15, 2006, from http://www.yourheroicjourney.com/Journey.shtml

Hart, N. (1976). When marriage ends. London: Tavistock.

Hartrick Doane, G. (2002). Am I still ethical. The socially mediated process of nurses' moral identity. Nursing Ethics, 9 (6), 623-635.

Heidegger, M. (1962). Being and time. Oxford: Basil Blackwell.

Hendry, C. (2005). Midwifery workforce project. Midwifery News, 39, 14-15.

Heron, J., \& Reason, P. (1997). A participative inquiry paradigm. Qualitative Inquiry, $3(3), 274-294$.

Higgs, J., \& Titchen, A. (Eds.). (2001). Professional practice in health, education and the creative arts. London: Blackwell Science Ltd.

Hill, A. (1982). The history of midwifery from 1840 to 1979, with a specific reference to the training and education of the student midwife. Unpublished MA Thesis, University of Auckland.

Hochschild, A. (1983). The managed heart: Commercialisation of human feelings. California: University of California Press.

Holland, K. (1999). A journey to becoming: The student nurse in transition. Journal of Advanced Nursing, 29 (1), 229-236.

Houston, J. (1987). The search for the beloved: Journeys in mythology and sacred psychology. New York: G.P. Putnam's Sons. 
Houston, J. (1996). A mythic life. New York: Harper Collins Publishers Inc.

Johns, C. (1995). Framing learning through reflection within Carper's ways of knowing in nursing. Journal of Advanced Nursing, 22, 226-234.

Johnson, T. (1992). The myth of the great secret: An appreciation of Joseph Campbell. California: Celestial Arts Publishing.

Jones, S. (2002). Methodological strategies and issues in qualitative research [electronic version]. Journal of College Student Development, July/August. Retrieved February 9, 2006, from www.findarticles.com/p/articles/mi qa3752/is 200207/ai n9121404/print

Kabat-Zinn, J. (2005). Coming to our senses: Healing ourselves and the world through mindfulness. New York: Hyperion Books.

Kedgley, S. (1996). Mum's the word. The untold story of motherhood in New Zealand. Auckland: Random House New Zealand Ltd.

Keenan, R. (2006). Understanding the competence review process. Kai Tiaki Nursing New Zealand, 12 (9), 26-27.

Koch, T. (1994). Establishing rigour in qualitative research: The decision trail. Journal of Advanced Nursing, 19, 976-986.

Koch, T. (1998). Story telling: Is it really research? Journal of Advanced Nursing, 28 (6), 1182-1190.

Kornfield, J. (1994). A path with heart. New York: Bantam Books.

Kovach, M. (2005, May). Indigenous knowledge(s) and research: Creating space, different ways of knowing within the academy. Proceedings from the First Nations, First Thoughts Conference. Centre of Canadian Studies, University of Edinburgh. Retrieved August 20, 2006, from http://cst.ed.ac.uk/2005conference/papers/Kovach_paper.pdf

Lakoff, G., \& Johnson, M. (1980). Metaphors we live by. Chicago: University of Chicago Press.

Litchfield, M. (1999). Practice wisdom. Advances in Nursing Science, 22 (2), 62-73.

MacNeil, M. (1997). From nurse to teacher: Recognizing a status passage. Journal of Advanced Nursing, 25, 634-642.

Mahoney, M. (2003). Constructive psychotherapy: A practical guide. New York: The Guilford Press.

McLardy, E. (2002, October). Boundaries, work, and home. New Zealand College of midwives, 27, 33-34. 
McNiff, J. (1993). Teaching as learning. London: Routledge.

McNiff, S. (2004). Art heals: How creativity cures the soul. Massachusetts: Shambhala.

Midwifery Council of New Zealand. (2004). Midwifery scope of practice, qualifications and competencies consultation document. Wellington: Midwifery Council of New Zealand.

Miller, W., \& Crabtree, B. (1994). Clinical research. In N. Denzin., Editor, \& Y. Lincoln, Editor, (Eds.), Handbook of Qualitative Research, (pp. 340-352). Thousand Oaks: Sage.

Ministry of Health. (2003). Health Practitioners Competence Assurance Act 2003.

Ministry of Health. (2007). Nurse Practitioners in New Zealand. Retrieved January 10, 2007, from www.moh.govt.nz/nursepractitioner

Moustakis, C. (1990). Heuristic research: Design, methods and application. Newbury Park, CA: Sage.

Murray, T. (1998). Using role theory concepts to understand transitions from hospitalbased nursing practice to home care nursing. The Journal of Continuing Education in Nursing, 29 (3), 105-111.

Myss, C. (1996). Anatomy of the spirit: The seven stages of power and healing. New York: Three Rivers.

Newman, M. (2002). The pattern that connects. Advances in Nursing Science, 24 (3), $1-7$.

Newman, M. (2003). A world of no boundaries. Advances in Nursing Science, 26 (4), 240-245.

New Zealand Health Information Service. (2005). Midwifery workforce: Summary results from the 2005 health workforce annual survey.

New Zealand Nurses Organisation. (1998). Building partnerships: Developing the future of nursing. Wellington: New Zealand Nurses Organisation.

New Zealand Nurses Organisation. (2007). Nurse Practitioners. Retrieved January 10, 2007, from www.nursingcouncil.org.nz/nursepractitioner.html

Nicholson, N. (1984). A theory of work role transitions. Administrative Science Quarterly, 29 (2), 172-191.

Noble, K. (1994). The sound of the silver horn: Reclaiming the heroism in contemporary women's lives. New York: Ballantine Books. 
Nortier, F. (1995). A new angle on coping with coping with change: Managing transition! Journal of Management Development. 11 (4), 32-46.

Nursing Council of New Zealand. (2004). Framework for the approval of professional development programmes to meet the continuing competence requirements for nurses. Retrieved January 10, 2006, from http://www.nursingcouncil.org.nz/Framework\%20and\%20standards\%20for \%20PDRP.pdf

Nursing Council of New Zealand. (2005). Health Practitioners Competence Assurance Act. Retrieved May 18, 2006, from www.nursingcouncil.org.nz/hpca.html

Nursing Council of New Zealand. (2006). Definition of practising for the purposes of the Health Practitioners Competence Assurance Act 2003. Retrieved December 10, 2006, from www. nursingcouncil.org.nz.

O’Connor, T. (2005). Midwifery matters. Kai Tiaki Nursing New Zealand, 11 (3), 11.

O'Connor, T. (2006). Midwifery - A workforce under pressure. Kai Tiaki Nursing New Zealand, 12 (3), 18-19.

Osbon, D. (Ed.). (1991). A Joseph Campbell companion. New York: Harper Collins Publishers Inc.

Packer, M., \& Addison, R. (Eds.). (1989). Entering the circle: Hermeneutic investigation in psychology. New York: State University of New York Press.

Pairman, S. (1998). The midwifery partnership: An exploration of the midwife/woman relationship. Unpublished dissertation: Master of Arts in Midwifery. Victoria University of Wellington.

Pairman, S. (2002). Towards self determination: The separation of the midwifery and nursing professions in New Zealand. In E., Papps (Ed.), Nursing in New Zealand: Critical issues, different perspectives ( ${ }^{\text {st }}$ edition, pp. 14-27). Auckland: Pearson Education New Zealand Ltd.

Pairman, S. (2005). From autonomy and back again: Educating midwives across a century, Part One. New Zealand College of midwives Journal, 33, October, 610 .

Pairman, S. (2006). From autonomy and back again: Educating midwives across a century, Part Two. New Zealand College of midwives Journal, 34, April, 11-14.

Papps, E., \& Kilpatrick, J. (2002). Nursing education in New Zealand-past, present and future. In E. Papps., Editor (Ed.), Nursing in New Zealand: Critical issues, different perspectives (1st edition., pp. 1-13). Auckland: Pearson Education New Zealand Ltd.

Parse, R., Coyne, B., \& Smith, M. (1985). Nursing research: Qualitative methods. Maryland: Brady Communications Company Inc. 
Pearson, C. (1991). Awakening the hero within. San Francisco: Harper.

Pearson, J. (2005). Empowering the profession through education. Kai Tiaki Nursing New Zealand, 11 (10), 2.

Pennebaker, J., \& Seagal, J. (1999). Forming a story: The health benefits of narrative. Journal of Clinical Psychology, 55 (10), 1243-1254.

Polkinghorne, D. (1995). Narrative configuration in qualitative analysis. In A. Hatch., \& R. Wisniewski., (Eds,), Life history and narrative (pp. 5-23). London: Falmer.

Prout, A. (1989). Sickness as a dominant symbol of life course transitions: An illustrated theoretical framework. Sociology of Health and Illness, 11 (4), 336-359.

Richardson, L. (1990). Narrative and sociology. Journal of Contemporary Ethnography. 19 (1), 116-136.

Rogers, M. (1992). Nursing science and the space age. Nursing Science Quarterly, 5, 27-34.

Ryan, R., \& Deci, E. (2001). On happiness and human potentials: A review of research on hedonic and eudaimonic well-being. Annual Review Psychology, $52,141-166$.

Sandelowski, M. (1991). Telling stories: Narrative approaches in qualitative research. Image: Journal of Nursing Scholarship, 23 (3), 161-166.

Sarbin, T. (1986). The narrative as root metaphor for psychology. In T. Sarbin (Ed.), Narrative Psychology: The storied nature of human conduct, (pp.3-19). New York: Prager Publishers.

Schaefer, S. (1986). Feminine and masculine through balance toward freedom. In S. Schaefer., \& M. Matthews., \& B. Staley., (Eds.), Ariadnes awakening: Taking up the threads of consciousness, (pp. 3-50). Gloucestershire: Hawthorn Press.

Schouten, J. (1991). Selves in transition: Symbolic consumption in personal rites of passage and identity reconstruction. Journal of Consumer Research, 17 (4), 412-425.

Smith, M. (2002). Health, healing, and the myth of the hero journey. Advances in Nursing Science, 24 (4), 1-13.

Standen, R. (1987). The changing face of the hero. Wheaton: The Theosophical Publishing House.

Strid, J. (1987). Maternity in revolt. Broadsheet. 153, 14-17. 
Stronach, I., \& MacLure, M. (1997). Educational research undone: The post modern embrace. Buckingham: Open University Press.

Swallow, P., \& Sullivan, W. (2004). Whose map is it anyway? Proceedings of the Integral NLP Conference. Retrieved December 8, 2006, from http://www.cleanlanguage.co.uk/Swallow-Sullivan-whose-map.html

Trim, S. (2006). Meeting the Nursing Council of New Zealand's requirements for an annual practicing certificate as a nurse by those currently practicing in an employment position as a midwife. (Discussion paper) Wellington: Nursing Council of New Zealand.

Tucakovic, M. (2005). Nursing as an aesthetic practice. Indiana: Author house.

Tully, E. (1999). Doing professionalism differently: Negotiating midwifery autonomy in Aotearoa/New Zealand. Unpublished dissertation: Doctor of Philosophy in Sociology. University of Canterbury.

Tully, E., \& Mortlock, B. (1999). Professionals and practices. In P. Davis., Editor, \& K. Dew., Editor (Eds.), Health and society in Aotearoa New Zealand (1st edition., pp. 165-180). Auckland: Oxford University Press.

Turner, V. (1974). The ritual process. New York: Cornell University Press.

Turner, V. (1982). From ritual to theatre. New York: PAJ Publications.

Van Gennep, A. (1960). The rites of passage. Chicago: The University of Chicago Press.

van Manen, M. (1997). Researching lived experience. Ontario: The Althouse Press.

Wynd, C. (2003). Current factors contributing to professionalism in nursing. Journal of Professional Nursing, 19 (5), 251-261. 